\title{
Burn injuries among young children : incidence, aetiology and determinants of behavioural risk factors
}

Citation for published version (APA):

van Rijn, O. J. L. (1991). Burn injuries among young children : incidence, aetiology and determinants of behavioural risk factors. [Doctoral Thesis, Maastricht University]. Maastricht University. https://doi.org/10.26481/dis.19910620or

Document status and date:

Published: 01/01/1991

DOI:

10.26481/dis.19910620or

Document Version:

Publisher's PDF, also known as Version of record

\section{Please check the document version of this publication:}

- A submitted manuscript is the version of the article upon submission and before peer-review. There can be important differences between the submitted version and the official published version of record.

People interested in the research are advised to contact the author for the final version of the publication, or visit the DOI to the publisher's website.

- The final author version and the galley proof are versions of the publication after peer review.

- The final published version features the final layout of the paper including the volume, issue and page numbers.

Link to publication

\footnotetext{
General rights rights.

- You may freely distribute the URL identifying the publication in the public portal. please follow below link for the End User Agreement:

www.umlib.nl/taverne-license

Take down policy

If you believe that this document breaches copyright please contact us at:

repository@maastrichtuniversity.nl

providing details and we will investigate your claim.
}

Copyright and moral rights for the publications made accessible in the public portal are retained by the authors and/or other copyright owners and it is a condition of accessing publications that users recognise and abide by the legal requirements associated with these

- Users may download and print one copy of any publication from the public portal for the purpose of private study or research.

- You may not further distribute the material or use it for any profit-making activity or commercial gain

If the publication is distributed under the terms of Article $25 \mathrm{fa}$ of the Dutch Copyright Act, indicated by the "Taverne" license above, 


\section{Burn injuries among young children}

Incidence, aetiology and determinants of behavioural risk factors 



\title{
Burn injuries among young children
}

\section{Incidence, aetiology and determinants of behavioural risk factors}

\author{
PROEFSCHRIFT \\ Ter verkrijging van de graad van doctor \\ aan de Rijksuniversiteit Limburg te Maastricht, \\ op gezag van de Rector Magnificus, Prof. Mr. M.J. Cohen \\ volgens het besluit van het College van Dekanen, \\ in het openbaar te verdedigen \\ op donderdag, 20 juni 1991 om 16.00 uur
}

door

Olga Josephina Leonarda van Rijn

geboren te Maastricht op 22 april 1962 


\section{Promotores:}

Prof. dr. G.J. Kok

Prof. dr. P.G. Knipschild

\section{Co-promotor:}

Dr. L.M. Bouter

\section{Beoordelingscommissie:}

Prof. dr. M.J. Drop (Voorzitter)

Prof. dr. J.M. Greep

Prof. dr. H.J. Klasen, Academisch Ziekenhuis Groningen

Prof. dr. J.A. Knottnerus

Dr. W.H.J. Rogmans, Stichting Consument \& Veiligheid, Amsterdam

CIP-DATA KONINKLIJKE BIBLIOTHEEK, DEN HAAG

Rijn, Olga Josephina Leonarda van

Burn injuries among young children : incidence, aetiology and determinants of behavioural risk factors / Olga Josephina Leonarda van Rijn. - Maastricht : Datawyse. III.

Thesis Maastricht. - With ref. - With summary in Dutch.

ISBN 90-5291-054-5

NUGI 735

Subjecı heading: burn injuries ; children ; prevention.

Produktie en layout: Datawyse Maastricht, Ruud Leliveld Druk: Krips Repro, Meppel

Omslag: Guus van Rooy ontwerp; Hans van Dijk fotografie; Kirsten van Rijn model

De uitgave van dit proefschrift werd mede mogelijk gemaakt door de financiële steun van:

De Nederlandse Brandwonden Stichting, Duphar Nederland B.V. en de Stichting Kind en Brandwond 


\section{Contents}

CHAPTER 1

Introduction 7

CHAPTER 2

The incidence of medically treated bums in the Netherlands $I I$

\section{CHAPTER 3}

How to study the aetiology of burn injury:

the epidemiological approach 25

\section{CHAPTER 4}

The aetiology of burns in developed countries:

review of the literature 37

\section{CHAPTER 5}

Aetiology of burn injuries among children aged 0-4:

results of a case-control study 51

CHAPTER 6

Determinants of behavioural risk factors for burn injuries 69

CHAPTER 7

Importance of planned health education for burn injury prevention 85

CHAPTER 8

Discussion 99

SUMMARY 109

SAMENVATTING $/ 13$

DANKWOORD $\quad 1 / 7$

CURRICULUM VITAE 119 



\section{General introduction}

This dissertation is based on research into burn injuries among 0-4 year old children in the Netherlands. It focusses on incidence, aetiology, and determinants of the behavioural risk factors for burn injuries. It also provides some guidelines for the planning and development of a health education program directed at primary prevention of burn injuries among young children.

The research project was triggered by a request from the Dutch Burns Association, asking for a health education program directed at primary prevention of burn injuries. We thought it unwise to develop such a program without the necessary information about the incidence, risk factors, risk groups and determinants of the behavioural risk factors for burns. Therefore, we started with a systematically planned analysis of this public health problem. Financial support for this analysis was given by the Dutch Burns Association.

Results of previous studies and consultations with other experts in this field taught us that burn injuries are among the most serious injuries that may afflict the human body. The long-term physical and psychological consequences are often very profound (Gross, 1864; Artz, 1979; Feck et al., 1979; Hermans \& Olthuis, 1984). Studies in this field show that the incidence rate of medically treated burns over all levels of medical care in the Netherlands is probably about 300 per 100,000 persons per year (Van Montfoort, 1988), and this figure is about three times higher for 0-4 year old children. Scalds account for almost $60 \%$ of all burns in this age category (Klasen \& Sauer, 1979; Thomas et al., 1984; Haberal et al., 1987). Furthermore, there appears to be no consensus about the most important risk factors for burn injuries. Empirical studies estimating the independent contributions of putative risk factors to the burn injury risk are almost completely lacking. This lack of well-designed studies, in combination with the fact that the $0-4$ year age category is a high risk group for burns, motivated us to focus on burns among children of this age category.

Wallace (1951) once stated that prevention is the beginning for all who work in the burn field. Health education as a strategy of prevention seems to be 
a promising tool for effecting behavioural changes which are conducive to safety behaviour with respect to the prevention of burn injuries. However, there is one essential condition for the application of health education, namely that it should be planned systematically. The importance and rationale of this dogma are illustrated by examples from our own research project in chapter 7 . This systematic planning (Green et al., 1980; 1986; Kok, 1988; Bouter et al., 1990) consists of four steps, which can be formulated in the following questions:

1. How important is the health problem and what is the relation between the health problem and individual behaviour? (problem anallysis)

2 Which are the causes or determinants of these behavioural risk factors? (determinants of behaviour)

3 How can we motivate people to behave in a more healthy way? (behavioural intervention)

4 What is the effect of this intervention and what are the reasons for its success or failure? (evaluation)

These four steps constituted the theoretical framework for our dissection of the burn injury problem. However, this dissertation only deals with the first two steps and ends with some guidelines for the development of a behavioural intervention.

The problem analysis should provide answers to the questions "How serious is the problem?", "What is already known about the aetiology of the problem?" and "What behaviour is involved?" To answer these questions, we conducted three studies. The first study, into the incidence of medically treated burns in the Netherlands, provided information about the magnitude and severity of burn injury problems in the Netherlands (Chapter 2). This information was gathered by three Dutch registration systems at three different levels of medicall care: burn units, general and university hospitals, and general practitioners. Special attention was paid to the degree of precision of the incidence rates.

The second study reviewed the existing literature on the aetiology of burn injuries (Chapter 4). The methodological limitations of the studies carried out in this field were striking. For instance, none of the studies of risk factors has compared the burn population with a population of uninjured controls.

In order to gain more insight into the causality of the relation between burn injuries and several putative (behavioural) risk factors, we performed a casecontrol study. Chapter 3 deals with the methodological considerations and consequences of several choices when designing an epidemiological study on risk factors for burn injuries. These considerations were taken into account 
when designing our own case-control study, which was conducted anong 335 Dutch 0-4 year old children. Both (parents of) cases and controls filled in a questionnaire inquiring about putative risk factors for burn injuries. This list of risk factors includes risk taking and risk perception, the design of the house and a number of characteristics of the child and the parents. The methods and results of this study are presented and discussed in Chapter 5. This chapter can be seen as a summary of an earlier publication in Dutch (Van Rijn et al., 1989).

Besides the insight into the aetiology, the effectiveness of health education is determined by knowledge about the behavioural determinants of established risk factors for burn injuries. A study on these determinants was conducted among Dutch and Turkish parents (living in the Netherlands) of 0.4 year old children. These parents were asked to implement several safety behaviours in a consistent way at home. Information was gathered about the advantages, disadvantages and barriers associated with a range of safety behaviours for burn injuries. Chapter 6 describes the method and results of this study, and formulates guidelines for the planning and development of a health education program directed at primary prevention of burn injuries among young children. This chapter is also a summary of an earlier publication in Dutch (Van Rijn et al., 1990).

Chapter 8 contains a discussion of our findings with emphasis on the methodological limitations of our studies. Subsequently, some general conclusions and a number of guidelines for future studies are presented.

This dissertation ends with Dutch and English summaries in which the most important findings of this thesis are highlighted, followed by some acknowledgements and a curriculum vitae in Dutch.

\section{$\square \quad$ REFERENCES}

Artz C.P (1979) Epidemiology, causes and prognosis. In: Artz, Moncrief, Pruitt (eds) Burns, a team approach. Philadelphia: Saunders Compagny.

Bouter L.M., Rijn O.J.L. van, Kok G.J. (1990) Importance of planned health education. Burns. $16,198$.

Feck G., Baptiste M.S., Tate C.L. (1979) Burn injuries: epiderniology and prevention. Accidents, Analysis \& Prevention. 11, 129.

Green L.W., Kreuter M.W. (1986) Heall theducation and Health promotion. Palo Alto: Mayfield.

Green L.W., Kreuter M.W., Deeds S.G. et al (1980) Health Education Planning: a Diagnostic Approach. Palo Alto: Mayfield.

Haberal M., Oner Z., Bayraktar U. et al (1987) Epidemiology of adults' and childrens' burns in a Turkish burn center. Burns. 13, 136. 
Hennans R.P., Olthuis G.A.A (1984) De organisatie wan de brandenzorg in Nederland. Ned. Tijdschr. Geneeskd. 128, 2136.

Klasen H.J. Sauer E.W. (1979) Oorzaken van brandwonden bij kinderen (0-14 jaar). Tijdschr. Soc. Geneesk. 57, 765.

Kok G.J. (1988) Health motivation: health education from a social psychological point of view. In: \$. Maes, C.D. Splelberger, P.B. Defares (Eds) Topics in health Psychology (pp 295-300). New York: Wiley \& Sons Ltd.

Montfoort G.L.M. van, Galen W.Ch.C van, Harris S. (1988) Ongevallen in Nederland: een onderzoek naar prive ${ }^{-}$, werkeers-, sport-, en bedrijfsongevallen in de periode augustus 1986 - augustus 1987. Amsterdam: Stichting Consument \& Veiligheid.

Rijn O.J.L., van, Bouter L.M., Meertens R.M., Grol M.E.C., Kok G.J., Mulder S. (1989) Brandwonden bij 0-4 jarige kinderen, verslag van een etiologisch patiërt-controle-onderzoek. Amsterdam: Stichting Consument \& Veiligheid.

Rijn O.J.L. van, Meertens R.M., Bouter L.M., Grol M.E.C., Kok G.J. (1990) Determinanten van veiligheidsgedrag van ouders ter preventie wan brandwonden bij 0 -4 jarige kinderen. Een exploratieve studie. Amsterdam: Stichting Consument \& Veiligheid.

Thomas K.A., Hassanein R.S., Christophersen E.R. (1984) Evaluation of group well-child care for improwing burn prevention practices in the home. Pediatrics. 74,879 .

Wallace A.B. (1951) The exposure treatment of burns. The lancet. 260 , 501. 


\section{2}

$\square$ Incidence of medically treated burns in the Netherlands*

Olga J.L. van Rijn, Marjolein E.C. Grol, Lex M. Bouter, Saakje Mulder \& Amold D.M. Kester

\section{$\square \quad$ ABSTRACT}

During the period of January 1988 to December 1989, medically treated burn injuries in the Netherlands were recorded prospectively by three registration systems. These systems cover patients treated in burn units, in general and university hospitals, and by general practitioners. Incidence rates and $95 \%$ confidence intervals were calculated, and basic epidemiologic data about severity and localization of the burns and about accident circumstances were collected. The overall incidence rate of medically treated burns over all levels of medical care is estimated to be about 280 per 100,000 persons per year. This overall incidence figure appeared to be about 3 times as high for 0-4 year old children: 775 per 100,000 persons per year. At all levels of medical care, scalds are the most frequent type of burn, resulting in an overall incidence rate among $0-4$ year old children of 430 per 100,000 persons per year. Incidence rates are lowest among the elderly $(55+)$, but this age group suffers a higher mortality from burns. Furthermore, it turned out that males are more prone to serious burns than females, whereas females are more often treated for less severe burns. Most of the accident circumstances for serious burns were related to profession, whereas most of the circumstances for less severe burns were related to household activities.

* Accepted for publication in Burns. 


\section{INTRODUCTION}

Primary and secondary prevention of burn injuries requires information on the severity of bum injuries derived from all levels of medical care (burn units, general and university hospitals ${ }^{*}$, emergency departments, and general practitioners (GPs)). In the Netherlands, information about the incidence of burn injuries can be derived from the mortality registration of the Netherlands Central Bureau of Statistics (CBS) which registers burns as a cause of death (CBS, 1989), and also from the registration of hospital admissions of the National Medical Surveillance (LMR) (LMR, 1988). These registration systems cover, in principle, the entire Dutch population. The same holds for burn patients treated as inpatients or outpatients in the three burn units in the Netherlands (Rotterdam, Groningen, Beverwijk), which participate in a registration network of the Consumer Safety Institute (SCV) (Mulder, 1989). An estimation of the incidence of burn injuries in hospitals (inpatient or outpatient) caused by accidents (other than road and industrial accidents) can be derived from the Home and Leisure Accident Surveillance System (PORS) of the SCV (PORS, 1989). This system covers $10 \%$ of those hospitals in the Netherlands which have an accident and emergency department offering a 24 hour service $(\mathrm{N}=139)$ (PORS, 1989). Burns treated by GPs are registered by some local registration systems, such as the Continuous Morbidity Registration Nijmegen (NUHI, 1985), the Monitoring Project (Lamberts, 1984) and the Transition project (Lamberts, 1990). Apart from these locall sentinel systems, the Netherlands Institute of Primary Health Care (NIVEL) collects, via its Continuous Morbidity Registration (CMR) network, morbidity data over a network of 51 GPs, which covers a representative sample of $1 \%$ of the total population.

This article provides information on the magnitude of the burn injury problem in terms of recent incidence data for the Netherlands, from all levels of medical care, over a period of two years (1988-1989). These Dutch figures will be compared with incidence rates from other countries. Furthermore, the article presents basic epidemiologic data on severity, localization and accident circumstances of all types of (registered) burn injury patients.

* In this article 'hospitals' will refer to both general and university hospitals. 


\section{METHODS}

Information on cases of burn injury was mainly drawn from the burn unit and hospital registration system (of the SCV) and the GP registration system (NIVEL), over the past two years (1988-1989). Incidence rates were calculated by relating these numbers to the (relevant subgroup of) the Dutch population (CBS, 1988; CBS, 1989; CBS, 1990). To indicate the degree of precision of the incidence estimates, $95 \%$ confidence intervals $(\mathrm{CI}(95 \%))$ were calculated. This degree of precision is indicated by the width of the confidence interval: the wider the interval the less precise the estimation of the incidence rate and vice versa. A confidence interval, which thus provides lower and upper bounds for the true value of the incidence rate, is based on a Poisson distribution of the number of burns. The $95 \%$ confidence interval for the incidence rate (I) is calculated as follows (Kahn \& Sempos, 1989):

$$
\hat{\mathrm{I}}(1-1.96) / \sqrt{N})<\mathrm{I}<\hat{\mathrm{I}}(1+1.96 \sqrt{N})
$$

$\hat{\mathrm{I}}=$ observed incidence rate

$\mathrm{I}=$ true value of the incidence rate

$\mathrm{N}=$ number of burns

Basic epidemiologic data about the accident circumstances and severity of the burn injuries were collected. The burn unit registration system gathers information on, for instance, demographic characteristics of the victim, the type of burn injury, the severity of the burn injury and the activity of the patient at the time of the accident leading to the injury. The coded forms are regularly mailed to the SCV, where the data are added to the burn unit data base (Mulder, 1989). For the collection of the data of burn patients treated in hospital, the general PORS coding forms were used (PORS, 1989) collecting, for instance, information about the type of accident, the part of the body involved and the accident circumstances. All GPs participating in the GP registration system (NIVEL, 1989) receive a weekly form, on which certain illnesses, occurrences and actions are reported. In addition to some permanent items, some temporary items are added to this form each year. At our request, burn injuries were added to the form for a period of two years (1988-1989). For the participating practitioners this implied that they had to fill out a questionnaire for every burn injury patient who consulted them. This questionnaire consisted of nearly the same questions as those used for the burn unit and hospital registration. The differences in questionnaires were that the burn unit and hospital registration did not 
ask about ethnicity and about background information about the accident circumstances, and that the hospital registration did not ask about the severity of the burns.

\section{RESULTS}

\section{Incidence}

Table 1 shows the crude incidence rates for bum injuries for all age categories, based on the registration of burns as a cause of death (CBS, 1988) and as a reason for admission to hospital (LMR, 1988; LMR, 1989) for the most recent registration period over which data were available. Furthermore, this table provides information on the incidence rates of burn injuries, treated as inpatient or outpatient cases, based on registration by the burn units (Mulder, 1989; Mulder 1990), hospitals (PORS, 1989; PORS, 1990) and general practitioners (NIVEL, 1989; NIVEL, 1990) for the period 1988-1989. For all incidence rates, the corresponding CIs(95\%) are given.

As shown in table 1, the death rate from burns is relatively low; less than 1 per 100,000 persons per year. The LMR has a complete overlap with the

Table 1. Incidence rates of medically treated burns in the Netherlands $(1987,1988,1989)$

\begin{tabular}{lccll}
$\begin{array}{l}\text { Level of medical care } \\
\text { (Registration source) }\end{array}$ & $\begin{array}{l}\text { Number } \\
\text { of burns* }\end{array}$ & $\begin{array}{l}\text { Incidence } \\
\text { rate** }\end{array}$ & $\begin{array}{l}\text { CI- } \\
(95 \%)^{* * * *}\end{array}$ & $\begin{array}{l}\text { Period of } \\
\text { observation }\end{array}$ \\
\hline Burns as a cause of death (CBS)) & 85 & 0.6 & $(0.5-0.7)$ & '87 \\
Admission to hospital (LMR) & 3512 & 11.9 & $(11.6-12.4)$ & "87-'88 \\
Burn units, all burns (SCV) & 2401 & 8.1 & $(7.8-8.4)$ & $' 88-' 89$ \\
$\quad$ inpatient treatment & 844 & 2.9 & $(2.7-3.1)$ & "88-'89 \\
$\quad$ outpatient treatment & 1557 & 5.3 & $(5.0-5.5)$ & $' 88-' 89$ \\
Hospital, all burns (PORS) & 2519 & 85.3 & $(81.9-88.6)$ & $' 88-' 89$ \\
$\quad$ inpatient treatment & 206 & 7.0 & $(6.1-7.9)$ & $' 88-' 89$ \\
$\quad$ outpatient treatment & 2307 & 78.1 & $(75.0-81.3)$ & $' 88-' 89$ \\
General practitioners (NIVEL) & 543 & 185.3 & $(169.6-200.9)$ & $' 88-' 89$ \\
\hline
\end{tabular}

* Number of patients registered;

** Number of burns per 100,000 persons per year;

*** $95 \%$ confidence interval. 
inpatients from the burn unit registration and with those from the hospital registration. However, it should be mentioned that PORS registers home and leisure accidents only as inpatient treatment if the patient is admitted immediately after treatment at the emergency department. Thus, PORS records patients only at the time of first admission (because for a second admission they do not pass the emergency department) (PORS, 1988), whereas the LMR records these patients separately each time (LMR, 1988). Furthermore, PORS does not include burns due to road and industrial accidents, or burns due to non-accidental causes.

The incidence rates for burn injuries appear to be lower at higher levels of medical care. The incidence rate for burns treated by a GP is about two times the rate for burns treated in hospital and more than twenty times the rate for burns treated in a burn unit. Burn patients in burn units are relatively often treated as inpatients compared to patients who seek care in a hospital.

Table 2. Burn incidence rates in the Netherlands by type of burn and level of medical care (1988-1989)

\begin{tabular}{|c|c|c|c|c|c|c|}
\hline \multirow{2}{*}{$\begin{array}{l}\text { Type of burn } \\
\text { Level of } \\
\text { medical care } \\
\text { (Source) }\end{array}$} & \multicolumn{2}{|l|}{ Scald } & \multicolumn{2}{|l|}{ Flame } & \multicolumn{2}{|l|}{ Other ${ }^{* * * * * *}$} \\
\hline & $\begin{array}{l}\text { Incidence } \\
\text { Rate* } \\
(\mathrm{CI}(95 \%))^{* * *}\end{array}$ & $\mathbb{N}^{* * * *}$ & $\begin{array}{l}\text { Incidence } \\
\text { Rate* } \\
(\mathrm{CI}(95 \%))^{*}\end{array}$ & $\mathrm{~N}^{* * * *}$ & $\begin{array}{l}\text { Incidence } \\
\text { Rate* } \\
(\mathrm{CI}(95 \%))^{* * *}\end{array}$ & $N^{* * * * *}$ \\
\hline $\begin{array}{l}\text { Burn Unit } \\
(\mathrm{SCV})\end{array}$ & $\begin{array}{l}3.8 \\
(3.6-4.0)\end{array}$ & 1116 & $\begin{array}{l}2.3 \\
(2.2-2.5)\end{array}$ & 691 & $\begin{array}{l}2.0 \\
(1.9-2.2)\end{array}$ & 594 \\
\hline $\begin{array}{l}\text { Hospital } \\
\text { (PORS) }\end{array}$ & $\begin{array}{l}52.5 \\
(49.9-55.1)\end{array}$ & 1551 & $\begin{array}{l}9.7 \\
(8.6 \times 10.8)\end{array}$ & 287 & $\begin{array}{l}23.1 \\
(21.3-24.8)\end{array}$ & 681 \\
\hline $\begin{array}{l}\text { General } \\
\text { Practice } \\
\text { (NIVEL) }\end{array}$ & $\begin{array}{l}86.0 \\
(75.4-96.6)\end{array}$ & 252 & $\begin{array}{l}14.7 \\
(10.2-19.1)\end{array}$ & 43 & $\begin{array}{l}84.6 \\
(74.0-95.2)\end{array}$ & 248 \\
\hline
\end{tabular}

\footnotetext{
* Number of burns per 100,000 persons per year;

** $95 \%$ confidence interval;

*** Number of patients registered;

**** Contact burns, flash burns, chemical burns, electric burns, sun burns.
} 
Table 2 shows the incidence rates for various types of burn, by level of medical care over the same two year period. Because the major causes of burns were restricted to two origins, scalds and flame, only these types of bums are described explicitly in the table. The other origins are categorised as 'other burns'.

Table 2 shows that at all levelis of medical care, scalds are the most frequent type of burns. In burn units, scalds are reported twice as often as flame burns, while hospitals and GPs report scalds, respectively, about five and six times as often as flame burns. The high incidence of other burns reported by GPs consists mainly of contact burns ( 51 per 100,000 persons per year).

Table 3 shows the age-specific burn incidence rate by level of medical care. This table shows that, over all levels of medical care, the incidence among 0-4 year old children is much higher than that among the other age categories. The burn injury incidence rate for treatment in a hospital for this age category is almost eight times the rate for persons aged 55 and over ( 243 versus 32 per

Table 3. Burn incidence rates in the Netherlands by age and level of medical care (19881989)

\begin{tabular}{|c|c|c|c|c|c|c|c|c|}
\hline \multirow{2}{*}{$\begin{array}{l}\text { Age category } \\
\text { Level of } \\
\text { medical cate } \\
\text { (source) }\end{array}$} & \multicolumn{2}{|l|}{$0-4$} & \multicolumn{2}{|l|}{$5-14$} & \multicolumn{2}{|l|}{$15-54$} & \multicolumn{2}{|l|}{$55+$} \\
\hline & $\begin{array}{l}\text { Incidence } \\
\text { Rate* } \\
(\mathrm{CI}(95 \%))^{* * *}\end{array}$ & $\begin{array}{l}\mathrm{N} * * * * \\
*\end{array}$ & $\begin{array}{l}\text { Incidence } \\
\text { Rate* } \\
(\mathrm{Cl}(95 \%))\end{array}$ & $\begin{array}{l}\mathbb{N * * * *} \\
* *\end{array}$ & $\begin{array}{l}\text { Incidence } \\
\text { Rate* } \\
(\mathrm{CI}(95 \%))^{*}\end{array}$ & & $\begin{array}{l}\text { Incidence } \\
\text { Rate* } \\
(\mathrm{CI}(95 \%))^{* *}\end{array}$ & $\mathrm{~N} * * *$ \\
\hline $\begin{array}{l}\text { Burn Unit } \\
(\mathrm{SCV})\end{array}$ & $\begin{array}{l}23.6 \\
(21.3-25.8)\end{array}$ & 426 & $\begin{array}{l}5.5 \\
(4.7-6.2)\end{array}$ & 198 & $\begin{array}{l}8.5 \\
(8.1-8.9)\end{array}$ & 1494 & $\begin{array}{l}4.1 \\
(3.6-4.6)\end{array}$ & 269 \\
\hline $\begin{array}{l}\text { Hospital } \\
\text { (PORS) }\end{array}$ & $\begin{array}{l}243.2 \\
(220.5-265.9\end{array}$ & $\begin{array}{l}440 \\
9)\end{array}$ & $\begin{array}{l}75.2 \\
(66.2-84.1)\end{array}$ & 272 & $\begin{array}{l}90.8 \\
(86.3-95.2)\end{array}$ & 1596 & $\begin{array}{ll}32.4 & 2 \\
(28.0-36.8)^{2} & \end{array}$ & 211 \\
\hline $\begin{array}{l}\text { General } \\
\text { practice } \\
\text { (NIVEL) }\end{array}$ & $\begin{array}{l}512.0 \\
(397.7 \cdot 626.4\end{array}$ & 4) & $\begin{array}{l}132.6 \\
95.0-170\end{array}$ & 1) & $\begin{array}{l}188.2 \\
168.0-208\end{array}$ & $\begin{array}{l}331 \\
8.6)\end{array}$ & $\begin{array}{l}133.6 \\
(105.5-161.7)\end{array}$ & 87 \\
\hline
\end{tabular}


100,000 persons per year). The incidence rates are lowest among the elderly (55+), but this age group suffers a relatively high mortality rate due to burns (8.5 per 100,000 persons per year; CBS, 1990).

Combining the data of table 2 and 3 , it appears that, over all levels of medical care, scalds are the most common type of burns in all age categories, except for that of patients aged 15-54 and treated by GPs. In this age category other burns, mainly contact burns, predominated. Assuming that the incidence rates may be added over the three levels of medical care, scalds appear to account for almost $60 \%$ of all burns in the $0-4$ year old category, resulting in an overall incidence rate of 430 per 100,000 persons per year.

The sex-specific burn injury incidence rates in table 4 show that males are more prone to serious burn injuries treated in burn units than females, whereas females are more frequently treated by a GP for burn injuries than males. The incidence for patients treated in a hospital seems to be a bit higher for men than for women. Combining the types of burns with the sex-specific data it appears

Table 4. Burn incidence rates in the Netherlands by sex and level of medical care (19881989)

\begin{tabular}{|c|c|c|c|c|}
\hline \multirow{2}{*}{$\begin{array}{l}\text { Sex } \\
\text { Level of medical } \\
\text { consumption } \\
\text { (Source) }\end{array}$} & \multicolumn{2}{|l|}{ Male } & \multicolumn{2}{|l|}{ Female } \\
\hline & $\begin{array}{l}\text { Incidence } \\
\text { Rate* } \\
(\mathrm{CI}(95 \%))^{* *}\end{array}$ & $\mathrm{~N}^{* * * *}$ & $\begin{array}{l}\text { Incidence } \\
\text { Rate* } \\
(\mathrm{CI}(95 \%))^{* *}\end{array}$ & $N^{* * *}$ \\
\hline $\begin{array}{l}\text { Burn unit } \\
\text { (SCV) }\end{array}$ & $\begin{array}{l}10.6 \\
(10.1-11.1)\end{array}$ & 1548 & $\begin{array}{c}5.4 \\
(5.0-5.7)\end{array}$ & 802 \\
\hline $\begin{array}{l}\text { Hospital } \\
\text { (PORS) }\end{array}$ & $\begin{array}{l}87.1 \\
(82.3-91.9)\end{array}$ & 1271 & $\begin{array}{l}83.5 \\
(79.7-88.1)\end{array}$ & 1246 \\
\hline $\begin{array}{l}\text { General practitioner } \\
\text { (NIVEL) }\end{array}$ & $\begin{array}{l}154.3 \\
(133.9 \cdot 174.7\end{array}$ & 220 & $\begin{array}{l}190.0 \\
(168.0-212.1)\end{array}$ & 286 \\
\hline
\end{tabular}

* Number of burns per 100,000 persons per year;

** $95 \%$ confidence interval;

****Number of patients registered. 
that scalds and contact burns are more common types of burns for women than for men. In contrast, flame, chemical and flash burns were more common types of burns for men than for women.

The registration by the GPS showed that $11 \%$ of the burn injury patients were not of Dutch ethnicity (Turkish $6 \%$, Moroccan $2 \%$, Chinese and other $3 \%$ ), while only about $4 \%$ of the Dutch population are not of Dutch ethnicity (CBS, 1988). The numbers of allochthonous versus Dutch $0-15$ year old children among the total Dutch population are $4 \%$ versus $6 \%$, whereas the present study showed that about $55 \%$ of the allochthonous patients and $20 \%$ of the Dutch patients were below the age of 15 . This finding indicates that, relatively speaking, more young allochthonous than Dutch patients are treated by GPs. Data about ethnicity are not available from the burn unit and hospital registration.

\section{$\square \quad$ The burn injury}

Burn injuries can be described in terms of depth (degree), extent (percentage of body surface area (BSA) involved), and agent involved (nature of the burn) (Van Rijn et al., 1989; Bouter et al., 1989). The latter is often described in relation with the circumstances leading to burn injuries.

\section{- Severity of the burn injury}

In the literature, three different operationalizations for severe burn injuries are used which, respectively, define severe burn injuries as: 1) second degree burns in which more than $15 \%$ of the body surface area is affected 2) third degree burns in which more than $2 \%$ of the body surface area is affected 3 ) all burns in which more than $10 \%$ of the body surface area is affected (Van Rijn et al., 1989). Applying these operationalizations to our own data, the following results emerge. About $60 \%$ of the patients treated at burn units had a burn injury which covers more than $10 \%$ of the BSA (criterium 3 ). About $30 \%$ of the patients treated in burn units had a second degree burn injury covering more than $15 \%$ of the BSA (criterium 1), while $15 \%$ of the patients in burn units had a third degree burn injury in which more than $2 \%$ of the BSA was affected (criterium 2).

As expected, it can be concluded that the percentage of patients with a third degree burn injury treated by GPs is very low (about $4 \%$ ). Most burns seen by the GP are only first or second degree. The percentage BSA affected varies from 1 to $10 \%$. Data about the severity of the burns of the patients treated in hospital are not available. 


\section{- Accident circumstances}

The most important accident circumstances for serious scalds and flame burns treated in burn units were related to profession (causing the so-called occupational injuries) $(26 \%)$, to household activities $(23 \%)$, or to playing $(22 \%)$. For scalds and flame burns treated in a hospital, the most important origin was related to household activities (25\%), to personal care $(16 \%)$, or to playing $(13 \%)$. (It should be noted here that burn injuries treated in hospital could not be related to 'profession' because PORS only registers home and leisure accidents). For the scalds and flame bums treated by a GP, the main causes were household activities (35\%), activities of professional kind (15\%), and playing (14\%). For bums treated by a GP it appeared that $80 \%$ of all scalds among $0-4$ year old children occurred while they were trying to get hold of an object filled with hot liquid, which was standing on the stove, or because they spilled hot beverages from cups standing on low tables. This finding is in accordance with the literature (Klasen 1980; Boxma et al., 1984; Van Rijn et al., 1989). As for flame burns, $35 \%$ of those treated by a GP were due to children playing with fire, $10 \%$ for smoking in bed; others because clothes caught fire $(5 \%)$. The background information about the other $50 \%$ of the flame burns treated by the GP is not available. The same holds for the background information about the accident circumstances for burn patients treated in a hospital or in burn units.

In some cases of severe bum injuries, contributing factors were identified. Alcohol was incriminated in $3 \%$ of the cases treated in burn units (in that way that these cases had used alcoholic drinks while getting burned), followed by disability $(2 \%)$ suicide $(2 \%)$, and criminal assault or child abuse $(1 \%)$. These factors were not registered for patients treated in hospital or by a GP.

\section{- Localization of the burn injuries}

Concerning the localization of the burns, only data of patients treated in hospital or by a GP are available. It was found that, for these two levels of medical care, the arms and/or hands are the parts of the body most frequently affected, followed by the legs and/or the feet. Burn injuries of the head are more often treated in hospital than by a GP (14\% of the patients in hospital versus $5 \%$ of the patients seen by a GP have a burn injury of the head). Figure 1 presents the localization of burn injuries for patients treated in hospital and by a GP. (It should be noted that the registration forms for hospital patients allow two, those for the patients seen by a GP only one (the most important) localization of the burn injuries to be marked). 
Patients treated in hospital (PORS)

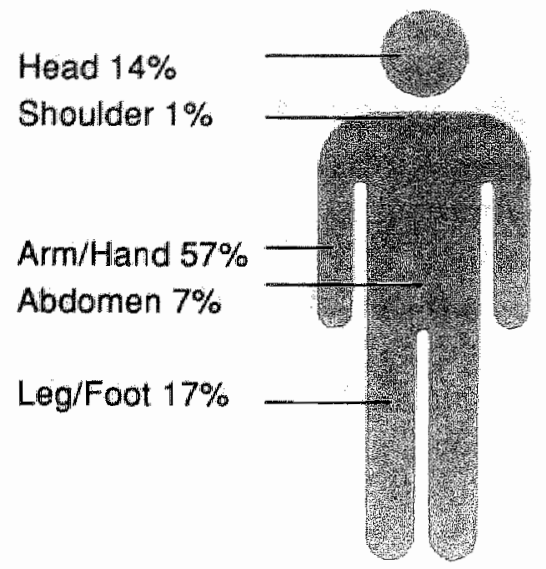

Patients treated by a GP (NIVEL)

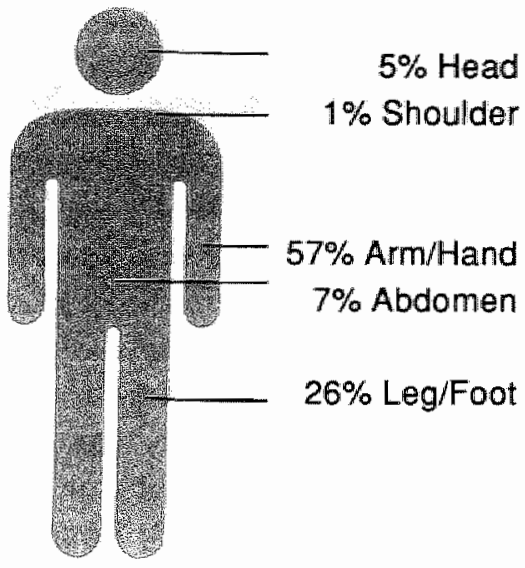

Figure 1: Localisation of the burn injuries treated in a hospital or by a GP

\section{$\square$ DATA COMPARED TO OTHER COUNTRIES}

Assuming that the incidence figures presented for the various levels of medical care may be added, the overall incidence rates for medically treated burns in the Netherlands is estimated to be about 280 per 100,000 persons per year. For other countries, several estimates of the incidence of medically treated burns have been reported in the literature. Published incidence rates for medically treated burns in Denmark and the USA are given in table 5.

Although the incidence rates presented in table 5 are not completely comparable, because of the use of different registration systems, the use of different definitions for the severity of the burn injuries, and the fact that they deal with various levels of medical care, some cautious conclusions can be drawn. Compared to the Dutch incidence figures, some substantially different results have been found. An example is the high incidence rate for scalds in children shown by Glasheen et al. (1982), which appears to be about 2.5 times higher than the corresponding rate for the Netherlands. Sørensen found an incidence of burns treated by GPs which was about twice as high as the Dutch incidence rate (185 versus 350 per 100,000 persons per year). The other incidence, for patients treated in hospital, was between 20 and 30 per 100,000 persons per year; the corresponding figure for the Netherlands is about 4 times higher: 93 per 
Table 5. Reported incidence rates of medically treated burns

\begin{tabular}{|c|c|c|c|c|c|}
\hline Author & Country & $\begin{array}{l}\text { Year of } \\
\text { publication }\end{array}$ & $\begin{array}{l}\text { Incidence } \\
\text { rates* }\end{array}$ & $\mathbb{N} *$ & Remarks \\
\hline Sprensen & $\mathrm{DK}$ & 76 & 350 & 2900 & All burms treated by GPS \\
\hline Thomsen el al. & DK & 78 & 400 & 2200 & All burns over all levels of med,care \\
\hline Lyngdorf et al. & DK & 86 & 300 & 1424 & All burns over all levels of med.care \\
\hline Feck et al. & USA & 79 & 30 & 5791 & All hospitalized burn injuries \\
\hline MacKay et al. & USA & 82 & 200 & 562 & All hospitalized burn injuries \\
\hline Glasheen et al. & USA & 182 & 1100 & 1552 & Scalds in children over all levels \\
\hline Locke et al. & USA & 90 & 20 & 2750 & All hospitalized burninjuries \\
\hline This study & NL & 90 & 280 & 5463 & All burns over all levels of med.care \\
\hline
\end{tabular}

* Number of burns per 100,000 persons per year;

** Number of patients registered.

100,000 persons per year. Looking at the incidence figures reported over all levels of medical care, we find the overall incidence rates vary from 200 to 400 per 100,000 persons per year.

\section{$\square$ DISCUSSION}

The results of this study suggest an overall incidence rate of medically treated burns in the Netherlands of about 280 per 100,000 persons per year. This finding is about the same as an earlier survey-based estimate of the Dutch incidence figure, which amounted to 300 per 100,000 persons per year (Van Montfoort et al., 1988). The overall incidence rate for 0-4 year old children appears to be almost three times as high: 775 per 100,000 persons per year. Over all levels of medical care, scalds are the most frequent type of burns, with an overall incidence rate among 0-4 year old children of 430 per 100,000 persons per year. In burn units, scalds are reported twice as often as flame burns, while hospitals and GPs report, scalds to be, respectively, about five and six times as frequent as flame burns. The incidence rates are, relatively speaking, lowest among the elderly (55+), but this age group suffers a higher mortality rate due to burns (CBS, 1990). Furthermore, it turned out that males are more prone to 
serious burns than females, whereas females are more often treated for less severe burns.

Over $50 \%$ of the burn injuries were located on the arm and/or the hand. Most of the accident circumstances for serious burns were related to profession, whereas most of the circumstances for less severe burns were related to household activities. In accordance with other studies (e.g. Klasen, 1980; Boxma et al., 1984; Van Rijn et al., 1989), most accidents among children were found to occur because they spilled hot beverages from overtumed cups. Comparing the Dutch incidence figures with data from other countries, overall incidence rates are found to be roughly the same, while individual figures with respect to particular levels of medical care were rather different. The most plausible explanation seems to be the use of different registration systems and the use of different definitions for the severity of the burn injuries.

In addition to the remarks about the results, some remarks about the validity of our study should be made. Firstly, our overall incidence rate, which is an addition of three incidence rates based on registration of burns treated in burn units, in hospitals and by GPs, should be interpreted cautiously. The main reason is the overlap between the various registration systems. Data concerning the magnitude of this overlap are not available. Logically, the overall incidence rate must therefore be regarded as an upper limit.

Furthermore, the rate of underreporting by the PORS, which probably also holds for its burn injuries registration, is assumed to be 10\%, (PORS, 1988). This rate however is low, compared to that of a similar surveillance system in Great Britain, which has an underreporting rate of about 30\% (PORS, 1988). The validity of the data from the burn units and hospitals is safeguarded as much as possible by sustaining the motivation of the staff of the participating hospitals, by making unambiguous arrangements concerning the codes to be used and by cross-checking the data (PORS, 1988). As for the data gathered by the burn unit registration and by the registration of burn patients treated by a GP, no information about the amount of underreporting is available.

Other surveillance systems for GPs in the Netherlands estimate predominantly higher incidence rates for burn injuries. The incidence rates for burn injuries estimated by the Continuous Morbidity Registration Nijmegen, the Monitoring Project and the Transition Project are, respectively, 570, 440 and 350 per 100,000 persons per year (NUHI, 1985; Lamberts, 1984; Lamberts, 1990), while the incidence from the NIVEL registration amounted to 185 per 100,000 persons per year. The explanation for the differences between these incidence rates seems to be the use of different registration strategies and different definitions for burn injuries. Moreover, the total number of participat- 
ing GPs and the distribution of these GPs over the Netherlands differ substantially between these registration systems. The network of the NIVEL registration is the biggest, allowing extrapolations to national incidence figures which are not possible from the other, local networks (Grol et al., 1990).

An unambiguous answer to the question why the estimation of the incidence rate by the NIVEL differs from that provided by the other systems is not availlable. An investigation of the validity and reliability of all registration networks for GPs would provide more information about this.

This study has provided information about incidence rates over all levels of medical care, indicating the 0-4 year old age category to be the most important risk group for bum injuries. Furthermore, the conclusion can be drawn that at all levels of medical care, scalds are the most frequent type of burns, again resulting in the highest incidence rate among 0-4 year old children. For health educators this implies that they might be justified in concentrating on the development of educational programs directed at the prevention of scalds in 0-4 year old children, in order to reduce the incidence of burn injuries.

\section{$\square \quad$ Acknowledgement}

This paper was written as a part of the research project 'Prevention of burn injuries in the Netherlands", subsidized by the Dutch Burns Association. We would like to thank the Netherlands Institute of Primary Health Care and the Consumer Safety Institute for the use of the data from their surveillance systems.

\section{$\square$ REFERENCES}

Bouter L.M., Knipschild P.G., Rijn O.J.L. van et al (1989) How to study the aetiology of burn injury: the epidemiological approach. Burns. 15, 162.

Boxma H., Dinkelman R.J., Broekhuizen A.H. (1984) Epidemiologie van verbrandingsletsels in Nederland. Ned. Tijdschr. Geneesk. 45, 2131.

Centraal Bureau voor Statistiek (CBS) (1989) Ontslagen ziekenhuispatienten naar hoofddiagnose, leeftijd en geslacht voor het jaar 1987. Voorburg. Centraal Bureau voor Statistiek (CBS) (1990) Maandbericht Gezondheidssta tistiek, doodsoorzaken over 1987. Den Haag: SDU uitgeverij.

Feck G., Baptiste M.S., Tate C.L. (1979) Burn injuries: epidemiology and prevention. Accidents, Analysis \& Prevention. 11, 129.

Glasheen W.P., Attinger E.O., Haynes A.A. et al (1982) Identification of the high-risk population for serious burn injuries. Burns. $9,193$. 
Grol ME.C. Rijn O.J. van; Bouter L.M. et al., (1991) Brandwonden in de huisartspraktijk. TSO. 69,13 .

Kahn H.A. Sempos C.T. (1989) Statistical Methods in Epidemiology. Oxford: Oxford Uniwersity Press.

Klasen H.J. (1980) Brandwonden. In. de Jonge G.A., Rogmans W.H.J., Winsemius W. Preventie van ongevallen bij kinderen. Alphen a/d Rijn: Stafleu.

Lamberts H. (1984) Morbidity in general practice diagnosis related information from the Monitoringproject. Utrecht.

Lamberts H. (1990) "Transitieproject. intern rapport. Instituut voor Huisartsgeneeskunde. Amsterdam: Universiteit van Amsterdam.

Landelijke Medische Registratie (1989) Ontslagdiagnosen ziekenhuispatienten over 1987. Utrecht: Stichting Informatiecentrum voor de Gezondheidszorg.

l.andelijke Medische Registratie (1990) Ontslagdiagnosen ziekenhuispatienten over 1988. Utrecht: Stichting Informatiecentrum voor de Gezondheidszorg.

Locke J.A., Rossignol A.M., Burke J.F. (1990) Socio economic factors and the incidence of hospitalized burn injuries in New England Countries, USA Burns. 16, 273.

Lyngdorf P., Sørensen B and Thomsen $M_{*}$ (1986) The total number of burn injuries in a Scandinavian population- a prospective analysis. Burns. 12,491.

MacKay A.M., Rothman K.J. (1982) The incidence and severity of burn injuries following project burn prevention. Am. J. Public Health. 3, 248.

Montfoort G.L.M. van, Galen W.Ch.C. van, Harris S. (1988) Ongevallen in Nederland; een onderzoek naar privé-, verkeers-, sport-, en bedrijfsongevallen, in de periode augustus 1986 - augustus 1987. Amsterdarn: Stichting Consument en Veiligheid.

Mulder S. (1989) Overzicht van de registratie van brandwondpatienten in de drie brandwondencentra in Nederland over 1988. Intern rapport nr. 41. Amsterdam: Stichting Consument en Veiligheid.

Mulder S. (1990) Overzicht van de registratie van brandwondpatienten in de drie brandwondencentra in Nederland over 1989. Intern rapport mr. 51. Amsterdam: Stichting Consument en Veiligheid.

Nederlands Instituut voor Onderzoek van de Eerstelijnszorg (NIVEL) (1989) Continue Morbiditeits Registratie peilstations Nederland, jaarverslag 1988. Utrecht: NIVEL.

Nederlands Instituut voor Onderzoek van de Eerstelijnszorg (NIVEL) (1990) Continue Morbiditeits Registratie peilstations Nederland, jaarverslag 1989. Utrecht: NIVEL.

Nijmeegs Universitair Huisartsen Instituut (NUHI) (1985), Morbidity figures from General practice: data from four general practices. Nijmegen: Katholieke Universiteit.

Prive Ongevallen Registratie Systeem (PORS) (1989) Jaarverslag 1988. Amsterdam: Stichting Consument en Veilligheid.

Privé Ongevallen Registratie Systeem (PORS) (1990) Jaarverslag 1989. Amsterdam: Stichting Consument en Veiligheid.

Rijn O.J.L. van, Bouter L.M., Meertens R.M. (1989) The aetiology of burns in developed countries: review of the literature. Burns. $15,217$.

Sorensen B. (1976) Prevention of burns and scalds in a developed country. J. Trauma. 4, 249.

Thomsen M., Bjorn L., Sørensen B.(1978) The total number of bum injuries in a Scandinavian population: a repeated estimate. Burns. 5, 72 . 


\section{How to study the aetiology of burn}

injury: the epidemiological approach*

Lex M. Bouter, Paul G. Knipschild, Olga J.L. van Rijn \& Ree M. Meertens

\section{$\square \quad$ ABSTRACT}

Effective prevention of burn injury should be based on a sound aetiological knowledge. This article deals with epidemiological methods to study burn injury incidence as a function of its risk factors. Central methodological issues are comparability of baseline prognosis, comparability of measurements (of effects in cohort studies and of risk factors in case-control studies), and comparability of external circumstances. These principles are clarified by means of a number of fictitious examples of risk factors for burn injury. It is explained that in preventive trials comparability may be achieved by randomization, blinding and placebo intervention. The main tools in non-experimental studies are deliberate selection and multivariate analysis. Special attention is given to the definition of the source population and to reducing measurement incomparability in case-control studies. Some well designed case-control studies following these principles might bring effective burn injury prevention some steps nearer.

Published in Burns (1989) 15, 3, 162-167. 
Nowadays epidemiology is not restricted to the study of epidemics of infectious diseases anymore. Modem epidemiology deals with the occurrence of all sorts of defects and diseases, such as congenital malformation, cancer, dementia, and also injury, including burn injury. Studying the mere occurrence of burn injuries answers only a very limited number of questions. For a meaningful insight into the aetiology, the occurrence of bum injuries is to be studied as a function of its risk factors. Prevention of burn injuries becomes only feasible when the quantitative contribution of the most important risk factors is known. Next to knowledge about the aetiological role, it will be important to assess the extent to which these risk factors are open to manipulation by means of, for instance, legislation or health education. A number of putative risk factors is not open to manipulation (e.g. gender, age, social economic status), but these factors can be used to identify risk groups with a relatively high incidence of burn injury. Within these risk groups manipulation of other risk factors might be especially effective.

In general, only manipulation of risk factors contributing substantially to burn injury occurrence will lead to an effective prevention. Absence of such factors means that prevention will be very difficult to perform and draws the attention to a further optimization of first-aid, medical treatment and rehabilitation for burn injury victims. In other words, effective prevention should be based on an explicit problem analysis (Green et al., 1980). The epidemiological fundaments of this problem analysis are discussed below. Readers interested in further aspects of the development of preventive strategies to the work of Haddon (1980 a,b) and the textbook of Green (1980).

This article deals with epidemiological methods to study the aetiology (i.e. risk factors) of bum injuries. Special attention will be paid to useful study designs. Fictive examples are given along the way in order to illustrate the methodological considerations. A review of the available empirical data on the aetiology of burn injury will be presented separately (Van Rijn et al., 1989). Below no specific references will be given, although many of the ideas in this paper were not developed by the authors but by leading contemporary epidemiologists (Miettinen, 1985; Feinstein, 1985; Rothman, 1986). For those who want to start a non-experimental epidemiological study we suggest the reading of Jennifer Kelsey's book (Kelsey et al., 1986). This book also gives an introduction in data analysis. More advanced statistical methods can be found in the textbook of David Kleinbaum (Kleinbaum et al., 1982). Below firstly some remarks are made on the definition of a burn injury and on the assessment of the occurrence rate. Secondly, the rationale behind epidemiological studies into the risk factors for burn injury is given. Thirdly, the concept of comparabil- 
ity is explained, in the context of the conventional randomized double-blind placebo-controlled experiment, and suggestions are given to increase its efficiency. Fourthly, because experimental studies are not feasible in many situations, an introduction is provided to the design of non-experimental studies, with the same emphasis on comparability. Special attention is paid to the design of case-control studies. Finally, the problems of incomparability of measurements in case-control studies are discussed.

\section{$\square$ OCCURRENCE}

It is surprising to see how often the occurrence of burn injuries is discussed without a clear definition. Conceptually burn injuries can be described in terms of depth (degree), percentage of body area burned and agents involved (e.g. fire, hot fluids, electricity and radiation). The latter is often misleadingly mentioned as the (sole) cause. Below it will become clear that the agent involved, although being the last observable factor in the causational network leading to injury, offers as a rule no practical guidelines for prevention. Exposure to the agent, that is thermal energy in one form or another, constitutes indeed a necessary cause for burn injury. But total avoidance of this agent is usually not feasible. Prevention should focus on important risk factors that constitute together with the agent at issue sufficient causes for burn injury. It is always necessary to be specific on what is to be considered a burn injury. If the definition is too broad, burn injuries probably will turn out to occur in $100 \%$ of the population. This statement clearly is not very informative. Usually the occurrence of burn injuries is studied in terms of medical consumption. Registration of patients seen in specialized burn clinics, inpatients and outpatients treated by specialists or cases of burn injury that come to the attention of the general practitioner, provide the data available in the literature. This practice is based on the idea that significant burn injuries require medical attention. But not all necessary medical control will take place, especially not for the less severe lesions. Furthermore, some medical attention will be received outside the framework of the registration, while some cases will be counted double or triple. Investigators of the occurrence of burn injuries should complete their registration with the help of additional questionnaires. This calls for studies into the validity of these questionnaires in terms of sensitivity (underreporting) and specificity (overreporting). Counting the number of injured persons is rather meaningless when there is no knowledge about the reference population. Preferably occurrence has to be reported as the fraction of cases of burn injury within a clearly defined popula- 
tion. This opens the possibility to compare the occurrence rate between groups at different times, between areas and among subgroups with different characteristics, thus identifying subgroups especially prone to bum injury. When the occurrence of burn injuries is discussed, nearly always incidence is meant: the number of new burn injuries in a certain period of time. Strictly speaking, incidence can only be studied in a population which has a $0 \%$ prevalence of (that specific) bum injury. It is the rate (speed) with which bum injuries arise in a population at risk. To be less abstract the incident rate for a certain subgroup of the population can be translated into the individual risk for a member of this subgroup. For instance, if the incidence rate for burn injury is 3 per 1000 person-years in a certain population, this implies (some assumptions given) a $0.3 \%$ annual individual risk. Of course, this is an average among members of a group usually defined by one or two demographic parameters. Within that group there may be large differences between subgroups with certain risk factor levels.

\section{$\square$ RISK FACTORS}

There is no single disease which is determined monocausally. Some diseases or injuries occur (by definition) only when a certain risk factor is present (e.g. tubercle bacillus or agent inducing burn lesions), but even then other factors usually play a very important role. As to burn injuries, the situation probably is very complicated. Potential risk factors can be subdivided into many categories, such as gender, age, social economic status, stressful life-events, depression or other personality traits, chronic disease and inability, alcohol abuse, marital problems, methods of preparing meals and coffee, heating device, clothing, electric wiring and so on. The many potential risk factors are, moreover, interrelated. This implies that studying the separate quantitative contribution of a certain risk factor to the level of burn injury incidence is far from easy. It is even questionable whether this puzzle can ever be solved satisfactorily.

Untroubled by this complicatedness a large number of recommendations are found in the literature suggesting ways to prevent burn injuries. These are often based on a mixture of plausibility, casuistry (case reports and case series) and prejudice. Sometimes a quasi empirical reasoning is given to underline the importance of certain preventive measures. Suppose, for instance, that $20 \%$ of the mothers of children with a burn injury treated in a certain clinic mention recent marital problems. This, of course, does not mean that one in every five burn injuries among children is caused by the consequences of marital friction. 
It is possible that the prevalence of recent marital problems among parents of uninjured children is also $20 \%$. A second relatively frequent fallacy is the tendency to translate differences of burn injury incidence at an aggregated level too easily to the individual level. For example, the injury of coffee induced scalds among young children appears to have decreased in the last decade. In the same period an increasing number of educational brochures on the prevention of burn injuries among children has been published. This does not necessarily mean that education has reduced the incidence. The increased prevalence of automatic coffee-makers during the same period might be a better explanation. But also the latter explanation is questionable as long as it is unknown whether these devices are used relatively frequent in households with uninjured children.

\section{$\square \quad$ EXPERIMENTAL STUDIES}

At this moment the knowledge of most putative risk factors for burn injuries is sparse (Van Rijn et al., 1989). In performing epidemiologic studies on the aetiology of burn injuries two ways are open: experimental and non-experimental designs. Characteristic of experimental studies is that the investigator intervenes in one (or more) putative risk factors and subsequently observes whether and to what extent this intervention changes the incidence. To detect such a change the incidence has to be compared to the (baseline) incidence for the situation that the study population is not exposed to the intervention at issue. Obviously it is not feasible to study burn injury incidence in the same group subsequently exposed and not exposed to an intervention dealing with one or more putative risk factors. A solution to this problem is to observe two groups (with and without the intervention) at the same time. It is very important now to have comparability of baseline prognosis. This means that the groups should differ only prognostically as far as the intervention and its consequences changes the incidence. Suppose, for instance, one wants to study the effect of a short course for mothers dealing with burn injury prevention on the incidence of burn injury among their young children. It is likely that mothers volunteering for such a course are in general more careful, possibly leading to an already lower incidence of burn injury among their children. It is not valid now to compare the incidence among children of mothers who take the course, but who were already more careful beforehand, to that of children of mothers who do not take the course. For this reason random allocation should be performed in order to remove any judgement by the investigators or participants as to who will 
attend the course. By following this procedure it is hoped that both groups will be comparable with respect to future burn injury incidence among their children before the intervention takes place. An additional way to make the intervention and the control group prognostically more comparable is restriction. In the example participation might be restricted meaningfully to mothers with low social economic status.

A second point of attention is the comparability of (effect) measurements. Measuring the incidence of burn injuries among the intervention and the control group 'by two standards' will invalidate the results. Investigators do have their prejudices: In the example they may note a less serious burn injury more readily when it concerns a child of a mother in the control group. This problem can be solved best by blinding. The investigator who gathers the information about the effects must be unaware who is in the intervention group and who in the control group. A self-evident supplement to blinding concerns the formulating (beforehand) of precise criteria as to what is to be considered a burn injury.

Comparability of baseline prognosis and of (effect) measurements makes the study internally valid. There is, however, a third point of attention. For scientific reasons it is also important to consider the independent consequences of the intervention on other risk factors. When we want to study the specific causal contribution of the manipulated risk factor, it is necessary to assign all extra maneuvers which accompany the intervention to the control group as well. Otherwise the lack of comparability of external circumstances may confound the association between putative risk factor of interest and burn injury incidence. In our example it can be easily imagined that attending a course on burn injury prevention also leads to increased attention to risk factors not mentioned during the lessons. The control group does not benefit from this elevated awareness of risky situations. On the other hand it is also possible that persons in the control group take some other preventive precaution, because they were not allowed to attend the course. One solution to this problem is to compare the effect of the preventive course to a placebo, i.e. a dummy course which is very similar to the "real' course, but can not be assumed to have any specific bearing on burn injury incidence. Making use of a placebo makes the external circumstances more comparable and also provides an opportunity to blind the study population as well as the investigator performing the effect measurements ('double-blind'), Of course, in practice placebo interventions will be often very difficult to operationalize.

Experiments dealing with the aetiology of burn injuries are not easy to perform due to ethical restrictions. Moreover, experiments require that at least 
some clear ideas about important preventable risk factors are available and require huge numbers of participants. The latter is closely connected to the 'low' incidence rate of bum injuries. Assume, for instance, that the incidence rate is 4 per 1000 person-years and we follow no less than 5000 participants in our trial during one year. Half of them receive an intervention reducing bum injury risk with $50 \%$. Thus 5 cases will be found in the intervention group and 10 in the control group. Unfortunately, this difference is not statistically significant at alpha $=0.05$. Theoretically this situation can be improved by augmenting the number of participants further, restricting the study to groups at high risk and adopting less strict criteria for the effect parameter. The latter seems the most promising for the study of burn injuries. For instance, less severe burns not requiring medical attention could be included. Even the number of (minor) accidents may be viewed upon as an indication of the (much lower) incidence of burn injury. Of course, clear criteria must be established beforehand and blinding will be very important in these situations.

\section{$\square \quad$ NON-EXPERIMENTAL STUDIES}

When experiments are impossible or preliminary to perform, the alternative is to get involved in non-experimental ('observational') studies. We have the opinion that these can indicate whether certain putative risk factors may be important and which factors must be studied further in an experimental design. Non-experimental studies are only informative if they are performed reasonably well, mimicking the basic ideas of comparability in experiments. The main tools in non-experimental studies to prevent incomparability are deliberate selection and multivariate analysis. An experiment is a cohort study in which the investigator decides (although randomly) who is and who is not exposed to the risk factor under study. In an 'observational' cohort study (follow-up study) no intervention takes place and the investigator simply observes what happens to groups with certain characteristics and certain habits under certain circumstances. In its simplest form the cohort is subdivided into two groups, with and without the risk factor of interest. The difference (altributive risk) or the ratio (relative risk) of the incidence rates in the two groups indicates the quantitative meaning of this risk factor in terms of aetiology. Naturally, the subcohorts should be prognostically comparable with respect to all other (external) risk factors. Where randomisation and placebo intervention can not be executed, deliberate selection with respect to certain external risk factors can solve this problem (e.g. restriction to mothers with low social economic status in our 
example). An alternative is stratification (e.g. the division in homogeneous groups with respect to social economic status) followed by calculation of an association measure as a weighted average over the strata. Because there are probably many risk factors involved in the aetiology of burn injuries, the confounding effect of all known risk factors can only be adjusted for in a multivariate analysis. A weak spot of this statistical solution is that complete adjustment is not possible, because there are external risk factors which are still unknown or which cannot be measured precisely.

There are no major ethical restraints to these non-experimental designs and because no interventions are performed these studies can involve very large groups. Consider for instance a follow-up study with 20,000 young children, half of whom live in a household where the coffee is prepared with an automatic coffe-maker. Assume further that the incidence of coffee induced scalds among young children is 8 per 1000 person-years in the absence of a coffee-maker and that the relative risk for this situation is 4 . Now in one year 80 cases will be found in the group without the device and 20 cases in the group with the device. Much of the information on the association between automatic coffee-makers and risk for burn injury among young children is found in only 100 of all 20,000 participants. Among these cases one in every five originated in a household with a coffee-maker. In the very large group of 19,900 uninjured children about one in every two lives in a household with this device. To estimate this frequency also data collection among a sample of 200 children would have done the job. In that case the study consists of only 300 participants. This 'trick' is the central idea of the so-called case-control study. For a fast and remunerative orientation as to which risk factors are associated with burn injuries, performing a case-control study seems to be the obvious way.

As in a cohort study, the first step in a case-control study consists of defining a (source) population that is at risk for burn injury. The cases in the study must be restricted to those belonging to the source population (for example those living within the catchment area of a certain hospital). At the same time, a sample of the same source population must be drawn from persons who have escaped sustaining a burn injury for one reason or another (presumably associated with their risk factor profile). Uninjured persons who are members of a different source population should not be included in the study.

Next, the risk factor profile of all cases and controls is to be measured retrospectively. Now the comparability of risk factor measurement has the highest priority. Those who got injured are already known, so blinding is nearly impossible. It may even happen that the level of some risk factors is changed as a consequence of the injury. Therefore in a case-control study information from 
the cases of bum injury should be collected as shortly as possible after the accident. Whenever the risk factors cannot be measured directly, the participants must be questioned about their risk factor profile immediately prior to the accident leading to burn injury. Standardisation and blinding of the investigator can be realized by using precoded written (postal) questionnaires. This is helpful in preventing measurement incomparability. If personal interviews are unavoidable, it is sometimes possible to hide the study goals for the interviewer (and the participants).

Where blinding of the participants fails, there rises the question whether the cases and the controls are providing correct answers to all items. In general, people with a burn injury recall the circumstances of the accident and their own behaviour relatively well. Maybe even too well, worried as they are why it all happened to them. Some of them have even started to study the literature on burn injury prevention. Consequently they may give socially desirable answers to please the investigator. On the other hand, some cases with an excellent memory will experience a sense of shame. Afraid as they may be to be addressed admonitorily, these cases may conceal their risky behaviour to some extent. In general, it appears that people tend to fill in written questionnaires more honestly compared to answering questions in a personal interview.

In a case-control study the comparability of risk factor measurements is of utmost importance. So, for example, every participant receives a postal questionnaire with a standardized introduction and the same number of items, lay-out, phrasing, etc. This, however, does not prevent incomparability completely. Suppose that the cases try very hard to recall everything the investigator wants to know and they are willing to confess every 'sin'. Now, comparability of measurements is only attained when controls can be motivated to do exactly the same. It is doubtful whether a random sample of the source population can be motivated as strongly as (severely) injured persons. Therefore it may be preferable to have a non-random, but deliberately selected control group with comparable reasons to look back with mixed feelings to the recent past. Consequently the victims of another incident or accident from the source population might be selected for the control group. Of course, the assumption in this procedure is that the risk factor profile with respect to burn injuries of this control group is 'representative' of that of the source population. Choosing such a deliberately selected control group also has the advantage that both cases and controls can be questioned on a comparable basis about their risk factor profile immediately prior to their incident or accident.

There exists a tendency among investigators to pay much attention to the measurement of risk factors of interest and little or no attention to the measure- 
ment of extemal risk factors. This is a mistake. In a non-experimental study the profile of these extemal risk factors may be unequal for persons with and without the risk factors under study and may thus confound the association. Therefore valid and precise measurement of extemal risk factors is necessary in order to adjust for them in an adequate stratified or multivariate analysis. Furthermore, one of the advantages of a case-control design is that within the same set of data the attention in the analysis can focus on the risks associated with a number of risk factors. So the risk factor under study and the external risk factors are interchangeable, provided all are measured validly and precisely. Consequently, in a well designed case-control study the risk associated with a number of risk factors can be studied, under simultaneous adjustment for the influence of risk factors external to the relation at issue. Notice the difference with an experimental study in which normally the modification of onlly one risk factor (the intervention) can be studied.

For practical reasons the number of risk factors included in the case-control study may be restricted. A study of the aetiology of burn injury may thus meaningfully remain restricted to the elderly. A disadvantage of this approach is that it is not possible anymore to study the effect of the risk factors included in the study within other subgroups (e.g. children and adults)

In summary, the Achilles' heel of case-control studies is the comparability of measurements of the risk factors of interest and of all external risk factors which may confound any association of interest. Whenever possible, independent measurements must be taken as well. For instance, it would be of interest to do extra interviews with persons related to the cases and controls in an attempt to discover whether the associations found are changed substantially when using these possibly less precise, but probably more comparable data. If independent records exist about certain risk factors, an attempt may be made to go through these records and to use their data. "Case-controlling" seems easy enough, but the more you think of it, the more its execution appears to be as difficult as an experiment. Nevertheless, considering the 'state of the art', we think that some well designed aetiological case-control studies might bring effective primary burn injury prevention some steps nearer.

\section{Acknowledgement}

This paper was written as a part of the research project 'Prevention of burn injuries in the Netherlands" subsidized by the Dutch Burns Association. 


\section{REFERENCES}

Feinstein A.R. (1985) Clinical Epidemiology: The Architecture of Clinical Research. Philadelphia: Saunders Company.

Green L.W., Kreuter, M.W., Deeds, S.G. \& Patridge, K.B. (1980) Health Education Planning: A Diagnostic Approach. Palo Alto: Mayfield Publishing Company.

Haddon Jr., W. (1980a) Advances in the Epidemiology of Injuries as a Basis for Public Policy. Public Health Reports. 95, 411.

Haddon Jr., W. (1980b) The Basic Strategies for Reducing Damage from Hazards of All Kinds. Hazard Prevention. 16, 1.

Kelsey J.L., Thompson W.D. \& Evans A.S. (1986) Methods in Observational Epidemiology. New York: Oxford University Press.

Kleinbaum D.G., Kupper L.L. \& Morgenstern H. (1982) Epidemiologic Research: Principles and Quantative Methods. Belmont: Lifetime Learning Publications.

Miettinen O.S. (1985) Theoretical Epidemiology: Principles of Occurrence Research in Medicine. New York: John Wiley \& Sons.

Rijn O.J.L. van, Bouter L.M. \& Meertens R. (1989). The aetiology of burns in developed countries: review of the literature. Burns. 15, 217.

Rothman, K.J. (1986) Modem Epidemiology. Boston: Little, Brown and Company. 



\title{
4
}

\section{$\square$ The aetiology of burns in developed countries: review of the literature*}

\author{
Olga, J.L. van Rijn, Lex, M. Bouter \& Ree, M. Meertens
}

\section{$\square \quad$ ABSTRACT}

This article reviews the literature on the incidence and aetiollogy of burn injuries. Burn injuries are among the most serious injuries man can incur. Although prevention of burn injuries has been given a good deal of attention in the past, it has never been subjected to a systematic approach which could result in a thorough knowledge of the incidence and the major risk factors and risk groups. The methodological limitations of the studies carried out in this field are striking. For instance, none of the studies of risk factors has used a control population for comparison. No figures are available on the total number of burn injury patients in the Netherlands. Estimates are derived from the situation in other countries, which yields an incidence of 4 per 1,000 persons per year. Scalds are relatively common in the $0-4$ age category. This is usually assumed to be caused by the stage of development of motor and cognitive skills, coupled with incorrect assumptions about these skills by parents. Men are found to be more often the victims of burns than women. Coffee and tea are assumed to be risk factors. The supposed risk factors and risk groups need to be investigated in a controlled epidemiologic study, in order to allow establishment of preventive measures.

* Published in Burns (1989) 15, 4, 217-221. 
Burn injuries have long been described in the literature as among the most serious injuries that may afflict a human being (Gross, 1864; Artz, 1979; Feck et al., 1979; Hermans \& Olthuis, 1984). The main reason is that severity and long-term effects of the injury are often considerable. This paper will discuss the incidence and nature of burns, as well as the circumstances under which burns occur. In addition, possible risk factors will be discussed. It is important to note that the literature referenced is primarily drawn from European, American and Australian studies. There is scant literature from non-Western countries to provide data for comparison so it is not possible to assess the roles that custom and culture play in patterns of burn injuries.

Burn injuries are described in terms of 'depth' and 'extent'. The latter aspect is often measured by means of the 'rule of nine' (Wallace, 1951), in which the individual body areas represent a certain percentage of the total body surface area. This rule has to be adjusted in the case of children, as their bodily proportions are different. Roughly speaking, "extensive burns' are all burns which affect more than $10 \%$ of the body's surface (Hermans, 1982). The depth of the burn is expressed in terms of first, second or third degree. In addition to the extent and depth of the burn injury, the patient"s age and the affected part of the body also determine the severity of the injury. Thus in very young (age 0-4) and elderly patients, burns are sooner life-threatening than in the other age categories. And burns to the face, neck, hands and perineum are relatively serious, because shrinkage often occurs during the healing process, which may lead to contractures (Spijker, 1980). In the literature, burn injuries are often categorized on the basis of the nature of the burn. The most common categorization (Hermans \& Spijker, 1977) is the following:

- Scalds (caused by hot liquids)

- Flame burns

- Flash burns (resulting from radiant heat in explosions)

- Contact burns (resulting from touching hot objects)

- Chemical burns

- Electric burns (resulting from electric current)

- Other causes, including radioactivity and irradiation.

Since chemical and electric burns are too complex in nature (Philips-Duphar, 1979; Huffstad et al., 1975), and often bear little resemblance to other types of burn injuries, these two types of burns will not be discussed here. The depth of scalds is often very difficult to ascertain. In this type of burn injury, burns which are initially assumed to be second degree often tum out later to be third degree. 
This may have consequences for treatment. Hence a reappraisal of the depth diagnosis after 12 to 24 hours is essential in this type of burn injury (Broekhuizen, 1987). In scalds, it is also important to know the nature of the causative agent, since, for instance, hot water (with its high specific heat) tends to cause deeper burns than hot oil or fat. Flame and contact burns will generally be deep (Van der Putten \& Schouten, 1985; Philips-Duphar, 1979). Flash burns are rarely discussed in the literature, probably because of their low incidence. A category receiving a good deal of attention lately is that of sunburns. In the above categorization of burn injuries by nature, these belong with the "other causes'. Severe sunburn is comparable to superficial burn injuries (Bickers, 1982). Apparently, the number of sunburn cases is rising, as a result of the growing popularity of sunbathing in the Western world. This rising incidence is attributed to the desire to acquire a tan as soon as possible, and to the increasing use of pharmaceuticals which can render the skin abnormally sensitive to solar radiation (Van der Klauw, 1988). The depth of such sunburns is often 'only' first or second degree.

Over the last few years, much progress has been made in the treatment of burn injuries. However, the specialized care given to serious patients is timeconsuming and very expensive. Here too, prevention is better than cure. Effective prevention requires a thorough understanding of the major risk factors. Publications on this subject are scarce. Most papers discuss the medical treatment of burns, or describe the occurrence, nature or severity of the burns. But studies of risk factors involving comparisons between groups of patients with burn injuries and control groups are not available, although the importance of this type of research in relation to the study of the aetiology of burn injuries is generally recognized (Knudson-Cooper, 1984).

\section{$\square \quad$ INCIDENCE}

The incidence of burn injuries is clearly related to the severity of the burns. The incidence of (very) light burns can be said to amount to $100 \%$, but this figure is hardly interesting. Of greater importance are the data on more severe burn injuries, but here the problem of defining such severe burn injuries arises. The literature shows the use of three types of operationalization, which, define severe burn injuries as 
- Second degree burns in which more than $15 \%$ of the body surface area is affected (Spijker et al., 1980);

- Third degree burns in which more than $2 \%$ of the body surface area is affected (Koller, 1987);

- All burns in which more than $10 \%$ of the body surface area is affected (Hermans, 1982).

Incidence data based on these conceptual definitions are not available. However, burn injuries can also be described in terms of medical consumption, which allows a distinction between burn injuries treated by the general practitioner or by the specialist, on an inpatient or an outpatient basis, or in a specialized burn injury treatment centre. This distinction is made because of the great difference between all burn injuries and the subgroup of those who have been admitted to hospital. Incidence data based on medical consumption are available, though limited. A study of over 24,000 households in the Netherlands (Van Monfoort et al., 1988) estimates the number of burn injury patients receiving medical treatment in the Netherlands each year at 45,500 . It is assumed that about 31,000 of these patients are treated by the general practitioner. These assumptions result in an incidence rate of 3 per 1,000 medically treated burn patients per year, of which 2 per 1,000 patients treated by a general practitioner per year. Since the middle of 1983 , the Dutch Home and Leisure Accident Surveillance System (PORS) has kept a record of the burn injuries treated at First Aid Stations or other in- or outpatient departments in hospitals. Among the 18 types of injuries recorded, burn injuries take about the tenth place, with a share of ca. $2 \%$ (PORS, 1984, 1985, 1986). According to the Dutch National Medical Records (LMR), over 4,000 burn injury patients are hospitalized in the Netherlands each year. Of these patients, an average of 450 were admitted to the specialized burn injury treatment centres in 1984 and 1985 , while this figure rose to 650 in 1986 (Stichting Consument en Veiligheid, 1987, not published). Some of the data on medically treated bum injuries inside and outside the Netherlands, taken from the literature, are given in Table 1.

For a number of reasons, the incidence figures in Table 1 cannot be easily compared with one another. The main reason is the use of various definitions for the severity of the burn injuries. The incidence rates from Denmark (Sørensen, 1976; Thomsen, 1978; Lyngdorf, 1986) are based on epidemiological studies on the total number of burn injuries carried out in Copenhagen in 1965 , 1975 and 1983. Because of the fact that the registration system covered those treated in hospital as well as those treated by a general practitioner, it was possible to estimate the total number of burn injuries and to calculate the 
Table 1. Incidence rates based on medical consumption

\begin{tabular}{llcccl}
\hline Author & Country & Year & $\begin{array}{l}\text { Incidence } \\
1000 / \text { year }\end{array}$ & N* & Remarks \\
\hline Thomson & DK & 1978 & 4 & 2200 & All types of burn injuries \\
Glasheen et al. & USA & 1982 & 10,7 & 1552 & Only scalds in children \\
Feck et al. & USA & 1979 & 0,3 & 5791 & Burn injuries more than 10\% BSA \\
Lyngdorf & DK & 1986 & 3 & 1424 & All types ofburn injuries \\
Sørensen & DK & 1976 & 3,5 & 2900 & $\begin{array}{l}\text { Burn injuries treated by a general } \\
\text { practitioner }\end{array}$ \\
Montfoort et al. & NL & 1988 & 3 & 24000 & $\begin{array}{l}\text { All types ofburn injuries } \\
\text { Montfoort } e t \text { al. }\end{array}$ \\
& NL & 1988 & 2 & 24000 & $\begin{array}{l}\text { Burn injuries treated by a general } \\
\text { practitioner }\end{array}$ \\
\hline
\end{tabular}

* Number of patients

incidence of medically treated burns. Nevertheless, some cautious conclusions can be drawn from these data. The incidence of burn injuries is much higher among the 0-4 age category than among the other age categories. This corresponds with data from Dutch studies (e.g. Klasen, 1983; Rogmans, 1984). The explanation for this is often sought in the great urge for movement of children at this age, their lack of skill in walking and their lack of judgement (Klasen, 1983; Rogmans, 1984). In addition, parents often misjudge their children's developmental stage, which may also contribute to the high incidence of burn injuries (Rivara \& Howard, 1982). The low incidence figure reported by Feck, Baptiste and Tate (1979) can be attributed to the fact that they only include burn injuries which affect more than $10 \%$ of the body surface area, i.e. only very severe burn injuries. All other investigators report incidence figures around 3 or 4 per 1,000 persons per year.

\section{$\square \quad$ RISK GROUPS}

Scalds are the most frequent type of burns (e.g. Glasheen et al., 1981; Klasen \& Sauer, 1979; Rogmans, 1984; Haberal et al., 1987; Darko et al., 1986; Libber et al., 1984). In children between the ages of 0 and 4 , scalds account for $50 \%$ of all burn injuries (Thomas et al., 1984). For the other age categories the fugure is 
lower. In their study of burns in children $(\mathrm{n}=382)$, Klasen and Sauer (1979) even found a percentage of scalds of $80 \%$ in the $0-5$ age category. They distinguish between various types of hot liquid (including bath water, coffee, tea, soup) and report that coffee and tea are the most frequent causes of burns. A later study (Klasen \& ten Duis, 1986) of young children $(n=884)$ showed a similar percentage of scalds ( $77 \%$ ), with a reduced share for coffee. A possible explanation for this could be the increased popularity of the automatic coffee-maker. This will be discussed in more detail below.

Davies (1985) studied 1680 children with burn injuries, resulting for the 0-4 age category in a percentage of scalds similar to that reported by Klasen (1979). In addition, Davies found a clear difference between boys and girls in this age category: boys are more often the victims of scalds than girls. Similar findings have been reported by other investigators (Glasheen et al., 1982; Libber et al., 1984; Mackay-Rossignol et al., 1986). However, Davies (1985) reports that in the $0-1$ age category the percentage of scalds is about equal for boys and girls. It is striking that the number of burn injuries among children between the ages of 5 and 14 is so much lower than that in the $0-4$ category (Davies, 1985). Moreover, the former age category shows relatively more burns of other types than scalds, such as flame and contact burns. This has also been found by Mackay (1979) in a study of age-specific burn injuries $(n=2729)$. This author discovered that flame burns often occurred in boys between the ages of 10 and 14 , very often as a result of explosions involving petrol. This type of burns occurred eight times more often in boys than in girls. Flame burns are the most common type in the category of 60 years and over, and lethality is relatively high for these injuries (Anous \& Heimbach, 1986). Ostrow (1987) studied 327 burn injury patients over 65 years of age, and found that $51 \%$ of all burn injuries in this group were flame burns, $1.9 \%$ were scalds, and $18 \%$ were contact burns. The remaining $12 \%$ were electric, tar and other burns. The study showed that in this age category contact burns were more common in men. In the 20-39 age category the majority of burn injuries are apparently also flame burns (Boxma et al., 1984).

\section{$\square$ CIRCUMSTANCES}

The circumstances which lead to burn injuries can best be discussed on the basis of the nature of the burn. Since burns by hot liquids and by fire are relatively more common than others, only scalds and flame burns will be discussed here. 
As for scalds, tea and coffee are regarded as the most important causes (Klasen, 1980; Rogmans, 1984). Typical circumstances under which such scalds occur include that of children getting holld of an object filled with hot liquid, which is standing on the stove or the kitchen worktop. Another common situation is that of children pulling down a hot liquid container with the tablecloth (Klasen, 1980). In his study of scalds among Brisbane children, Philips (1986) showed that very young children (aged 0-2) incur relatively more scalds from overturned cups or mugs, while slightly older children (aged 2-6) receive burn injuries relatively more often as a result of hot water from baths, showers or taps. Davies (1985) also mentions hot water from baths, showers or taps as a major cause of burns. Among the 1036 young children with burn injuries he studied, $49 \%$ got their injuries from this source. Bum injuries caused by hot water from baths or taps appear to be far less frequent in the Netherlands than in Great Britain. This difference has been explained by the greater popularity of mixing taps in the Netherlands (Klasen, 1980). Most scalds occur in the home. In the kitchen, most accidents occur during the cooking or while making tea or coffee. In his study in Copenhagen, Sørensen (1977) found that nearly all scalding accidents occurred in the kitchen. Davies (1985) mentions children at play, who push each other under the shower or into a bath, as the prime cause of scalds. Rogmans (1984) mentions that in the Dutch situation, the course of events of scalding accidents in bathrooms is not always clear. The impression is that children often injudiciously turn on the hot water tap by themselves.

As for flame burns, a number of common circumstances can also be found in the literature. Byrom (1984) regards liquids (particularly petrol and paraffin) catching fire as the most common situation in which flame burns occur. This cause is also mentioned by Klasen (1980), but in his study of 316 burn injury patients between the ages of 0 and 14 , playing with fire was found to be a more common situation leading to flame burns. In particular during the summer months, a relatively large number of flame burns result from exploding butane gas containers. Saxby and Shakespeare (1985) described 47 burn injury patients admitted to the Wessex burn injury treatment centre as a result of exploding butane gas containers. Of these accidents, 18 were the result of failure to observe the instructions on the container. In the Netherlands too, exploding gas containers cause many burn injuries each year (Boxma et al., 1984). Finally, it has been found that many flame burns are caused by textile fabrics catching fire. Rogmans (1983) subdivides these products into clothing fabrics (clothes, cleaning cloths, rags) and furnishing fabrics (bedclothes, carpeting, curtains and 
upholstery). Clothing fabrics are most often set on fire by contact with gas stoves, electric lights and matches, while furnishing fabrics catch fire particularly from electrical appliances, gas stoves, burning cigarettes and matches.

It should also be borne in mind that in some cases of burn injuries in young children, there are indications of maltreatment: Particularly bum injuries with an 'abnormal pattern', where often only certain parts of limbs are burnt, may indicate deliberate infliction, especially if it concerns bum injuries which narrowly fail to be serious enough to warrant hospitalization (Lung et al., 1977).

\section{$\square \quad$ RISK FACTORS}

The proposed risk factors can be classified into demographic factors, situational and personal characteristics, and products, and they will be discussed in that order below.

\section{$\square \quad$ Demographic factors}

Strictly speaking, conclusions about risk factors can only be drawn if the presence of such factors in persons with burn injuries is compared with that in persons from a control group without burn injuries. As was mentioned above, the need for this type of research is generally accepted, but the existent literature on the subject of burn injuries shows no studies actually using this type of research. Hence this section of the paper will discuss a number of possible risk factors that are assumed to be related to the occurrence of burn injuries, although there is no solid empirical evidence for this.

As was described above, burn injuries occur more often in young children (aged 0-4). This is often attributed to the development of motor and cognitive skills, and to an incorrect opinion on the part of the parents about these skills. The influence of sex has been discussed above. On the whole, boys aged 0-14 are found to suffer more frequent burn injuries than girls. De Leeuw (1988) seeks to explain this difference in terms of acquired or encouraged 'masculine' or 'feminine' role behaviour. On the basis of his study of risk factors in 1552 persons admitted into the Virginia burn injuries centre with severe burn injuries over a period of 21 months, Glasheen (1982) concluded that, in general, men run a higher risk of burn injuries than women. In addition, this author claims that the non-white population runs a higher risk of severe burn injury than the white population. 


\section{$\square \quad$ Situational and personal characteristics}

Noyes (1979) demonstrated a positive correlation between stressful life events and the occurrence of burn injuries. Of the 67 burn injury patients admitted to the Iowa City burn injury centre in 1978, about half turned out to have a long history of physical and psychological disorders. Physical disorders included arteriosclerosis, hypertension and diabetes mellitus. Psychological disorders included alcoholism and anxiety neuroses. Such complaints were found to be related to stressful events such as divorce or loss of employment, occurring during the year preceding the accident at which they suffered their burn injuries. The study led to the identification of two groups of persons who have an increased risk of burn injuries: elderly women with physical complaints, and persons belonging to the lower socio-economic classes who have psychological problems. Again, the study could be criticized for not using a control group. In a study similar to that by Noyes (without a control group), Libber (1984) examined ca. 100 children aged $0-16$, who had been admitted to the Baltimore burn injury centre. He concluded that boys aged 1-2, who are the youngest in a large, single-parent family, and who belong to the lower socio-economic classes, run an increased risk of bum injuries. Knudson-Cooper (1984) adds to the list of risk groups those children at school age who have many problems adapting to school and who are hyperactive.

\section{Products}

As was discussed above, coffee and tea are often involved in accidents leading to burn injuries in childen aged 0-4. Because of this, Sørensen (1976) started a campaign for the prevention of burn injuries as a result of overturned coffee filters, by marketing two safe coffee filters. The share of 'overtumed coffee filters' in the causation of burn injuries then fell from $45 \%$ in 1971 to $32 \%$ in 1974. Whether this decrease can be attributed to the new coffee filters was not investigated any further. The drop may also have been caused (Klasen, 1986) by the increased use of automatic coffee makers. The role of coffee and tea as a risk factor for burn injuries is frequently discussed in the literature. In addition, less common risk factors are also regularly reported. Some of these factors will be briefly discussed here. An example is inflammable nightwear for children, which is often involved in accidents leading to burn injuries. Moreover, children often have such nightwear on when they are not actually in bed, which increases the risk of burns. Unlike other European countries, Dutch law has not yet banned easily inflammable textiles for clothing. Around New Year's Eve, many burn injuries are caused by fireworks. Furthermore, many young children 
in Denmark are reported to suffer burns when they put old, broken, bakelite power plugs into their mouths (Fogh-Anderson, 1984). Other products presenting risk factors include barbecue grills, candles, and electric kettles. However, these factors appear to be of minor importance compared to coffee and tea.

\section{DISCUSSION}

Despite the number of published studies of risk factors for burn injuries, hardly any controlled epidemiologic research is available which would allow sound conclusions about particular risk factors. The course of events leading to burn injuries in e.g. young children is frequently investigated, but parents whose children did not suffer burn injuries are never interviewed. Most studies of burn injuries focus on the nature and severity of the burns. In addition, a number of factors (particularly in the case of scalds in children) are described as risk factors (e.g. coffee and tea). But again, all of these studies were carried out without a control group. Nevertheless, recommendations for intervention are frequently made on the basis of such non-controlled studies. It is essential, therefore, that carefully planned epidemiologic studies, using an adequate control group, are undertaken. It will also be necessary to make a more complete estimate of the incidence of bum injuries, in order to establish the full extent of the problem. As soon as risk factors have been identified, it should be established which factors can be changed or influenced, and what methods would be most effective in bringing about the desired change in behaviour. In so far as the factors identified are mainly related to behaviour, health education would appear to be an important method. Should most of the factors identified turn out to be not directly related to behaviour, legal measures and regulations would be more effective. Eventually, evaluative studies will have to show whether influencing the risk factors actually leads to a decrease in the number of burn injuries.

\section{Acknowledgement}

This paper was written as a part of the research project 'Prevention of burn injuries in the Netherlands' subsidized by the Dutch Burns Association. 


\section{REFERENCES}

Anous M.M., Heimbach D.M. (1986) Causes of death and predictors in Burned Patients, more than 60 years of age. J. Trauma. 26, 135.

Artz C.P. (1979) Epidemiology, causes and prognosis. In: Artz, Moncrief, Pruitt (eds) Burns, a team approach. Philadelphia: Saunders Company.

Bickers D.R. (1982) Treatment of selected photosensitivity diseases. Med. Clin. North Am. 66, 927.

Boxma H., Dinkelman R.J., Broekhuizen A.H. (1984) Epidemiologie van werbrandingsletstels in Nederland. Ned. Tijdschr. Geneeskd. 45, 2131.

Broekhuizen A.H. (1987) Behandelingsprotocol Brandwonden. Amsterdam: Academisch Medisch Centrum.

Byrom R.R., Word E.L., Tewsbury C.G. et al. (1984) Epidemiology of flame burn injuries. Burns. 11, 1.

Centraal Bureau voor de Statistiek (1987) Maandbericht Gezondheidsstatistiek. jaargang 6, no 5 .

Darko D.F., Wachtel T.L., Ward H.W. et al. (1986) Analysis of 585 burn patients hospitalized over a 6-year period. Part II: aetiological data. Burns. 12, 391.

Davies J.W.L. (1985) The incidence and causes of burns and scalds in children in the United Kingdom. Occasional Paper no.7, Symposium on accidents in childhood: London.

Feck G., Baptiste M.S., Tate C.L. (1979) Burn injuries: epidemiology and prevention. Accidents, Analysis \& Prevention. 11, 129.

Fogh-Andersen P.F., Sørensen B. (1984) Electric oral burns in Danish children with special reference to prevention. Scand. J. Reconstr. Surg. 18, 107.

Glasheen W.P., Attinger E.O., Anne A. et al. (1981) Epidemiology of minor burn injuries. Burns. 8, 423.

Glasheen W.P., Attinger E.O., Haynes A.A. et al. (1982) Identification of the high-risk population for serious burn injuries. Burns. 9, 193.

Gross S.D. (1864) Handboek der heelkunde. Nieuwediep: de Buisonjé.

Haberal M., Oner Z., Bayraktar U. et al. (1987) Epidemiology of adults' and childrens' burns in a Turkish burn center. Burns. 13, 136.

Hermans R.P. (1982) Brandwonden, oorzaken, eerste hulp, behandeling door de huisarts, chirurgische behandeling, organisatie in Nederland. Tijdschr. Geneesmiddelenonderzoek. $7,1157$.

Hermans R.P., Olthuis G.A.A. (1984) De organisatie van de brandenzorg in Nederland. Ned. Tijdschr. Geneeskd. 128, 2136.

Hermans R.P., Spijker R.E. (1977) Brandwonden / medische hulp bij rampen. van Hoytema. Cursus: medische hulp bij rampen, $11 / 12$ mei 1977.

Huffstadt A.J.C. Klasen H.J. (1977) The present state of burn treatment; Postgraduate Course, May 1977, Curacao.

Klauw J.W. van der, Gill K. (1988) Kleine kwalen in de huisartsgeneeskunde. Huisarts en Wetenschap. 43, 232.

Klasen H.J. (1980) Brandwonden. In: de Jonge G.A., Rogmans W.H.J., Winsemius W. Preventie van ongevallen bij kinderen. Alphen a/d Rijn: Stafleu.

Klasen H.J. (1983) Letsels bij kinderen door ongevallen in huis. Ned. Tijdschr. Geneeskd. 47, 2124. 
Klasen H.J, ten Duis H.J. (1986) Changing panterns in the causes of scalds in young Dutch children. Burns. 12,563.

Klagen H. J., Sauer E. W. (1979) Oorzaken van brandwonden bij kinderen (0-14 jaar). Tijdschr. Soc. Geneeskd. 57,756.

Knudson-Cooper M.S. (1984) What are the research priorities in the behavioral areas for burn patients? J. Trauma. Suppl. 24, 197.

Koller J. (1987) Classification of inhalation injuries. In: Program/abstracts second congress european burns association. Klinikum der RWTH: Aken.

Leeuw E. de (1988) Voorlichting ter woorkoming van ongevallen in de privésfeer van kinderen tussen 0 en 5 jaar. In: Jonkers R., Haes W.F.M., Kok, G.J. et al (eds) Effelktiviteit van Gezondheidsvoorlichting en - Opvoeding. Kijswijk: Gezondheidsbevordering. p. 254

Libber S.M., Stayton D.J. (1984) Childhood burns reconsidered: the family and the burn injury. J. Trauma. $24,245$.

Lung R.J., Miller S.H., Davis T.S. et al. (1977). Recognizing burn injuries as child abuse. Am. J. Fam. Phys. 15, 134.

Lyngdorf P. (1986) Epidemiology of severe burn injuries. Burns. 12, 491.

MacKay A., Halpern J., McLoughlin E. et al. (1979) A comparison of age- specific burn injury rates in five Massachusetts communities. Am.J. Public Health. 69, 1146.

MacKay RossignoJ. A., Boyle C.M., Locke J.A. et al. (1986) Hospitalized Bum Injuries in Massachusetts. an assessment of incidence and product involvement. Am. J. Public Health. 11,1341 .

Montfoort G.L.M van, Gallen W.Ch.C, van, Harris, S. (1988) Ongevallen in Nederland: een onderzoek naar privé-, verkeers-, sport-, en bedrijfsongevallen, in de periode augustus 1986 - augustus 1987. Amsterdam: Stichting Consument en Veiligheid.

Noyes R., Frye S.J. Slymen D.J. et al. (1979) Stressful life events and burn injuries. J. Trauma. $19,141$.

Ostrow L.B., Bongard F., Sacks S.F. et al. (1987) Burns in the elderly. Am. Fam. Phys. 35, 149. Philips W., Mahairas E., Hunt D. et al. (1986) The epidemiology of child hood scalds in Brisbane. Burns. 12, 343.

Philips-Duphar. (1979) Brandwonden. Klinische aspekten huisarts, Eerste hulp en preventie. Amsterdam: Philips-Duphar Nederland B.V.

Privé Ongevallen Registratie Systeem. (1985) Jaaroverzicht 1984, Amsterdarn: Stichting Comsument en Veiligheid.

Privé Ongevallen Registratie Systeem. (1986) Jaaroverzicht 1985. Amsterdam: Stichting Consument en Veiligheid.

Privé Ongevallen Registratie Systeem. (1987) Jaaroverzicht 1986. Amsterdam; Stichting Consument en Veiligheid.

Putten F. van der, Schouten H. (1985) Uit de brand ben je. Alphen a/d Rijn: Stafleu. p. 11

Rivara F.P., Howad D. (1982) Parental knowledge of child development injury risks. Dev. Behavior Paediatr. 3, 103.

Rogmans W.H.J. (1984) Jonge kinderen en ongevallen risico"s buiten het verkeer. Dissertation. Amsterdam. p. 49

Rogmans W.H.J. (1984) Verbrandingen bij kinderen - omvang, achtergrond en preventiemogelijkheden. Med. Contact. 46, 1485.

Rogmans W.H.J., Braams J.H. (1983) Textielprodukten en verbrandingen. Amsterdam: Stichting Consument en Veilligheid. 
Saxby P.J., Shakespeare P.G. (1985) Burn injuries from portable butane camping stoves. Burns. $11,427$.

Sørensen B. (1976) Prevention of burns and scalds in a developed country. J. Trauma. 4, 249. Sørensen B., Werner H., Asmussen C.F. (1977) Coffee scalds- pursuant prophylaxis. Burns. 3, 166.

Spijker R.E., Kunst M.W., Klasen H.J. et al. (1980) Indicaties voor opneming in een brandwondencentrum. Ned. Tijdschr. Geneeskd. 124, 1469.

Stichting Consument en Veiligheid. (1987) Overzichtcijfers brandwondencentra. Amsterdam: Stichting Consument en Veiligheid. (niet gepubliseerd)

Thomas K.A., Hassanein R.S., Christophersen E.R. (1984) Evaluation of group well-child care for improving burn prevention practices in the home. Pediatrics. 74, 879.

Thomsen M., Bjørn L.. Sørensen B. (1978) The total number of burn injuries in a Scandinavian population: a repeated estimate. Burns. 5,72 . 



\section{Aetiology of burn injuries among children aged 0-4: results of a case-control study"}

Olga J.L. van Rijn, Lex M. Bouter, Amold D.M. Kester, Paul G. Knipschild \& Ree M. Meertens

\section{$\square$ ABSTRACT}

During the year 1987/1988 a case-control study was conducted, by means of a postal questionnaire, among parents of children aged $0-4$. Cases $(n=122)$ were 0-4 year old Dutch children who visited emergency departments with burn injuries. Controls $(n=213)$ were a sample of the Dutch population of $0-4$ year old children without burn injuries. Odds ratios based on logistic regression (OR-LR) and $90 \%$ confidence intervals $(\mathrm{Cl}(90 \%))$ were calculated for a number of putative risk factors.

The risk of burns was higher for children with other than Dutch (e.g. Turkish) ethnicity (OR-LR=5.6; $\mathrm{CI}(90 \%)=2.6-11.9)$. Children who lived in relatively small houses turned out to run a higher risk of burns (OR-LR $=2.5$; $\mathrm{Cl}(90 \%)=1.3-4.7)$. To our surprise, children belonging to lower socio-economic classes were found to have a decreased risk of burns (OR-LR $=0.3 ; \mathrm{CI}(90 \%)$ $=0.1-0.6$ ). Furthermore, among several manipulatable risk factors, the use of an oven window which gets hot while in use appeared to lead to an increased risk of burns (OR-LR=2.1; CI $(90 \%)$ 1.3-3.5). The same holds for the storage of hot

* Accepted for publication in Burns. 
drinks in their original pots instead of in vacuum flasks (OR-LR=2.0; $\mathrm{CI}(90 \%)$ 1.2-3.1). Cooking on a gas stove tumed out to be another risk factor (OR$L R=2.5$; $C I(90 \%) 1.1-10.0)$.

\section{$\square \quad$ INTRODUCTION}

An extensive burn is a catastrophic injury because its severity and long-term effects are often considerable (Artz, 1979; Feck et al., 1979; Hermans \& Olthuis, 1984; Van Rijn et al., 1989). In 1988 the incidence of burns treated by general practitioners (for all age categories) amounted to 2 per 1,000 person per year in the Netherlands (Grol et al., 1991), while the total incidence of medically treated burns was estimated at 3 per 1,000 persons per year (Montfoort et al., 1989). For children aged 0-4, the incidence of burns treated by general practitioners is as high as 6 per 1,000 persons per year (Grol et al., 1991). A number of studies have reported scalds to be the most frequent type of burns, accounting for more than $50 \%$ of all burn injuries among children aged 0-4 (e.g. Thomas et al, 1984; Van Rijn et al., 1989; Bouter et al., 1989; Bouter et al., 1990). This high incidence figure, in combination with the fact that burns are more often life-threatening in young children than in the other age categories (e.g. Spijker et al., 1980), led us to study the aetiology of burns in this population.

A review of studies on the aetiology of burn injuries (Van Rijn et al., 1989) showed that there is no consensus with respect to the most important risk factors for burn injuries: several studies have yielded conflicting results (e.g. Noyes et al., 1979; Libber \& Stayton, 1984; Davies, 1985). Furthermore, most of these studies had severe methodological limitations (Van Rijn et al., 1989). Measures of association (such as odds ratios or risk differences) between putative risk factors and the risk of burn injury are usually not presented in these publications. Moreover, most of the studies did not adequately control for confounding (Rothman, 1986). This makes it impossible to estimate the independent contributions of the individual risk factors to the injury risk. Consequently, we decided to perform a new study into the aetiology of bum injuries, in which we tried to overcome most of the methodological problems of earlier publications on this subject. 


\section{METHODS}

A case-control study was conducted among (parents of) children aged 0-4 in the Netherlands. The study population consisted of $0-4$ year old children. The parents of these children were the actual respondents, because they completed the questionnaire.

\section{$\square \quad$ Cases}

Cases were children aged $0-4$ who presented with burn injuries at the emergency department of one of 14 Dutch general or university teaching hospitals between September 1987 and August 1988. Burn injuries were defined as injuries caused by hot liquids, flames (and smoke inhalation), hot objects, electricity, chemical reaction or ultraviolet radiation. These cases were obtained from the "Home and Leisure Accident Surveillance System" (PORS) of the Dutch Consumer Safety Institute (PORS, 1989). This system registers home and leisure accidents in 14 Dutch hospitals, which form a sample of the 139 general and university teaching hospitals in the Netherlands with an accident and emergency department offering a 24 hour service. This sample is representative with respect to size of hospitall and level of urbanization (PORS, 1989).

\section{$\square \quad$ Controls}

The control group consisted of a sample of the Dutch population within the same age category. For every case of injury selected, two uninjured children were chosen. The control population was recruited through maternal and child health centers in four places in the Netherlands. Dutch parents of young children can easily be contacted through these centers because practically all visit them regularly, e.g. to have their children vaccinated. Over a two week period all parents of children aged 0-4 who visited the health center were asked to participate in the study. If the parents had more than one child, they were asked to answer the questionnaire for their oldest child in the $0-4$ age category.

\section{$\square \quad$ Questionnaire}

The questionnaire was handed out to the parents of the control group in the child health centers and was sent to the parents of all cases registered in the above mentioned surveillance system. It consisted of 113 items for the cases and 70 
items for the controls. Identical questions for both groups inquired about demographic characteristics of the child and the parents, the design of the kitchen and the bathroom of the house, risk taking and risk perception, knowledge about the prevention of (burn) injuries and other putative risk factors mentioned in the scientific and popular literature. In addition to this, cases were questioned about the circumstances of the accident and the subsequent bum injury. This article reports on all measured putative risk factors for bum injuries, but its brevity made it impossible to include information about risk taking and risk perception.

\section{$\square \quad$ Statistical analysis}

The association of putative risk factors with bum injuries was expressed as odds ratios (OR), which can be interpreted as relative risks (Rothman, 1986). If there is no association the OR equals 1 , while for an elevated risk the OR is higher than 1 , and an OR between 0 and 1 indicates that this level of the risk factor is associated with a reduced risk of burn injuries.

Control for confounding is necessary to estimate the independant contribution to the burn injury risk of the separate risk factors of interest. This was achieved by means of stratification and multivariate analyses. Therefore, the statistical analysis was performed in two stages. Firstly, ORs were calculated with adjustment for potential confounding by age. This adjustment was necessary since the age distribution of the controls deviated markedly from that which had been expected (CBS, 1990). The adjustment was performed by taking Mante]-Haenszel (MH) weighted averages of the ORs (OR-MH) over the three age strata $(0,1,2-4$ years). Test-based $90 \%$ confidence intervals which reflect the precision of the estimated ORs were obtained using the Miettinen method (Kleinbaum et al., 1982). A confidence interval gives the lower and upper bounds for the true value of the association. Thus, we can be reasonably confident that a factor is associated with an elevated risk if the lower bound of the confidence interval is higher than 1 . This also implies that the association is statistically significant at a 5\% level (one-sided test). We chose here to calculate intervals with $90 \%$ confidence, since the implications of an unjust verdict on an 'innocent' factor are not very grave. Figures on the prevalence of the putative risk factors among cases and controls are adjusted for differences in age by means of standardization. As a standard the age distribution among the total 0-4 year old Dutch population of 1988 was used.

In the second stage of the analysis, a multiple logistic regression (LR) model (Kleinbaum et al., 1982) was used to obtain ORs (OR-LR) for each of the factors included in the model, while adjusting for all the other factors. All 
potential confounding factors were included in the model as dichotomous or categorical variables. Furthermore, in order to check the uniformity of stratumspecific ORs, all first order interaction terms were entered into the model and tested for significance (Kleinbaum et al., 1982). The estimated ORs (OR-LiR) reflect the relative burn injury risk for the risk factor at issue, while the levels of all other factors in the model remain constant. In addition to this, 90\% confidence intervals were calculated, based on the asymptotic standard error of the estimated log OR (Kleinbaum et al., 1982).

\section{$\square$ RESULTS}

\section{$\square \quad$ Response}

Response was $62 \%$ for the cases $(n=124)$ and $89 \%$ for the control group $(n=217)$. Six respondents were excluded from the analyses because they did not complete the questionnaire. In the end, data on 335 0-4 year old children were analyzed, including 122 cases and 213 controls.

The mean age of the injured children was 1.3 years (the distribution over the 0,1 and $2-4$ years age categories being respectively, $17 \%, 53 \%$ and $30 \%$ ), while that of the uninjured children was 0.8 years. The lower mean age in the control group is probably due to the fact that children aged between 0 and 1 have to visit the maternal health care centers about twice as often as the other age categories. The distribution of 0,1 and 2-4 year old children in the Dutch population is, respectively, 20\%, 20\%, 60\% (CBS, 1990), while in our control population it was $55 \%, 23 \%, 22 \%$. This makes clear that children aged 0 were overrepresented in the control group. As a consequence, the risks associated with age could not be estimated directly in this study. To avoid confounding due to these differences in age, all data on the prevalence of risk factors among cases and controls were adjusted by standardization for age in three categories $(0,1,2-4$ years), and every odds ratio presented was adjusted for confounding by age.

\section{Injuries}

In the literature, burn injuries are generally categorized on the basis of the nature of the burn (e.g. Hermans \& Spijker, 1977; Van Rijn et al., 1989). The most common type of burns in our study were scalds $(n=77)$, which are typically caused by hot water or hot liquids like coffee, tea, soup or oil. The second commonest type were contact burns $(n=37)$, which are caused by touching hot 
objects like the gas stove $(n=9)$, the oven door $(n=10)$, the (electric) heater $(n=13)$, or the iron $(n=5)$. The remaining 8 cases consisted of flame burns $(n=3)$, electric burns $(n=2)$ or sun burns $(n=2)$.

Most of the scalds were located on the arm (39\%) or on the chest $(29 \%)$ of the child, while almost all contact burns were located on the hand or fingers of the child $(82 \%)$.

In assessing the severity of the burns, the extent of body surface affected can be expressed as a percentage of the total body surface area (BSA). In addition to this, three degrees of depth are usually distinguished. A severe burn injury is (a) a burn which, independently of the depth of the injury, covers more than $10 \%$ of the BSA (criterium 1; see Van Rijn et al., 1989), or (b) a second degree burn injury which covers more than $15 \%$ BSA (criterium 2), or (c) a third degree burn injury which covers more than $2 \%$ BSA (criterium 3). According to these three criteria, about $14 \%(n=17)$ of the cases had a severe injury. About $63 \%$ $(n=77)$ of the cases had a relatively small second degree burn injury ( $9 \%$ of the BSA), while the remaining $23 \%(n=28)$ had a first degree injury only, covering less than $10 \%$ of the BSA.

\section{$\square \quad$ Accident circumstances}

Among the 77 scalds, 38 were cases in which hot beverages had been spilled from overturned cups. In most of these cases $(n=29)$ the cup filled with the hot beverage was standing on a low table, so that the child could reach it very easily. Nine children had pulled down a hot liquid container with the tablecloth. Other common situations included overturning pulling over kettles, jugs or teapots by pulling at the flex. Most of these accidents happened while the parents were near, or even in the same room as the child.

Among the 37 contact burns, 13 occurred because the child had touched a hot oven, an ellectric fire, a room heater or other hot objects. These contact burns often seemed to be related to the motor development of the child; children who have only recently begun to walk can easily get burmed because they may lose their equilibrium and fall backwards onto a hot object. Four children had burned their hands by touching a hot iron. 


\section{Risk factors for burn injuries}

Putative risk factors for bum injuries can roughly be divided into two groups. The first group consists of safety behaviours on the part of the parents, such as the way in which they prepare and drink coffee and tea, or make the surroundings of their children safer. These factors are referred to as "manipulatable factors" because they can theoretically be changed by means of health education. The second group, the "poorly manipulatable factors", consists of non-behavioural risk factors which can occasionally be changed by regulation or legislation, but more often cannot be changed at all. Examples of these factors are socio-economic factors (education and housing circumstances), gender and number of children.

\section{$\square \quad$ Manipulatable factors}

To our surprise we found that more parents of uninjured children cooked on an electric stove compared to those of injured children. Thus, cooking on a gas stove turned out to be a risk factor for burn injuries (OR-MH=2.5, see table 1 ). Furthermore, it was found that the use of an oven with a window which gets hot is associated with a higher risk of burns $(\mathrm{OR}-\mathrm{MH}=2.0)$, since fewer parents of uninjured children used such an oven in comparison with those of injured children. Keeping hot drinks in their original pot instead of in a vacuum flask also turned out to be associated with a higher risk of burn injuries (OR$\mathrm{MH}=1.6$ ).

In addition to these statistically significant findings, there seemed to be a difference in the way that parents brew and drink coffee and tea. Fewer parents of uninjured children reported preparing coffee manually compared to those of injured children. (Making coffee manually means that the coffee is prepared by pouring boiling water onto ground coffee in a filter). Making coffee manually turned out to be weakly associated with a higher risk of burns when compared to making coffee with a electric coffee maker (OR-MH=1.5). However, inspection of the confidence intervals in table 1 shows that this association did not reach statistical significance at the $5 \%$ level. The same holds for the other associations in table 1 , which are discussed below.

The type of coffee filter was investigated as a putative risk factor for burn injuries only among parents who prepared their coffee manually. Four types of filters are shown in figure 1. Fewer parents of uninjured children used the unsafe coffee filter $\mathrm{B}(\mathrm{OR}-\mathrm{MH}=2.3$ ). Furthermore, the use of separate hot and 
Table 1. Manipulatable risk factors for burn injuries

\begin{tabular}{|c|c|c|c|c|c|}
\hline Risk faltor & $\begin{array}{l}\text { Cases } \\
N=122\end{array}$ & $\begin{array}{l}\text { Controls } \\
\mathbb{N}=213\end{array}$ & OR-MH & CI $(90 \%)$ & $\mathrm{AF}^{\#}$ \\
\hline Cas stove & $92 \%$ & $90 \%$ & & & \\
\hline ws electric stove & $8 \%$ & $10 \%$ & 2.5 & $1.1-10.0$ & $57 \%$ \\
\hline Oven window gets hot & $51 \%$ & $35 \%$ & & & \\
\hline us remains cold during use & $49 \%$ & $65 \%$ & 2.0 & $1.2-3.3$ & $26 \%$ \\
\hline Hot drinks in original pot & $64 \%$ & $53 \%$ & & & \\
\hline vs in a vacuum flask & $36 \%$ & $47 \%$ & 1.6 & $1.1-2.6$ & $24 \%$ \\
\hline Use of an unsafe filter & $50 \% *$ & $33 \% *$ & & & \\
\hline vs safe coffee filter & $50 \% *$ & $67 \% *$ & 2.3 & $0.6-9.3$ & \\
\hline Making coffee manually & $18 \%$ & $12 \%$ & & & \\
\hline vs with coffee maker & $82 \%$ & $88 \%$ & 1.5 & $0.8-2.8$ & \\
\hline Separate hot and cold taps & $13 \%$ & $12 \%$ & & & \\
\hline vs mixing tap & $87 \%$ & $88 \%$ & 1.5 & $0.7-3.0$ & \\
\hline Not turning pan handles & $14 \%$ & $15 \%$ & & & \\
\hline vs turning them away & $86 \%$ & $85 \%$ & 1.2 & $0.6-2.3$ & \\
\hline Temperature of water $>60$ & $53 \%$ & $47 \%$ & & & \\
\hline$v s<60$ degrees Celsius & $47 \%$ & $53 \%$ & 1.2 & $0.6-2.2$ & \\
\hline
\end{tabular}

\# Aetiologic Fraction; * $N=28 ; * * N=34$.
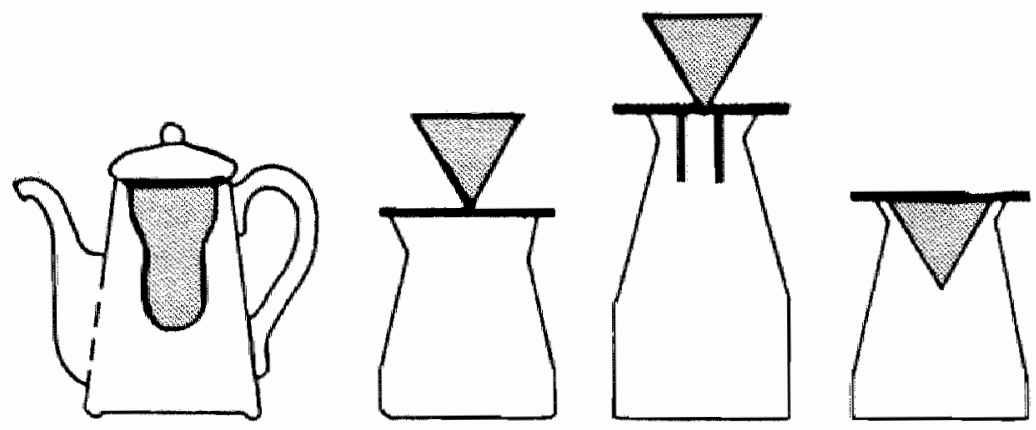

Figure 1: Types of coffee-filters

Source: Sørensen, 1976 
cold taps, not turning pan handles away and not having adjusted the temperature of the water, all appeared to be associated with a slightly higher risk of burn injuries.

For the statistically significant risk factors, table 1 also presents the aetiologic fractions (AF). This is an estimate of the theoretical maximum reduction of burns that could result from a total elimination of the risk factor at issue (Rothman, 1986). Aetiological fractions should be looked upon as rough indicators of the importance of a factor from a preventive point of view, assuming that the association has indeed a causal nature (Bouter et al., 1990).

Table 2. Poorly manipulatable risk factors for burn injuries

\begin{tabular}{|c|c|c|c|c|}
\hline Risk factor & $\begin{array}{l}\text { Cases } \\
\mathrm{N}=122\end{array}$ & $\begin{array}{l}\text { Controls } \\
\mathrm{N}=213\end{array}$ & OR-MH & $\mathrm{CI}(90 \%)$ \\
\hline Ethnicity: other than Dutch & $13 \%$ & $3 \%$ & & \\
\hline$w_{s}$ Dutch origin & $87 \%$ & $97 \%$ & 4.5 & $1.8-10.9$ \\
\hline Low education level parents & $70 \%$ & $85 \%$ & & \\
\hline ws high education level & $30 \%$ & $15 \%$ & 0.4 & $0.2-0.7$ \\
\hline Housing: small house & $16 \%$ & $9 \%$ & & \\
\hline ws large house & $84 \%$ & $91 \%$ & 2.1 & $1.1-4.4$ \\
\hline Unable to walk & $67 \%$ & $35 \%$ & & \\
\hline ws able to walk & $33 \%$ & $65 \%$ & 1.8 & $0.9-3.3$ \\
\hline Mother with a (part-time) job & $27 \%$ & $23 \%$ & & \\
\hline vs without job & $73 \%$ & $77 \%$ & 1.5 & $0.9-2.6$ \\
\hline Mother aged $18-30$ & $48 \%$ & $38 \%$ & & \\
\hline ys $31-48$ & $52 \%$ & $62 \%$ & 1.3 & $0.9-2.1$ \\
\hline Family with one child & $41 \%$ & $47 \%$ & & \\
\hline$w s$ more than one child & $59 \%$ & $53 \%$ & 0.9 & $0.6-1.4$ \\
\hline Gender of the child: boy & $52 \%$ & $51 \%$ & & \\
\hline$v s$ girl & $48 \%$ & $49 \%$ & 1.0 & $0.7-1.6$ \\
\hline
\end{tabular}




\section{Q Poorly manipulatable factors}

As table 2 shows, our results suggest a more than four-fold risk for children of other than Dutch (mainly Turkish) origin", in comparison to children of Dutch origin (OR-MH $=4.5$ ). To our surprise, a low level of education seemed to have a protective effect against burn injuries (OR-MH=0.4). Living in a small house $e^{* * *}$ was found to be associated to an increased risk of burn injuries (OR$\mathrm{MH}=2.1$ ).

Furthermore, children who were able to walk seemed to have (almost) twice as high a risk of burns compared to children who were not yet able to walk. Here again, however, it must be kept in mind that inspection of the confidence intervals shows that only the first three associations mentioned in table 2 reached statistical significance at the $5 \%$ level (one-sided test). Furthermore, it seemed that children whose mothers have a (part-time) job run a slightly increased risk of burns ( $\mathrm{OR}-\mathrm{MH}=1.5$ ). The same holds for children whose mothers are under the age of $30(\mathrm{OR}-\mathrm{MH}=1.3)$. No difference in risk was found between families with only one child compared to families with more than one child (OR-MH=0.9). "The OR for gender was 1.0 , indicating no differences in burn injury risk between boys and girls.

\section{$\square \quad$ LOGISTIC MODEL}

In order to control for mutual confounding among risk factors, the independent contribution of each putative risk factor was calculated by means of a logistic regression analysis. All the risk factors mentioned in tables 1 and 2 were included in the logistic model, with the exception of the variable 'type of coffee filter' and the variable 'able to walk'. These two variables were not included for reasons of collinearity (Kleinbaum et al., 1982): the variable 'type of coffee filter' was strongly correlated with the method of making coffee and the variable 'able to walk' with the age of the child. In the logistic regression model we checked for interaction among the factors included in the model by checking for heterogeneity among stratum-specific ORs. This check did not reveal any important variation in the estimated effects over the strata. Thus, in the final model no interaction terms remained. The variable 'age of the child' was

* Ethnic origin was determined by the ethnic origin of the father.

** Whether housing was classified as small or large was based upon the subjective evaluation of the respondents. 
Table 3. Odds Ratios from the logistic regression model

Risk factor

OR-LR CI (90\%) OR-MH

Ethnicity: other than Dưtch

ws Dutch origin

5.6

$2.6-11.9$

4.5

Low education level parents

ws high education level

$0.1-0.6$

0.4

Gas stove

us electric stove

$2.5 \quad 1.1-10.0 \quad 2.5$

Housing: small house

vs large house

$$
1.3-4.7
$$

Oven window gets hot

ws remains cold during use

$2.1 \quad 1.3-3.5 \quad 2.0$

Hot drinks in original pot

ws in a vacuum flask

$1.2-3.1$

Separate hot and cold taps

vs mixing tap

$0.8-3.1$

Mother aged 18-30

vs 31-48

$0.9-2.5$

Temperature of water $>60$

$v s<60$ degrees

$0.4-1.1$

Making coffee manually

vs with coffee maker

$1.3 \quad 0.6-2.4 \quad 1.5$

Family with one child

vs with more than one child

$1.3 \quad 0.7-2.5 \quad 0.9$

Not turning pan handles away

vs turning them away

$0.7-2.6$

Mother with a (part-time) job

vs without job

$0.7 \cdot 2.1$

Gender of the child: boy

vs girl

0.9

$0.6-1.4$

1.0 
entered into the logistic model as a potential confounding variable because of the selection bias described above. Thus, the logistic model in the end consisted of 15 variables: 14 putative risk factors and one potential confounding variable.

The results of this logistic model (table 3 ) indicate again that children with other than Dutch (mainly Turkish) ethnicity ran a higher risk of bum injuries (OR-LR=5.6). As for housing situations, it can be concluded that living in a small house is associated with a higher risk (OR-LR=2.5) of burns. A low level of education of the parents is associated with a lower risk of bums in their children (OR-LR $=0.3$ ). Furthermore, it appeared that the use of an oven window which gets hot during use is associated with a higher risk (OR-LR=2.1). The same holds for the storage of hot drinks in their original pots (OR-LR=2.0). Cooking on an electric stove seems to reduce the risk of burn injuries (OR$L R=0.4$ ). The correlations between the coefficients of these 6 (statistically significant) variables were not strong $(r<0.20)$, which implies that there is no substantial mutual confounding among these variables.

All the other associations calculated did not reach statistical significance. The odds ratios with their corresponding $90 \%$ confidence intervals from the logistic model are shown in table 3. The ORs-MH are shown once more in this table to enable comparison with the ORs-LR.

When the logistic regression analysis was restricted to cases of scalds only $(\mathrm{N}=77)$, approximately the same results emerged (although not statistically significant, due to the smaller number of cases involved).

\section{$\square \quad$ DISCUSSION}

Before discussing the results, the validity of our study deserves some attention. In a case-control study the major potential threats to validity relate to the choice of the study population, the comparability of information gathered from cases and controls, and the presence of confounding factors (Rothman, 1986).

First of all the study might be biased in favour of the more severe cases, because cases were recruited at emergency departments. However, it is our impression that less severe burn patients are also treated in out-patient departments. This impression is supported by the fact that only $14 \%$ of the cases were identified as severe burn injury patients, while $23 \%$ of the cases only had first degree burn injuries which affected less than $10 \%$ of the BSA. Therefore, the cases did not seem to be substantially selective in this respect.

Furthermore, the controls were selected by their attendance at the maternal and child health center during a two-week period of time while the cases were 
selected by their being treated for a burn injury over about a 12-month interval. Consequently, our study design would miss any effects associated with seasonal variation, and thus the study results may be biased by seasonal effects.

There was almost certainly selection bias for age due to the way the controls were selected. In the first stage of our analysis we adjusted for the latter by means of stratification, and in the logistic model by including this variable as a potential confounder. As was mentioned above, this implies that the risk associated with age could not be calculated directly in this study. However, it was possible to estimate the risk associated with the variable 'age of the child' indirectly, by using all 0-4 year old children in the Dutch population (CBS, 1990) as a control group and by comparing them with the cases in our study. Using children aged 0 as the reference category, it was found that those aged 1 run a three-fold risk of burns ( $O R=3.1)$, while the $2-4$ year old category shows a decreased risk of burns $(\mathrm{OR}=0.6)$.

We are not sure whether selection for ethnicity has played a part in the constitution of the control population, because we did not know whether Turkish parents visit the maternal and child health centers as often as the Dutch parents do. However, data on the total population in the Netherlands (CBS, 1990) show that the division of Turkish versus Dutch children aged 0-4 was $3.5 \%$ versus $96.5 \%$. For our control group these figures were $3 \%$ versus $97 \%$. Thus, with respect to the attendance at the health centers it can be concluded with some caution that the percentage of Turkish children is not substantially different from that among the Dutch population as a whole (Kuiper et al., 1985). Hence, our controls were probably not substantially selective with regard to ethnicity.

The relation between putative risk factors and burn injury risk might have been obscured because we mixed different types of burn injuries, which possibly have their own specific aetiology. However, when the logistic regression analysis was confined to scalds only, the results which emerged were almost the same as those presented in table 3 . When we used variable selection procedures based on statistical algorithms (Kleinbaum et al., 1982) for deciding which manipulatable factors to include in the final logistic model, we found, in the case of scalds, that the "use of a vacuum flask" was the only variable which contributed statistically significantly to the final model. When we did the same analysis for contact burns it appeared that the variable 'oven window which gets hot' was the only statistically significant variable in the logistic model.

Information about putative selection bias due to non-response is not available. Information bias relates to the question whether the information obtained for cases and controls is comparable. This type of bias occurs if either cases or 
controls overreport (or underreport) risk factors. Because the study is retrospective, the parents of the cases may have given biased answers if they felt guilty about (the circumstances of the injury. Another variety of information bias is recall bias, which can arise if the parents of the cases remember exposures more accurately than those of the controls (Rothman, 1986). The reason for this could be that the accident leading to the burn injury probably serves as a stimulus in recalling all the events that might have played some role. However, less subjective items such as the type of housing and the motor development of the child are less susceptible to this type of bias.

Another problem is connected with the imprecise (or even biased) measurement of the risk factors which could result from the fact that we used structured questionnaires, in which we relied on the opinions of the parents themselves. For some of the factors, such as the housing situation, different measurement procedures (e.g. observation) might have been more appropriate.

To control for confounding, multiple logistic regression analysis was performed. In this analysis every known potential confounder was adjusted for. Consequently, confounding was probably not a serious threat to the validity of the study. However, this procedure does not exclude bias due to unmeasured confounders or confounding due to imprecision and bias in the measurements.

It is important to note here that, although we are sure we have studied many important putative risk factors for burn injuries, completeness with respect to all the putative risk factors can never be guaranteed.

Another limitation of our study was the rather small size of the study population. This influences the precision of the study. Only relatively large differences between cases and controls would attain statistical significance. Furthermore, statistical significance does not always imply relevance or causality. For that reason it is doubtful whether a strict interpretation in terms of significance is justified (some instances of significance might be due to chance). Thus, the results of this study must also be interpreted in the context of preventive relevance and plausibility of causality.

With regard to the manipulatable risk factors, the results of this study confirm an elevated risk resulting from the use of an oven window which gets hot $(O R-L R=2.1)$ and from not keeping coffee or tea in a vacuum flask (OR$L R=2.0$ ). Cooking on a gas stove appeared to increase the risk for burns in comparison with cooking on an electric stove (OR-LR=2.5). However, this finding conflicts with our initial idea that electric cooking would increase the risk of contact burns. Thus, we did not expect the electric cooker to have a preventive effect. An explanation for this discrepancy might be that parents who 
used an electric cooker were more cautious while cooking than other parents because they recognised the dangers (see Wilde, 1982). For this reason we do not feel sure that electric cooking does indeed prevents burns.

As in other studies, a weak, statistically non-significant, elevated risk was found for making coffee manually (see e.g. Klasen, 1980). Another result which is consistent with other studies is the (statistically non- significant) finding that the use of a mixing tap (Klasen \& Ten Duis, 1986) is associated with a protective effect against burns in young children ( $O R-L R=0.6$ ).

As for the poorly manipulatable factors, the most striking finding is that children of other than Dutch origin (mainly Turkish) run an almost six-fold risk of burn injuries in comparison with Dutch children (OR-LR=5.6). In contrast with earlier studies (e.g. Noyes, 1979; Libber \& Stayton, 1984; Van der Maas et al., 1987) no evidence could be found in our data that children belonging to the lower socio-economic classes run an elevated risk of burns. Our results even provide some evidence for the contrary: children belonging to a lower socioeconomic class appeared to run a decreased risk of burns $(O R-L R=0.3)$. However, socio-economic class was operationalized as the level of education of the parents only and not by level of income or profession. An other possible explanation for this surprising result of the association with socio-economic class might be due to differences in response rate and the resulting selection bias. Response rates were very different for cases (62\%) compared with controls $(89 \%)$. Controls probably felt less free to decline participation in the study. Children who were living in small houses appeared to have a more than two-fold risk of burns compared to those living in large houses (OR-LR=2.5).

From a preventive point of view these poorly manipulatable risk factors cannot be changed by means of health education. Moreover, even regulations or legislation could probably not change these risk factors.

As for the manipulatable risk factors, health education may be a promising tool in the prevention of burn injuries among young children, since such burn injuries seem to have at least some specific behavioural causes. From our study it appears that the use of a safe oven window which remains cold while in use, the use of a vacuum flask for the storage of hot coffee and tea and cooking on an electric stove have a substantial preventive effect on the risk of burn injuries.

The aetiologic fractions of these factors (see table 1) indicate that these factors are important from a preventive point of view. Some other factors studied, which did not reach statistical significance, but which are easy to manipulate (e.g. making coffee with a coffee maker, adjusting the temperature of the water) may also be tentatively interpreted in the context of preventive relevance. The effectiveness of subsequent health education will also depend on 
the knowledge about the main determinants of these behavioural risk factors. Thus, before starting health education directed at primary prevention of burn injuries among young children, research on the determinants of these risk factors will first be performed (Van Rijn et al., 1990; Bouter et al., 1990).

Only then will we reach the stage of the development and implementation of a health education program, and know more precisely what to advise people in order to protect their children against burn injuries.

\section{$\square \quad$ Acknowledgment}

This paper was written as a part of the research project 'Prevention of burn injuries in the Netherlands', subsidized by the Dutch Burns Association.

\section{$\square$ REFERENCES}

Artz C.P. (1979) Epidemiology, causes and prognosis. In: Artz C.P., Moncrief J.A., Pruitt B.A. (eds) Burns, a team approach. Philadelphia: Saunders Company.

Bouter L.M., Knipschild P.G., Rijn O.J.L. van, et al (1989) How to study the aetiology of burn injury: the epidemiological approach. Burns. 15, 162.

Bouter L.M., Rijn O.J.L. van, Kok G.J. (1990) Importance of planned health education for burn injury prevention. Burns. 16, 198.

CBS (1990) Tabellen leeftijdsopbouw, jaarwerk 1989. Voorburg: Bevolkings statistieken CBS.

Davies J.W.L. (1985) The incidence and causes of burns and scalds in children in the united kingdom. Occasional paper no 7, Symposium on accidents in childhood: London.

Feck G. Baptiste, M.S., Tate C.L. (1979) Burn injuries: epidemiology and prevention Accident, Annual \& Prevention. 11, 129.

Green L.W. and Lewis F.M (1986) Measurement and evaluation in health education and health promotion. Palo Alto: Mayfield.

Green L.W., Kreuter M.W., Deeds S.G. et al (1980) Health education planning: a diagnostic approach. Palo Alto: Mayfield.

Grol M.E.C., Rijn O.J.L., Bouter L.M., et al (1991) Brandwonden in de huisartspraktijk. T. Soc. Gezondheidszorg. 69, 13.

Hermans R.P. and Olthuis G.A.A. (1984) De organisatie van de brandenzorg in Nederland. Ned. Tijdschr. Geneeskunde. 128, 2136.

Hermans R.P., Spijker R.E. (1977) Brandwonden / medische hulp bij rampen. van Hoytema. Cursus: medische hulp bij rampen, 11/12 mei 1977.

Klasen H.J. and ten Duis H.J. (1986) Changing patterns in the causes of scalds in young Dutch children. Burns. 12, 563.

Kleinbaum D.G., Kupper L. L., Morgenstern H. (1982) Epidemiologic Research: principles and quantitative methods. Belmont: Lifetime Learning Publishing.

Kok G.J. (1986) Gezondheidsmotivering, GVO als wetenschapsgebied. Gezondheiden Samenleving. 7,58 . 
Kuiper C.M., Schlesinger-Was E.A., Vaandrager G.J. (1985) Preventieve gezondheidszorg voor kinderen van migranten. T. Soc. Gezondheidsz. 67, 365.

Libber S.M. and Stayton D.J. (1984) Childhood burns reconsidered; the family and the bum injury. J. Trauma. 24, 245.

Maas P.J., van der, Mackenbach LJ., Gunning-Schepers L.J. (1987) Social- economische gezondheidsverschillen: op weg naar een onderzoeksstrategie. In: De ongelijke verdeling wan gezondheid. Verslag van een conferentie gehouden op 16-17 maart 1987. WVC, Rijswijk.

Montfoort G.L.M van, Galen W.Ch.C van, Harris S. (1989) Ongevallen in Nederland: een onderzoek naar privé-, verkeers-, sport-, en bedrijfsongevallen, in de periode augustus 1986 - augustus 1987. Amsterdam: Stichting Consument en Veiligheid.

Noyes R, Frye S.J., Slymen D.J. (1979) Stressful life events and burn injuries J. Trauma. 19, 141.

PORS, Jaaroverzicht privé ongevallen registratie systeem. (1989) Amsterdam: Stichting Consument en Veiligheid.

Rijn, O.J.L. van, Bouter, L.M., Meertens, R.M., et al (1988) Brandwonden bij 0-4 jarige kinderen, verslag van een etiologisch patiënt-controle-onderzoek. Amsterdam: Stichting Consument en Veiligheid.

Rijn O.J.L. van, Bouter L.M., Meertens R.M. (1989) The aetiology of burns in developed countries: review of the literature Burns. 15, 217.

Rijn O.J.L. van, Meertens R.M., Bouter L.M., et al (1990) Determinants of behavioural risk factors for burn injuries. Accepted for publication in Burns.

Rothman K.J. (1986) Modern Epidemiology. Little, Brown and company: Boston/Toronto.

Sorensen B. (1976) Prevention of burns and scalds in a developed country. J. Trauma. 4, 249.

Spijker R.E., Kunst M.W., Klasen H.J. (1980) Indicaties voor opneming in een brandwondencentrum. Ned. Tijdschr. Geneeskd. 124, 1469.

Thomas K.A., Hasanein R.S., Christophersen E.R. (1984) Evaluation of group well-child care for improving burn prevention practices in the home. Pediatrics. 74, 897.

Wilde G.J.S. (1982) The theory of risk homeostasis. Risk analysis. 2, 209. 



\title{
Determinants of behavioural risk factors for burn injuries*
}

\author{
Olga J.L. van Rijn, Ree M. Meertens, Gerjo Kok \& Lex M. Bouter
}

\section{$\square \quad$ ABSTRACT}

Systematically developed health education should be based on a thorough knowledge of the determinants of the behavioural risk factors. Compared to other health related behaviours, safety behaviour has some specific characteristics, which complicate studying its determinants. Firstly, there are a multitude of circumstances leading to injuries, which means that it is not possible to pinpoint one desired behaviour to be linked with the prevention of injuries. Secondly, people are often not familiar with (the advantages and disadvantages of) all the possible preventive measures. Thirdly, the usefulness of preventive measures may depend on housing situations.

So far, no elegant way of coping with these problems in examining the determinants of safety behaviour seems to have been suggested in the literature. In this article an approach to studying the determinants of safety behaviour is presented. The general description of this approach is illustrated by a study on the determinants of the behavioural risk factors for burn injuries in young children, which was conducted among Dutch and Turkish parents of children aged $0-4$. The results indicate, for instance, that parents who implemented the safety behaviour reported that safety behaviour had become habitual to them.

\footnotetext{
Accepted for publication in Burns.
} 


\section{INTRODUCTION}

Effective primary prevention of injuries depends first of all on a sound knowledge of the most important risk factors, especially of those risk factors which are open to manipulation by means of health education (Kok \& Green, 1990). However, planning an effective health education intervention requires more than only insight into these risk factors per se (Bouter et al., 1990). The effectiveness of health education is also determined by knowledge of the main causes, the behavioural determinants, of these risk factors. Studies on the behavioural determinants try to answer the question "what motives do people have to behave as they do?" Not behaving in a safe way may, for instance, be due to lack of knowledge about the desired behaviour, to problems of a financial nature, to seeing more disadvantages than advantages for the desired behaviour, or to the fact that some people are not able to perform the desired behaviour (Bouter et al., 1990). An example can show why studies on behavioural determinants are necessary. An important risk factor of serious injuries in childhood traffic accidents is the lack of use of child restraint devices (CRDs) in cars when transporting a young child. Because many parents do not use these CRDs in a consistent way, a health education programme stressing the necessity of using them seems to be indicated. However, a study on the behavioural determinants of using CRDs showed that almost all parents did posses CRDs and were convinced of their safety-improving effects. About $25 \%$ of the parents, however, stopped using these CRDs because their children forcefully resisted being put into them. Thus, rather than stressing the safety of CRDs, an intervention to increase the use of CRDs should augment the skills of parents to deal with children who resist being put into the CRD.

This example illustrates that a study of the determinants may prevent the development of costly but useless, or even harmful health education programmes, while important aspects may be revealed (Pieterse et al., 1990). Furthermore, it is only when the determinants of a health problem are known that it is possible to determine whether these behavioural determinants can be changed by means of health education or if non-behavioural factors are the most important ones, by facilitation, regulation or even legislation. In the literature, determinants as predictors of (health) behaviour, are often divided into three categories: attitudes, social influences (Ajzen \& Fishbein, 1980) and self-efficacy (Bandura, 1986; de Vries, 1989).

Injury prevention or control by means of health education inherently requires strategies for influencing people's behaviour. Knowledge of the reasons why people show risky behaviour, enables health educators to develop health 
education interventions which aim at modifying behaviour. Interventions try to achieve this goal by providing knowledge about the desired behaviour, by modelling and giving feedback, or by skills development (Roberts et al., 1987).

\section{$\square \quad$ Problems in studying the behavioural determinants of safety behaviour}

Compared to other health related behaviours, such as smoking or compliance to medical advise, behaviour related to the prevention of injuries has some specific characteristics which complicate studying the determinants of this behaviour. Firstly, people can incur injuries in almost every conceivable way, since there is a multitude of circumstances and factors leading to injuries (de Leeuw, 1988). This means that there are often many desired behaviours that are linked with the prevention of injuries. Thus, one has to study the determinants of all these desired behaviours. This may be contrasted with, for instance, smoking behaviour, for which there is only one desired behaviour, namely "do not smoke". Secondly, to use the example of smoking again, one may expect smokers to be able to report on the advantages and disadvantages of smoking and of not smoking; they probably have experience with both behaviours. However, in the case of safety behaviour people are often not familiar with all the possible safety measures, and it is not realistic to expect people to comment on the advantages and disadvantages of behaviours which they have never performed. A third problem is that not all safety behaviours are suitable for all housing situations. (If, for instance, houses have only one room for the kitchen and the living room, it is not easy to keep the child away from the kitchen while cooking). Therefore, the need to invent alternatives which are better fitted to personal circumstances and preferences is urgent in this case. The above mentioned factors are probably the reason why research in the field of determinants of safety behaviour has lagged behind similar research in other health related behaviours, and why there is not one conceptual framework within which this kind of research is developed. Possible solutions for these three problems are presented in the approach described below.

\section{The approach}

To reduce the plethora of desired behaviours which are related to the prevention of injuries, two options seem to be available. Firstly, suggestions for preventive actions may be based on the frequency (incidence rates) with which certain 
circumstances lead to injuries. An example: young children in Denmark were reported to suffer burns when they put old bakelite power plugs into their mouth (Fogh-Anderson, 1984). This study led to a ban on this type of plug.

However, problems may arise if preventive actions are selected only on the basis of the circumstances which often lead to injuries. Assume, for instance, that electric coffee-makers are often responsible for burn injuries. The question whether a health education programme should advise people to make coffee by hand cannot be answered with yes or no, because this depends on the number of people using an electric coffee-maker, and of those making coffee by hand. If 95\% of the people use electric coffee-makers, it may logically be expected that more accidents happen when using coffee-makers than when making coffee by hand. In fact, making coffee by hand may be even more dangerous, and the advice not to use electric coffee-makers anymore may augment the overall risk of burn injuries.

A way to solve this problem is to examine the risk factors of injuries first. When risk factors are derived from studies which allow cause-effect conclusions to be drawn, such as experimental studies in which the investigator intervenes in one (or more) putative risk factors and subsequently observes whether and to what extent this intervention changes the incidence, this seems to be the ideal method (Bouter et al., 1989). However, other types of studies only allow conclusions about relations between factors and injuries. In casecontrol studies, for instance, it may occur that a factor seems to be an important risk factor, but did not lead to injuries in the research population. This may happen, for instance, when the risk factor is related to a (measured or unmeasured) third factor, which did lead to injuries. A solution to the above mentioned problems is to make the selection of risk factors on the basis of two criteria: the strength of risk factors (while taking into account the manipulatability of these factors) and the incidence rates of accident circumstances.

The second problem (unfamiliarity with the advantages and disadvantages), may be dealt with by asking respondents to implement the new safety behaviours for a longer period of time at home. After this period respondents are able to comment on the advantages and disadvantages of the behaviours and on the barriers they have encountered while executing the desired behaviours. The solution for the second problem also provides a solution for the third problem, since respondents are given the opportunity to think about possible alternatives, suitable for their own situation. For the purpose of eliciting the ideas the respondents have developed about alternatives, a qualitative method with open ended questionnaires is preferable. 
This paper illustrates the approach presented above by means of a study, among Dutch and Turkish parents of children under the age of 4 , of the behavioural risk factors for burn injuries Furthermore, it discusses the implications of the results for a burn injury prevention programme directed at parents of young children.

\section{APPROACH APPLIED TO BURN INJURIES IN YOUNG CHILDREN}

\section{$\square \quad$ Burns in 0-4 year old children}

Compared to other age categories, children under the age of 4 are most at risk for burn injuries (e.g. Klasen, 1986; Van Rijn et al., 1989). Most of these burns are caused by hot liquids like tea or coffee (e.g. Glasheen et al., 1981; Rogmans, 1984; Van Rijn et al., 1989). These so-called scalds account for $50 \%$ of all burn injuries among all age categories (Thomas et al., 1984). Public education programmes directed at primary prevention of bum injuries in children can perhaps reduce the incidence and severity of burn injuries, but the programmes which have been implemented in this field so far have had only limited success (Pless \& Arsenault, 1987; Linares \& Linares, 1990). An example is the project 'Burn prevention' (MacKay et al., 1979; MacKay and Rothman, 1982; McLoughlin et al., 1979; 1982) which was designed to increase awareness about burn hazards and decrease the incidence of burn injuries. A study revealed no significant effect of this project in terms of increased knowledge and reduced incidence and severity of burn injuries.

\section{$\square \quad$ Method}

\section{- Research population}

The study was conducted among parents of children under the age of 4 . These parents were recruited among visitors of maternal and child health centers in three places in the Netherlands (Maastricht, Voerendaal and Rotterdam). Because the findings of a previous case-control study (Van Rijn et al., 1990) had shown that children of Turkish origin seemed to run a more than fivefold higher risk of burn injuries compared to children of Dutch origin, separate studies on the determinants were conducted among Turkish and Dutch parents of 1-4 year old children. The reason for not including the age category $0-1$ was that most of the safety measures were not applicable to them because of their age. In order 
to have equal numbers of children in the age category $1-2$ and $3-4$, we decided to choose groups of eqaul size of these two age categories on beforehand.

\section{- Procedure}

Nine safety measures for preventing scalds and contact burns in children were designed. The selection of these preventive measures was based on the findings of a previous case-control study (Van Rijn et al., 1990) with respect to the strength and the manipulatability of the risk factors (as far as known) and on the incidence rate. One preventive measure sometimes gives a solution for more than one risk factor (such as measure 2, mentioned below). The selection procedure yielded the following measures.

1 Place cups filled with hot beverages (e.g. coffee, tea, soup) on such a place that your child cannot reach them

2 During meal preparation keep your child away from the kitchen

3 Avoid drinking hot beverages with a child on your lap

4 Make coffee by using an automatic coffee-maker

5 Leave coffee and tea in a vacuum flask

6 Place radiant heaters on such a place that your child cannot reach them

7 Make it impossible for your child to reach the stove; place a safety fireguard in front of it

8 Use a mixing tap in the kitchen and in the bathroom

9 Adjust the temperature of the hot water to 60 degrees or less

The last three measures, categorised as "single measures", are measures parents have to take only once (for instance, buying a safety guard). The first six measures, categorised as "permanent measures", are more difficult in that they suggest a permanent behavioural change.

Parents of young children who participated in the study received a free booklet containing written information about these nine measures, illustrated with instructive drawings. These drawings are shown in figure 1 .

The parents were asked to implement the desired behaviours in a consistent way at home over a period of two weeks. The purpose of this implementation was not to achieve behavioural change on the part of the parents in this period, but to get information about the most important advantages, disadvantages and barriers the parents encountered. After the two week period the parents were interviewed at home, using open ended questionnaires. The interviews, which were conducted in Turkish for the Turkish parents, lasted about one hour. In 

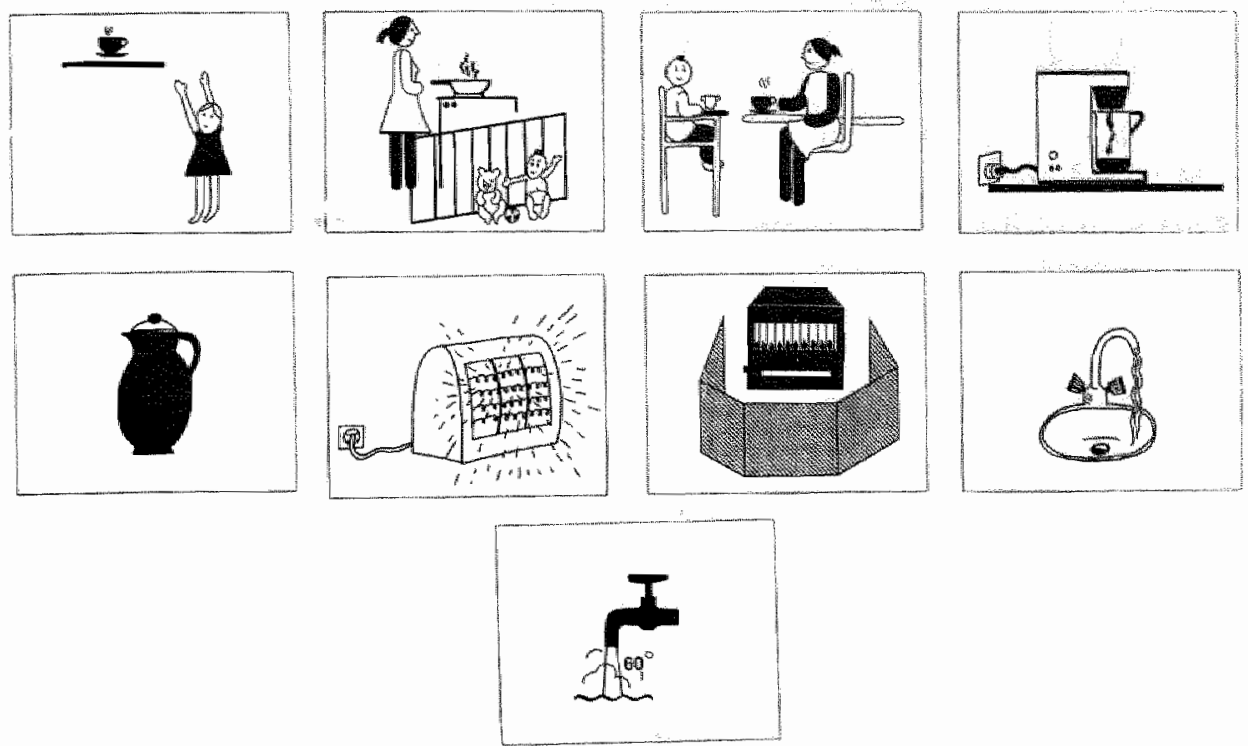

Figure 1: Instructive drawings about the nine safety measures for burn injuries

addition to questions about the advantages, disadvantages and barriers associated with preventive measures, the parents were asked about possible alternatives for the desired behaviour as well as about some demographic data and characteristics of the child. If the parents had more than one child of the 1-4 age category, they were asked to answer the questions for the oldest child.

Most of the interviews were interpreted by two other, independent assessors. Because we suspected that the meaning of the answers could not be interpreted in many different ways, there were no independent checks for intercoder reliability. In those few cases where different interpretations existed, we reviewed all accounts until we reached consensus on coding decisions.

\section{$\square \quad$ RESULTS}

\section{$\square \quad$ Response}

Of the 30 parents who agreed to take part in the study, 28 (15 Dutch and 13 Turkish parents) finally participated. The reason for one of the two Turkish parents who left the study at an early stage was that she went back to Turkey; 
the reason the other parent gave was that it was after all too difficult for her to take part in the study.

Most of the Dutch parents had two children, whille most of the Turkish parents had one child. An overview of the response and the numbers of children of the parents involved is shown in table 1 .

Table 1. Overview of responses and numbers of children of the parentsinvolved

\begin{tabular}{|c|c|c|c|c|c|c|c|}
\hline \multirow[t]{2}{*}{ Ethnicity } & \multirow{2}{*}{$\begin{array}{l}\text { Target } \\
\text { nir. }\end{array}$} & \multirow{2}{*}{ Response } & \multirow[t]{2}{*}{ Residence } & \multicolumn{4}{|c|}{ Number of parents with children aged } \\
\hline & & & & 1 & 2 & 3 & 4 years \\
\hline Dutch & 15 & $100 \%(\mathrm{~N}=15)$ & $\begin{array}{l}\text { Maastrictut } \\
\text { south of the } \\
\text { Netherlands }\end{array}$ & 3 & 10 & 1 & 1 \\
\hline Turkish & 15 & $87 \%(\mathrm{~N}=13)$ & $\begin{array}{l}\text { Maastricht/ } \\
\text { Rotterdam }\end{array}$ & 6 & 5 & 2 & 0 \\
\hline
\end{tabular}

\section{$\square \quad$ Advantages, disadvantages and barriers associated with the safety measures}

Table 2 summarizes the advantages, disadvantages and barriers associated with the six "permanent measures" (measures 1 to 6 ) which were mentioned by the parents. This table also gives information about the numbers of parents who implemented the measures. 'The number of parents concerned' in this table refers to the number of parents who actually are in the opportunity to implement the measure.

As shown in table 2, a striking result is that none of the Dutch parents succeeded in keeping the child away from the kitchen (measure 2), while five of the Turkish parents always succeeded in preparing meals without the presence of the child. The most important explanation for this is that the Turkish parents prepared their meals very early in the morning, when the child is still asleep. The results with respect to measures 1 (placing of cups) and 3 (not drinking with a child on your lap) show that, respectively, 17 and 23 respondents mentioned safety as the most important advantage of these behaviours. Of the parents who did implement measure 1,15 named safety as an advantage, while only 2 of the parents who did not implement measure 1 mentioned this advantage. For measure 3 the relevant figures are, respectively, 19 and 4 . Parents who understand the link between safety measures and the occurrence of 
Table 2. Consequences of implementation of the 6 permanent measures number of parents who implemiented the measures, for Dutch and Turkish parents separately. In brackets the number of parenis who mentioned this consequence is given.

\begin{tabular}{|c|c|c|c|c|c|c|c|}
\hline \multirow{3}{*}{$\begin{array}{l}\text { Measure } \\
\text { number }\end{array}$} & \multirow{3}{*}{ Consequence of implementation } & \multicolumn{6}{|c|}{ Implementation of nueasures by } \\
\hline & & \multicolumn{3}{|c|}{ Dutch panents } & \multicolumn{3}{|c|}{ Turkisth parents } \\
\hline & & yes & no & & yies & no & \\
\hline 1 Placing of cups & 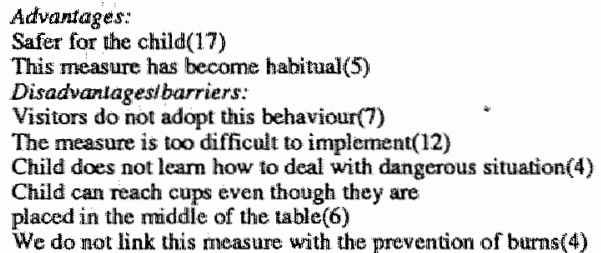 & 8 & 7 & $15 *$ & 9 & 4 & $13 *$ \\
\hline 2 Kitchen & 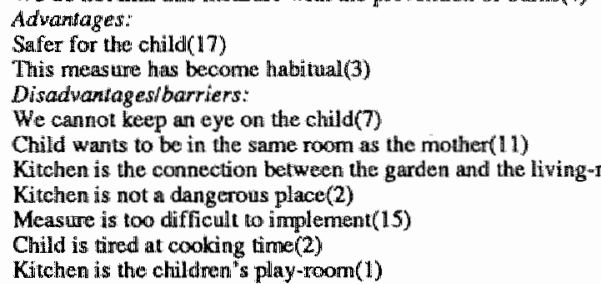 & $\operatorname{room}(3)$ & 15 & $15 *$ & 5 & 8 & $13 *$ \\
\hline 3 Lap & $\begin{array}{l}\text { Advantages: } \\
\text { Safer for the child(23) } \\
\text { This measure has become habitual(4) } \\
\text { Disadirantages'barriers: } \\
\text { Child wants to sit at mother's lap(10) } \\
\text { Other people (husband visitors) do take } \\
\text { the child on their lap while drinking(6) }\end{array}$ & 8 & 7 & $15 *$ & 11 & 2 & $13^{*}$ \\
\hline 4 Coffe Makker & 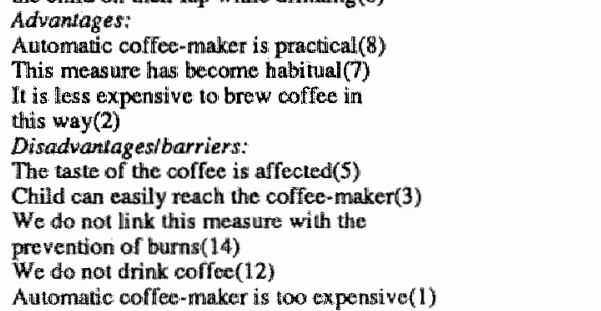 & 11 & 4 & $15^{*}$ & 3 & 10 & $13 *$ \\
\hline \$ Vacuum flask & 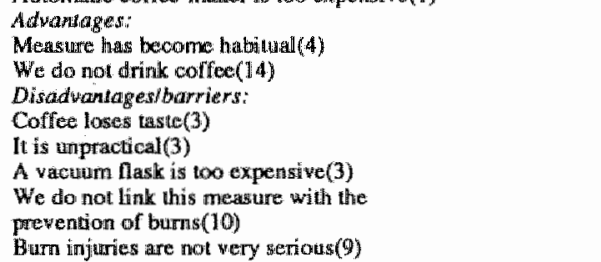 & 7 & 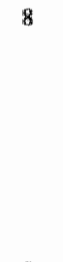 & $15^{*}$ & 2 & 11 & $13 *$ \\
\hline 6 Radiant lheater & 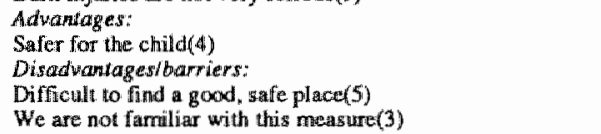 & 2 & $\Downarrow$ & 3 & 2 & 0 & $2^{*}$ \\
\hline
\end{tabular}

* Number of parents concerned. 
burn injuries seemed to be more inclined to apply the desired behaviours than parents who did not believe there is such a link. A reason for not carrying out the desired measures was that the new behaviour did not fit in with the cultural patterns or lifestyles of the parents. A typical example of this is measure 4 (automatic coffee-maker) for the Turkish parents: hardly any of these parents drink coffee and hence they do not use an automatic coffee-maker.

Another finding which can be derived from the results in table 2 is that health considerations are often unimportant in the decision whether or not to implement the "permanent measures". It seems that considerations such as costs, likes and dislikes and difficulty are more important. As for the latter, a safery behaviour which is not difficult to perform or which is rather passive may be expected to be performed sooner than behaviour which is difficult to perform. In our study we found that none of the Dutch parents succeeded in implementing the second safety measure (keep child away from kitchen). They all mentioned the inconvenience of the measure as the most important disadvantage and the reason for not conducting this desired behaviour.

Finally, the results show that the presence of visitors (or other people) formed a barrier against implementing the safety measures. The Turkish respondents mentioned this pressure from other people more often than the Dutch. They reported that they found it very difficult to make other people behave in the advised way. In the case of measure 1 (placing cups), these respondents reported that they found it improper to force visitors to place cups, for instance, in the middle of the table. Expressions like "...I find it difficult to tell others how to behave" and "...I do not like to impose my own rules upon my visitors" point in this direction.

The results of the implementation of the three "single measures" are presented in table 3. Again here, 'the number of parents concerned' in this table refers to the number of parents who actually are in the opportunity to implement the measure.

Analysis revealed that parents who took (one or more) safety measure(s) believed more strongly that the measure(s) they had taken improved the child's safety with respect to burn injuries, compared to parents who had not introduced them. For example, 6 of the parents who implemented measure 8 mentioned safety, while none of the parents who did not implement this measure mentioned safety as an advantage. Furthermore, it was found that the most dominant reason for carrying out a measure was that the parents were familiar with it or that this behaviour had become habitual to them.

Another interesting result when comparing parents who did introduce safety behaviour with parents who did not introduce it, is that the parents' lack of 
Table 3. Consequences of implementation of the 3 single measures; number of parents who implemented the measures, for Dutch and Turkish parents separately. In brackets the number of parents who mentioned this consequence is given.

\begin{tabular}{|c|c|c|c|c|c|c|c|}
\hline \multirow{3}{*}{$\begin{array}{l}\text { Measure } \\
\text { number }\end{array}$} & \multirow[t]{3}{*}{ Consequentse of implementation } & \multicolumn{6}{|c|}{ Implementation of measures by } \\
\hline & & \multicolumn{3}{|c|}{ Dutch parents } & \multicolumn{3}{|c|}{ Turkish parents } \\
\hline & & yes & no & & yes & no & \\
\hline 7 Stove & $\begin{array}{l}\text { Advantages: } \\
\text { We can leave the room(1) } \\
\text { Disadvantages/barriers: } \\
\text { Safety fireguard is ugly( }(4) \\
\text { The child is too young, it cannot touch the stove(4) } \\
\text { Safety fireguard is unstable(1) } \\
\text { Child can incur burns from the fireguard(2) } \\
\text { We do not know where to buy a fireguard(4) } \\
\text { Difficult to attach fireguard to the stove(1) } \\
\text { It is too expensive to buy a fireguard(2) } \\
\text { We are not familliar with this measure( } 8)\end{array}$ & 1 & 6 & $7^{*}$ & 0 & 5 & $5 *$ \\
\hline 8 Mixing tap & $\begin{array}{l}\text { Advantages: } \\
\text { Safer to use a mixing tap }(6) \\
\text { Possible to adjust the water temperature(10) } \\
\text { Disadvantages/barriers: } \\
\text { Children can incur burns from the hot tap( } 8) \\
\text { Child is too young to open the tap( } 2) \\
\text { We do not link this measure with the } \\
\text { prevention of burns(10) }\end{array}$ & 14 & 1 & $15^{*}$ & 13 & 0 & $13^{*}$ \\
\hline $\begin{array}{l}9 \text { Adjust the } \\
\text { temperature }\end{array}$ & $\begin{array}{l}\text { Advantages: } \\
\text { Reduction in risk of burns(5) } \\
\text { Disadvantages/barriers: } \\
\text { We do not know how to adjust the temperature(18) } \\
\text { Child can also get burns from } 50 \text { degrees water( } 5) \\
\text { Not familiar with this measure(7) }\end{array}$ & 3 & 12 & $15^{*}$ & 2 & 11 & $13^{*}$ \\
\hline
\end{tabular}

* Number of parents concerned.

knowledge or abilities with respect to the safety measures presented was often the decisive reason for not conducting the desired safety behaviour. This was the case, for instance, with measure 7 (safety guard); parents did not buy a safety guard because they did not know where to buy it.

Finally, respondents formulated barriers which withheld them from performing the desired behaviour. An example: for some of the parents it was impossible to adjust the temperature of the water because it was adjusted centrally by the building society. Turkish parents sometimes mentioned financial barriers. For example, they did not purchase a safety fireguard because it was too expensive. 
Besides giving an overview of the advantages, disadvantages and barriers associated with nine safety measures for preventing burn injuries in young children, the aim of this study was to gain some insight into possible allernative measures introduced by the parents if they were not in the opportunity to introduce the nine prescribed measures. Parents appeared to be very creative in inventing alternatives, especially altematives to the "permanent measures". The alternatives for measure $\mathbb{1}$ (placing of cups) varied from serving only cold drinks when children are present, having tea break when toddlers are napping and putting away the child in a baby-chair, to keeping cups in the hand while drinking. The Dutch parents mentioned many alternatives to measure 2 (keeping child away from kitchen), such as: turning the pan handles away while cooking, putting away the child in a baby-chair or in a play-pen, or not using the electric oven. Furthermore there was one parent who brewed coffee manually without boiling the water.

Parents were also asked to indicate the different situations in which they succeeded or failed to implement the measures. Results showed that parents rellatively often failed to implement the measures when others were present who were not willing to execute the measures; when time and money was not available or when parents were tired or irritated.

Based on these findings it cannot be concluded that the single measures, which were supposed to call for less educational maneuvers, are more frequently applied than the "more difficult" permanent measures. The reason for this might be that the convenience of the measure is (usually) not the decisive reason for conducting the desired behaviour. Other factors, such as the perceived significance of the measures and the familiarity with the measures may be of overriding importance.

\section{DISCUSSION}

This paper describes a method of gathering information about possible determinants which play an important role in the realization of safety behaviour (for burn injuries). The study has provided insight into: (1) the reasons why parents behave in a safe or unsafe manner with respect to the risk of burn injuries to their children; (2) possible starting points for the development of a behavioural intervention directed at primary prevention of burn injuries in young children and (3) the value of the chosen approach for studying the determinants of safety behaviours. 
As to the first point, the most important reasons for behaving in a safe or unsafe manner in our study can be summarized as follows. For most parents, the reasons for not conducting the desired behaviour were that they were not familliar with it; that the behaviour was not habitual to them, that they were not able to resist the pressure of others, such as visitors or partners who did not implement this behaviour; or that -in the case of the Turkish parents- the new behaviour did not fit in with their cultural patterns or lifestyles. Parents who introduced a certain safety measure were able to associate the safety behaviour with the prevention of burn injuries, more than those who did not introduce this measure. Not perceiving the link between safety measures and the occurrence of burn injuries may be due to the fact that -as was mentioned in the introduction- there is a multitude of circumstances and factors leading to (burn) injuries. For parents of young children it is of course impossible to know all the safety behaviours associated with all the types of injury prevention. Furthermore, parents who did not consistently introduce the measures considered safety behaviour to have more disadvantageous than advantageous effects. Lack of knowledge, in the sense of not knowing how to execute the behaviour, also appears to be an important factor in the failure to conduct safety behaviour.

Though the results of this study perhaps are not very surprising, they are very useful for the development of a health education programme aiming at burn injury prevention in young children. Overall, the results of this study suggest that health educators should pay attention to the following difficulties.

1 Achievement of behavioural change is difficult, especially if the old (unsafe) behaviour has become habitual for the parents.

2 Parents do not always link the new safety behaviour with the prevention of burn injuries to their child.

3 If parents do have the intention to change their behaviour, there are three factors that make it difficult to actually achieve this behavioural change:

- Parents may find it hard to resist the pressure of other persons present. If these persons are not willing to adopt the new safety behaviour, it is very difficult to achieve behavioural change.

- The behavioural change may not fit in with the cultural pattern or lifestyle of the parents.

- Parents may not know how to perform the new behaviour.

The implications for a burn injury prevention programme could be formulated as follows. The first difficulty (achievement of behavioural change), makes it preferable to recruit the parents of the children aged $0-4$ for a health education 
programme before their own (and perhaps unsafe) behaviour has become habitual to them. This means that the parents need a health education programme immediately after they have had their first child, or even before that moment.

In a health education programme it is advisable to prepare the parents for the problems they are going to meet while introducing the new safety behaviour (for instance in keeping children away from the kitchen during meal preparation). If parents are trained to cope with the inconvenience of a safety measure, they are more likely to perform the behaviour. Parents need to be informed about the fact that the more safety behaviour becomes habitual, the easier it is to perform. Health educators should try to reduce the disadvantages of the new safety behaviour by stressing the fact that safety behaviour does not always entail very difficult maneuvers.

Perhaps parents are more willing to adopt a different behaviour if they know how serious burn injuries in young children are. In a health education programme it is advisable to stress the fact that burn injuries are among the most serious injuries children can incur. Although the relation between anxiety and health education is a controversial topic in the field of preventive medicine (Leventhal, 1984) it is possibly acceptable in this case, where the parents are not sufficiently informed about the risks and the seriousness of burn injuries in children, and about the preventive measures that can be taken.

The second difficulty (linking safety measures and burn injuries) makes it advisable to stress several circumstances which often lead to burn injuries (Van Rijn et al., 1990). Health educators should also stress the possibilities of finding (safe) alternatives to the desired behaviour.

According to the third difficulty (problems in executing changed behaviour, even if the intention exists), health educators should teach parents social skills which they can use to resist the pressure of visitors and partners not to behave in a safe manner. Furthermore, health educators should transmit to the parents the knowledge and skills relevant to fulfilling the task of performing safety behaviour. This means that if health educators advise parents to make it impossible for their child to reach the stove by placing a safety fireguard in front of it, they must also give information about where parents can buy these fireguards, how they should be attached to the stove and what the price of these fireguards is. For the Turkish parents a health education programme should provide some extra information, which is adapted to their cultural background.

This paper has suggested and tested a method of gathering information about the determinants of the behavioural risk factors. It can be concluded that this approach may be fruitful, because it has yielded valuable information about the advantages, disadvantages and barriers associated with a range of safety 
behaviours. This information can be used for the development of health education programmes aiming at the reduction of injuries.

\section{$\square \quad$ Acknowledgement}

This paper was written as a part of the research project 'Prevention of burn injuries in the Netherlands', subsidized by the Dutch Burns Association.

We would like to thank Semahat Külcü for translating the interviews from Turkish into Dutch and for her help in the analysis of the data.

\section{$\square$ REFERENCES}

Ajzen I., \& Fishbein, M. (1980) Understanding attitudes and predicting social behavior. Prentice Hall: Englewood Cliffs.

Bandura A. (1986) Social foundations of thought and action: a social cognitive theory. New York: Prentice-Hall.

Bouter L.M., Knipschild P.G., Rijn J.L.O., Meertens R.M., (1989) How to study the aetiology of burn injury. The epidemiological approach. Burns. 15, 162.

Bouter L.M., Rijn O.J.L. van, Kok G.J. (1990) Importance of planned health education for burn injury prevention Burns. 16, 198.

Fogh-Anderson P.F., Srensen B. (1984) Electric oral burns in Danish children with special reference to prevention. Scand. J. Reconstr. Surg. 18, 107.

Glasheen, W.P., Attinger E.O., Anne A. (1981) Epidemiology of minor burn injuries. Burns. 8,423 .

Kok G.J., Green L.G. (1990) Research to support health promotion in practice: a plea for increased cooperation. Accepted for publication in Health Promotion International.

Klasen H.J. (1986) Changing patterns in the causes of scalds in young Dutch children. Burns. $12,563$.

Leeuw E. de (1988) Voorlichting ter voorkoming van ongevallen in de privé-sfeer van kinderen tussen 0 en 5 jaar. In: Jonkers R., Haes W.F.M., Kok G.J., et al (eds) Effektiviteit van Gezondheidsvoorlichting en - Opvoeding. Rijswijk: Gezondheidsbevordering. p. 254.

Leventhal H.A. (1984) A perceptual-motor theory of emotion. In: Berkowitz (Eds) Advances in experimental social psychology. Vol 17. New York: Academic Press.

Linares A.Z., Linares H.A. (1990) Burn prevention: the need for a comprehensive approach. Burns. 16, 281.

MacKay A., Halpern J., McLoughlin E. et al (1979) A comparison of age-specific burn injury rates in five Massachusetts communities. Am. J. Public Health. 69, 1146.

Mackay A. and Rothman K.J. (1982) The incidence and severity of burn injuries following project burn prevention. Am. J. Public Health. 72, 248.

McLoughlin E., Healer C., Crawford J.D. (1979) Burn education intervention: a controlled study. Burns. 6, 26.

McLoughlin E., Vince C.J., Lee A.M., Crawford J.D. (1982) Project burn prevention: outcome and implications. Am J. Pub. Health. 3, 241. 
Pieterse M.E. Kolk G.J., Verbeek J. (1990) Determinants of the acquisition and usage of child restraint devices: a survey among Dutch parents. University of Limburg.

Pless I.B., Arsenault L. (1987) The role of health education in the prevention of injuries to chilldren. J. of social Issues. $2,87$.

Rijn O.J.L. van, Bouter L.M., Kester A.D.M., Knipschild P.G., Meertens R.M. (1990). Aetiology of burn injuries among young children aged 0-4: results of a case-control study. Accepted for publication in Burns.

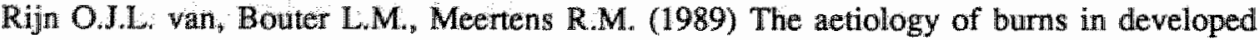
countries: review of the literature. Burns. $4,217$.

Roberts M.C. Layfield D.A. (1987) Promoting child passenger safety: a comparison of two positive methods. J. of Pediatric Psychology. 12, 257.

Rogmans. W.H.J. (1984) Jonge kinderen en ongevalsrisiko"s buiten het verkeer. Dissertation. Amsterdam: University of Amsterdam.

Thomas K.A., Hassanein R.S., Christophersen E.R. (1984) Evaluation of group well-child care for improving burn prevention practices in the home. Pediatrics. 74,879 .

Vries H. de (1989) Smoking prevention in Dutch adolescents. Dissertation. University of Limburg. Maastricht. 
$\square$ Importance of planned health

\title{
education for burn injury prevention*
}

\author{
Lex M. Bouter, Olga J.L. van Rijn \& Gerjo Kok
}

\section{$\square \quad$ ABSTRACT}

The planning of health education in the prevention of burn injuries is typically incomplete and not stated explicitly, while the evaluation is executed only partially or is altogether non-existent. This article presents a theoretical framework for the planning and evaluating of health education for those at risk of burns. Systematic planning consists of an assessment of the magnitude and severity of the problem, an analysis of the behavioural risk factors, a study of the determinants of the most risky modes of behaviour, the design of an optimal intervention, and the implementation of this intervention. The evaluation phase concerns the effects on these five levels (implementation, intervention, determinants, behaviour and injury risk).

Some common pitfalls are mentioned and special attention is given to the study of determinants of behaviour and to the design of the intervention. Furthermore, the importance of pretesting health education material is underlined. There appears to be a strong need for further research on the aetiology of burn injury and the relevant determinants of behaviour, before effective prevention can be realized.

* Published in Burns (1990) 16,3, 198-202 


\section{$\square \quad$ INTRODUCTION}

Available data on the incidence of burn injuries indicate that the problem is a substantial one in terms of morbidity, medical consumption and absence from work (Van Rijn et al., 1989b). Burn injuries are among the most serious injuries, because the long-term physical and psychological consequences are often considerable (Van Rijn et al., 1989a). As a solution, prevention is usually advocated, often in the form of health education. The planning of these health education activities is typically incomplete and not stated explicitly, while the evaluation is executed only partially or is altogether non-existent.

The central thesis in this article is that the effectiveness of health education in preventing burns is determined by the quality of the planning process (Green et al., 1980; Green \& Lewis, 1986). A thorough evaluation of the health education intervention is a condition sine qua non for establishing this effectiveness. Therefore, the process of planning and evaluation of health education aimed at the prevention of burn injuries is discussed below. The theoretical considerations will be illustrated by examples from our research project dealing with burn injury prevention among young children. Firstly, an overview of the several phases of the process will be presented, in addition to which several common pitfalls are mentioned. Secondly, special attention will be given to the study of the determinants of behaviour and to the design of the behavioural intervention itself. Thirdly, a number of conclusions are drawn and some priorities for future research are mentioned.

\section{PLANNING HEALTH EDUCATION}

A model for explicit planning and evaluation of health education is presented in figure 1. In planning as well as in evaluation five related steps can be discriminated. These ten steps in total can be indicated by their central questions. These questions are presented below and (partially) answered with respect to burn injury among young children.

\section{$\square \quad$ Step 1: How serious is the problem?}

This question deals with the incidence, sites and severity of burn injuries. Besides, some information on the personal characteristics of the injured patients is necessary in order to define specific risk groups. Although there are still some gaps in the literature (Van Rijn et al., 1989b), nowadays a global consensus 


\section{Planning}

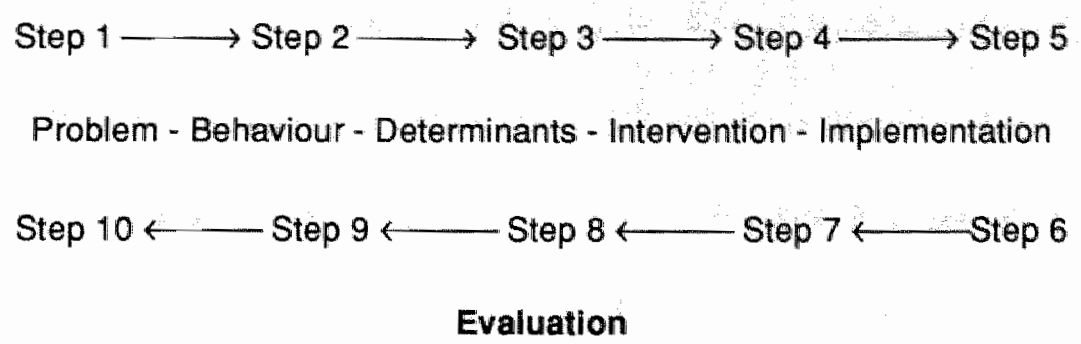

Figure 1. Model of planning and evaluation of health education.

exists on the main points. As an example, table 1 presents the basic epidemiological data on burns in the Netherlands (Van Rijn et al., 1990a). The overall incidence of medically treated burns is probably about 2.5 per 1,000 persons per year. This figure seems to be three times as high among 0-4 year old children, of which scalds account for almost $60 \%$. These data suggest that health education could reasonably focus first on the prevention of scalds among young children.

Table 1. Incidence ${ }^{*}$ of medically treated burns in the Netherlands.

\begin{tabular}{lll}
\hline & General Practitioner $^{* *}$ & Hospital $^{* * *}$ \\
\hline All ages & 1.7 & 0.8 \\
04 yr. & 5.6 & 2.0 \\
04 yr., scalds only & 3.2 & 1.2 \\
\hline
\end{tabular}

\footnotetext{
* Incidence per 1,000 persons per year;

** Data from the Netherlands Institute of Primary Health Care;

**** Data from the Consumer Safety Institute, including inpatients and patients seen at emergency departments of general hospitals.
}

\section{$\square \quad$ Step 2: What behaviour is involved?}

In the literature an abundance of putative behavioural risk factors for burn injury are mentioned (Van Rijn et al., 1989b). However, studies adequately establishing and quantifying the aetiological role of these factors are very sparse. In an earlier article (Bouter et al., 1989) we discussed the methodologi- 
cal principles of aetiological studies. Recently a case-control study investigating the risk factors for burns among young children was performed based on these principles ( $V$ an Rijn et al., 1989a). Table 2 presents some of the main risk factors which were identified in this study.

The odds ratios presented in Table 2 provide an estimate of the relative risks (Bouter et al., 1989). This is the ratio of the incidence of burns when the risk factor at issue is present and when it is absent. It appears that an impressive number of behavioural risk factors for burns among young children deal with the use and the preparation of coffee and tea. Table 2 presents also information on the proportion of the population for which a risk factor is present, and on the aetiological fractions. The latter is an estimate of the theoretical maximal reduction of burns that would be the consequence of a total elimination of the risk factor at issue (Rothman, 1986). Aetiological fractions should be looked upon as rough indicators of the importance of a factor from a preventive viewpoint.

Table 2. Behavioural risk factors for burns among young children ${ }^{*}$

Risk Factor $\quad \mathrm{OR}^{* *} \quad$ Prevalence $^{* * *} \mathrm{AF}^{* * * * *}$

Making coffee by hand

us automatic

0.12

$6 \%$

Coffee pot placed far from

vs near stove

0.13

$7 \%$

Hot drinks in original pot

us vacuum flask

$24 \%$

Oven window gets hot vs stays cold during use $26 \%$

Separate hot water tap $v s$ mixing tap

$$
\begin{aligned}
& \text { in kitchen } \\
& \text { in bathroom }
\end{aligned}
$$

From a recent case-control study (Van Rijn et al., 1989a);

Odds Ratio;

****** Proportion of households with 0-4 year old children;
Aetiologic Fraction 


\section{$\square \quad$ Step 3: What are the determinants of the behaviour?}

Recently a study was conducted among Dutch and Turkish parents that tried to identify the determinants of desirable behaviour (for instance, avoiding drinking hot beverages with a child on your lap) in nine common situations or activities that appeared to be associated with the risk of burn injuries among children. To collect this information the parents of the children were asked to implement these desirable forms of behaviour in a consistent way at home over a period of two weeks. After this period they were asked to mention the most important advantages and disadvantages of the desirable behaviour (Van Rijn et al., 1990b). Preliminary results from this study of the determinants of the behavioural risk factors for burns among children aged 0-4 indicate that parents fail to recognize dangerous situations which could provoke burn injuries. Parents were often not aware of risk factors (Van Rijn et al., 1990b), like those presented in Table 2. Almost all parents believed that their children had a risk for burns below the average (Van Rijn et al., 1989a).

\section{Step 4: What options are there for change?}

This step deals with the modification of the behaviour in a safer direction. In this context two decisions have to be made.

- The behavioural targets and the target group of the intervention have to be defined.

- A decision has to be made about which strategy will be the most effective for the desired behavioural change.

Health education intervention could stress the relevant empirical findings and clarify the relation between certain modes of behaviour and injury risk. Special attention might be given to explaining that all burns happen unexpectedly and that the risk is equal for all young children. Furthermore, the message should contain practical and feasible guidelines for the desirable preventive behaviour, and should deal with the barriers that are likely to arise.

\section{Step 5: How can that be implemented?}

Next the channel and the moment of the health education intervention have to be decided upon. In the Netherlands parents of young children can be contacted easily through the health care system. For instance, the education could be provided simultaneously with the vaccination programme that starts when the child is three months old. The message could be contained in leaflets, posters or video tapes. From the problem analysis (Van Rijn et al., 1989b) it appeared that 
children of ethnic minorities (e.g. Turks) were at higher risk compared to children of Dutch origin. Therefore special efforts ought to be made in reaching parents from such subgroups.

\section{[ Step 6: Has the implementation been carried out as planned?}

This step is designed to ensure that the intended population of parents of young children actually received the health education intervention. It is evident that this is a necessary, although not a sufficient, condition for effectiveness.

\section{$\square \quad$ Step 7: Has the intervention been released as planned?}

The central question in this step is whether the parents, including those of the ethnic minorities, understood the message contained in the health education intervention. Failure to clarify fully the modes of preventive behaviour are expected to be another source of ineffective prevention of burns.

\section{Step 8: Have the determinants of the behaviour changed?}

This phase is concerned with establishing whether the prevalence of the determinants of the desired behaviour has risen satisfactorily. In our example this part of the evaluation should focus on knowledge of the magnitude of the risk for burns and on ways of avoiding the dangers. Special attention ought to be given to the experiences of the parents with respect to the advantages and disadvantages in carrying out the desirable behaviour.

\section{$\square \quad$ Step 9: Has the behaviour changed?}

Health education aims at modifying behaviour. Therefore, quantifying behavioural change is important in the evaluation process. In our example, this entails analyzing whether the target population engages in preventive behaviour which conforms to the message of the programme.

\section{$\square \quad$ Step 10: Has the problem been lessened?}

Of course, this is the ultimate measure of efficacy: steps 6-9 can be considered the intermediate steps. In the example the post-intervention incidence of burn injury, more specifically of medically treated scalds among young children, will indicate the overall effectiveness of the health education intervention. For 
methodological reasons this straightforward measure is often not presented. It can be calculated that even a $50 \%$ decrease in incidence from 4 to 2 injuries per 1,000 young children per year fails to reach statistical significance (at alpha $=.05$ ) in a study involving 5,000 parents, half of them receiving the intervention and the other half being the control group (Bouter et al., 1989).

\section{$\square$ PITFALLS}

Unfortunately, the ten steps mentioned above are often not given appropiate attention. The most common mistake is that people jump from the problem to the intervention without answering the planning questions in between. Furthermore, because evaluation is rare, the ineffectiveness of such interventions remains hidden. Evaluation is necessary for testing previous decisions and for making corrections to improve the intervention. Careful planning can avoid a number of potential pitfalls that we will describe and illustrate with examples.

\section{Pitfall 1 \\ The development of an intervention for a problem that does not exist.}

In our example burn injuries are clearly a substantial problem, especially when analyzed in terms of incidence figures and severity of the injuries. However, failure to conduct a thorough problem analysis could have led us to develop an intervention for an activity with a very low injury figure or relatively minor injuries. Similarly, insufficient knowledge about the personal characteristics of burn patients and the nature of their injuries could have led to the choice of a wrong target population. An example of the latter would have been a choice for preventing chemically induced burns among adults in the general population.

\section{Pitfall 2 \\ The development of an intervention addressing behaviour lacking a clear relationship with the problem.}

This would be the case when health education focusses on behaviour for which the odds ratio has a value around one and/or the prevalence is low (see step 2). For such modes of behaviour the aetiologic fraction will always be very minor, indicating that even the maximum yield of health education aimed at these 
factors will be insignificant. Examples of this from our case-control study (Van Rijn et al, $1989 \mathrm{a})$ are: using a tea pot with a loose lid $(\mathrm{OR}=1.0$; prevalence $=$ $43 \%)$ and boiling water in an electric kettle $(O R=2.0$; prevalence $=4 \%)$.

\section{$\square \quad$ Pitfall 3}

\section{The development of an intervention that is based on a misconceived or incomplete idea about the determinants of behaviour.}

A general finding in health education research is that when a relation is shown between a health problem and behaviour, knowledge about that relation is enough for some people to change their behaviour. For a substantial group, however, knowledge is not enough. This means that health education for the parents of young children should supplement information on the risky forms of behaviour with arguments dealing with the other determinants of behaviour. For instance, parents may be well aware that cups of coffee or tea should be kept out of reach of young children, but still feel uncomfortable about explaining this to every visitor (Van Rijn et al., 1990b).

\section{$\square \quad$ Pitfall 4}

\section{The development of a wrong intervention, for instance an intervention aimed at the wrong group.}

An example of this would be school health education with the message that children should not play with matches. This would probably turn out to be ineffective, because firstly the children most at risk do not yet attend school, and secondly playing with matches is not a very important cause of burns (pitfall 2).

\section{Pitfall 5}

The development of a potentially effective intervention with a wrong implementation.

For example, suppose that health education would be made available to the subscribers to a popular magazine for the parents of young children. Consequently, the information about the dangers of hot beverages would not reach the majority of parents. Furthermore, it is probable that the subscribers to such a magazine form a selected group of parents who are already well aware of the dangers described in the information that is provided. 


\section{$\square \quad$ Pitfall 6}

\section{Unjustified satisfaction about the intervention.}

This concerns the failure to evaluate the intervention thoroughly. For instance, it could take the form of satisfaction about the large numbers of brochures on burn injury prevention handed out to parents in the context of the vaccination programme, with no notice taken of whether the number of burns actually has been reduced and whether this reduction is due to the health education campaign.

\section{$\square$ DETERMINANTS OF BEHAVIOUR}

In general, health educators have to rely on the epidemiological literature (Bouter et al., 1989) identifying the magnitude of the problem and the behaviour that is (causally) involved (steps 1 and 2 in figure 1). When such behaviour is indeed identified, the next step for the health educator consists of the clarification of its determinants. Figure 2 presents a recently developed model of behaviour determinants (de Vries et al., 1988). This model states that external variables can influence behaviour along three different pathways. (These three pathways are described below).

1 An attitude is the weighing of all the advantages and disadvantages of performance of the behaviour, as seen by the individual. Health (injury prevention) is only one of the possible considerations and often an unimportant one. When health is a part of the attitude, we may suppose that health motivation is a combination of the perceived severity of the health risk, the perceived susceptibility to the health risk, and the perceived effectiveness of the preventive behaviour. But again, health considerations are mostly not dominant and other considerations like costs, (dis)like, status, etc., are often more important. As said before, knowledge about risks is, for most people, not enough. A painful example is the unhealthy life-style of many doctors.

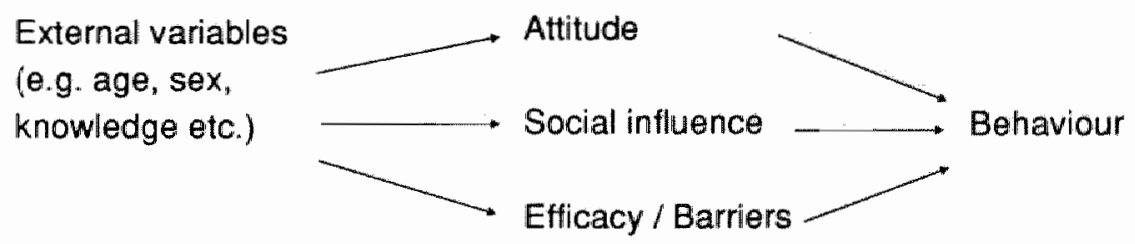

Figure 2. Model of behavioural determinants. 
2 Social influence is the influence of others; directly by what others expect, indirectly by what others do (modeling). Social influence is often underestimated as a determinant of behaviour. Social psychological studies show that social influence can lead to behaviour that conflicts with previous attitudes. The basis for social influence lies in two principles. Firstly, people like to have the right information, while the ideas of other people are sources of this information. Secondly, people like to be socially rewarded, such as by receiving compliments from others and by belonging to a group.

3 Efficacy / barriers stands for the determinant whether one is able to perform the (desirable) behaviour. Efficacy / barriers involves an estimation of the ability to perform the desirable behaviour, taking into account possible barriers inside or outside the person (inside: insufficient knowledge, skills, or endurance, etc.; outside: resistance from others, time and money not available, conflicting life style, etc.). If, for instance, parents of young children have the intention to put a safety ring around the cooking place, but when such a device is not for sale in their neighbourhood, it is unlikely that they will indeed behave as they intended to do.

Self-efficacy (efficacy) relates to beliefs about capabilities of performing specific behaviours in specific situations (de Vries et al., 1988). Efficacy is people's perception of their ability to perform the behaviour, while barriers are the real problems they face in actually behaving. Efficacy is shaped by experiences with barriers. There is a logical relation between (perceived) efficacy and (real) barriers, but beside that there is also an important relation between efficacy and success in performing the behaviour. People with a higher efficacy have a higher chance of succeeding, independent of the existing barriers. But the discrepancy between (perceived) efficacy and (real) barriers should not become too large. Health educators can try to increase the efficacy in order to motivate people to adopt the preventive behaviour. At the same time, however, they should help people to overcome barriers to performing that behaviour.

We have described in theory the three kinds of determinants of behaviour. With the exception of our own pilot study (Van Rijn et al., 1990b), there are, to our knowledge, no systematic empirical studies on the determinants of most putative behavioural risk factors for burns. This is clearly an omission in research and the gap needs filling urgently. Assuming that in the near future this kind of research will be conducted and specific determinants of behaviour will be known, how do we get from determinants to interventions? 


\section{BEHAVIOURAL INTERVENTION}

Changing by health education means changing by communication. Therefore the first goal is to gain attention and comprehension. Having achieved this and subsequently a change in determinants, the third and last goal is the maintenance of the change in behaviour. A once-only change is not enough; we want the desired behaviour to become a habit. The major problem in achieving maintenance of change in behaviour is the possible negative experiences people have when performing the desired behaviour (e.g. screaming children when they are barred from entering the kitchen during cooking). Health educators should always be realistic about the experiences following the change to the desired behaviour. Often these experiences are in the short term not very positive. Sometimes it is possible to present 'organised' positive experiences, for instance by presenting data about the number of burn injuries among young children that are prevented related to the year before.

Figure 3 combines the three health education goals with four communication variables in the so-called health education matrix, adapted from that devised by McGuire (1985). The cells of this matrix indicate decisions that have to be made, e.g. which source attracts the most attention, which channel is able to change social norms, which group of receivers should be specially prepared for negative experiences, etc. In the literature (McGuire, 1985) a rich quantity of empirical data can be found with respect to every possible decision.

\begin{tabular}{|l|l|l|l|l|}
\cline { 2 - 5 } \multicolumn{1}{c|}{} & Source & Message & Channel & Receiver \\
\hline Attention \& comprehension & & & & \\
\hline $\begin{array}{l}\text { Change in attitudes, social influence, } \\
\text { efficacy / barriers }\end{array}$ & & & & \\
\hline Maintenance of behavioural change & & & & \\
\hline
\end{tabular}

Figure 3: The health education matrix

Pretesting of educational materials is meant to check whether the materials have the intended effect on the receivers, especially with respect to attention and comprehension (Damoiseaux, 1989). It is not enough that all kinds of specialists on burn injuries agree that the information in the materials is correct. The next 
step is to have communication specialists judge the materials, and a final step is to try out the materials on a sample of the target group (Damoiseaux, 1989). Only then is it possible to prevent all kinds of possible unwanted side effects that have not been recognized by the health educators themselves. Pretesting is therefore very much needed and should be integrated in the materials development process. To our knowledge no study exists dealing with pretesting health education material on the prevention of burns.

One of the most promising intervention strategies, that becomes increasingly popular in health education, is the community approach (de Leeuw, 1989). Community approaches are characterized by five elements:

1 They are directed at the existing social networks, neighborhoods, social clubs, worksites, schools, etc. That social network is essential in achieving the educational goals: attention, comprehension, change of determinants, maintenance of behaviour change.

2 They are multi-sectoral, involving health educators, national and local health services, national and local governments, industry, housing and building organizations, etc. Health educational activities should be supported by regulations and facilities.

3 They are multi-media activities: mass media as general facilitators followed by interpersonal communication, local mass communication and the use of intermediaries, like general practitioners or teachers.

4 They see health as a part of lifestyle. Programmes on burn injury prevention should not deal with bum injuries as an isolated issue but as a part of a healthy life style for the persons themselves or their children. This concerns risk-taking behaviour, responsibility, exemplary role, etc.

5 They can be very effective by using paraprofessionals as a source. The basic idea of paraprofessionals entails the training of volunteers from the target group itself to become educators, since they can more easily reach the educational goals by a better understanding of the needs of the target group, their psychological characteristics, the social organization and the structural limitations.

Community interventions are seen as the only effective strategy to reach the so-called 'difficult-to-reach' groups like immigrants or low socio-economic status groups. 


\section{CONCLUSION}

Until now prevention of burn injuries has been dominated by medical and technical experts. To be effective these efforts should be supplemented by health education specialists. It seems possible to achieve a reduction of burns within the next ten to twenty years. In the field of burn injury prevention, health education seems to be a promising tool for behavioural change, because burn injuries appear to have some specific behavioural causes that can be manipulated. It is important, however, to realise that the effectiveness of health education depends on the quality of the planning. That means a careful analysis of the problem, the behaviour, the determinants, the intervention, the implementation, and of the strength of the relationship between these five aspects. It is our opinion that with respect to the prevention of burn injuries we still have not yet reached the stage that we know exactly what to advise people. Epidemiological studies on the aetiology followed by research on the determinants of the behaviour at issue are necessary to fill in the gaps in our knowledge.

\section{$\square \quad$ Acknowledgement}

This paper was written as a part of the research project 'Prevention of burn injuries in the Netherlands', subsidized by the Dutch Burns Association.

\section{REFERENCES}

Bouter L.M., Knipschild P.G., van Rijn J.L.O. Meertens R.M. (1989) How to study the aetiology of burn injury: the epidemiological approach. Burns. 15, 162.

Damoiseaux V.M.G. (1989) The necessity of pretesting written information materials. (internal report University of Limburg).

Green L. W., Kreuter M.W., Deeds S.G. and Partridge K.B. (1980) Health Education Planning: a Diagnostic Approach. Palo Alto: Mayfield Publishing Company.

Green L.W. and Lewis F.M. (1986) Measurement and Evaluation in Health Education and health Promotion. Palo Alto: Mayfield Publishing Company.

Leeuw E.J.J. de (1989) The Sane Revolution: Health Promotion: Backgrounds, Scope, Prospects. Assen/Maastricht: Van Gorcum.

McGuire W.J. (1985) Attitudes and attitude changes. In: Lindsay G. and Aronson E. (eds) Handbook of Social Psychology: Volume II. New York: Guilfort.

Rijn O.J.L. van, Bouter L.M., Meertens R.M., Grol M.E.C., Kok G.J. and Mulder S. (1989a) Brandwonden bij 0-4 Jarige Kinderen: Verslag van een Etiologisch Patiẻnt-controle-onderzoek. Amsterdam: Stichting Consument \& Veiligheid.

Rijn O.J.L. van, Bouter L.M. and Meertens R.M. (1989b) The aetiology of burn injury: review of the literature. Burns. 15, 217. 
Rijn O JL. van, Grol M.E.C., Bouter L.M. (1990a) Incidence of medically treated burns in the Netherlands. Accepted for publication in Burns.

Rijn O JL. van, Meertens R.M., KoK G.J., Bouter L.M. (1990b) Determinants of behavioural risk factors for burn injuries. Accepted for publication in Burns.

Rothman KJ. (1986) Modern Epidemiology. Boston: Little, Brown \& Company. Vries H. de, Dijkstra M. and Kuhlman P. (1988) Self-efficacy: the third factor besides attitude and subjective norm as a predictor of behavioural intentions. Health Education Research. 3, 273. 


\section{Discussion}

The principal aim of the studies presented in this thesis was to gain insight into the question how burn injuries in 0-4 year old children might be prevented. To reach this goal four studies were conducted: a study of the incidence of medically treated burns in the Netherlands, a review of the literature on the aetiology of burn injuries, a case-control study of the most important risk factors and a study of the determinants of the behavioural risk factors that seemed to be manipulatable.

This final chapter discusses the results of these four studies and pays attention to their methodological limitations. In addition to this, some general conclusions will be drawn and guidelines for future studies will be formulated.

The effectiveness of health education in preventing burn injuries can be assumed to be determined largely by the quality of the planning process (Green \& Lewis, 1986; Bouter et al., 1990; see also Chapter 7). Systematic planning consists of four steps: see figure 1.

This dissertation consists of an elaboration of the first two steps of this model with respect to burn injuries. With regard to the problem analysis (step 1) three studies were conducted. The first study, of the incidence of burns in the

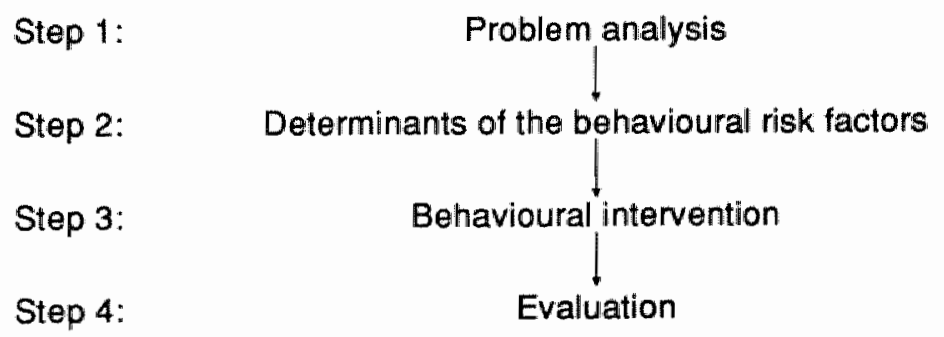

Figure 1: Model of the planning of health education (Kok, 1988) 
Netherlands (Chapter 2), showed that the overall incidence rate of medically treated bums over three levels of medical care (burn units, hospitals and general practitioners) is about 280 per 100,000 persons per year. The overall incidence figure is almost three times as high for $0-4$ year old children: 775 per 100,000 persons per year. At all levels of medical care, scalds are the most common injuries, having an overall incidence rate among $0-4$ year old children of 430 per 100,000 persons per year. This study allows the conclusion that $0-4$ year old children are the most important risk group for burn injuries, especially for scalds.

The second study (Chapter 4 ) reviews the available literature on the aetiology of burn injuries. It was found that, although prevention of burn injuries has been given a good deal of attention, a thorough knowledge of the incidence and the major risk factors is still lacking. The main methodological limitation of the studies carried out in this field is that none of them has used a control population for comparison. Motivated by this lack of well-designed studies in the international literature, we conducted a case-control study among parents of children aged 0-4 (the third study of the problem analysis). This study (Chapter 5) yielded information about several manipulatable and poorly manipulatable risk factors for burn injuries. As for the latter, it was found that the risk of burns was higher for children with other than Dutch (e.g. Turkish) ethnicity (OR$\left.\mathrm{LR}^{*}=5.6 ; \mathrm{CI}(90 \%)^{* *} 2.6-11.9\right)$. Children who lived in relatively small houses turned out to have a higher risk of burns (OR-LR=2.5: $\mathrm{CI}(90 \%)$ 1.3-4.7). To our surprise, children belonging to lower socio-economic classes were found to have a decreased risk of burns (OR-LR=0.3; CI $90 \%$ ) $0.1-0.6$ ). Among the several manipulatable risk factors which we studied, the use of an oven window which gets hot while in use appeared to be associated with an increased risk of burns (OR-LR=2.1; $\mathrm{CI}(90 \%)$ 1.3-3.5). The same holds for the storage of hot drinks in their original pots instead of in vacuum flasks (OR-LR $=2.0 ; \mathrm{CI}(90 \%$ ) 1.2-3.1). Cooking on a gas stove turned out to be another risk factor for bum injuries (OR-LR=2.5 CI(90\%) 1.1-10.0).

Based on the findings of the case-control study, a study (Chapter 6) of the determinants of some of the behavioural risk factors for burn injuries was conducted (step 2 of the model of planning health education). Because safety behaviour related to the prevention of burn injuries has some specific characteristics, we introduced a new approach to the study of its determinants. In this

\footnotetext{
* Odds ratios based on logistic regression (OR-LR)

$* * 90 \%$ confidence intervals (CI (90\%))
} 
approach, 28 Dutch and Turkish parents of children aged 0-4 were asked to implement several safety behaviours to prevent burns in a consistent way over a period of two weeks at home. After this period they were interviewed by means of an open ended questionnaire. The results indicated that parents who implemented the new safety behaviour in a (relatively) consistent way were able to associate this new behaviour with the prevention of burn injuries, more so than the parents who did not introduce them. Furthermore, the parents who implemented the safety behaviour reported that safety behaviour had become (more or less) habitual to them. It is concluded that the approach seems to be a fruitful way of investigating the determinants of (burn) injuries. Some valuable suggestions for the prevention of burn injuries emerged, which can be used for the development of a burn injury prevention programme. These suggestions will be discussed below.

\section{METHODOLOGICAL LIMITATIONS OF THE STUDIES}

Due to some methodological limitations the conclusions of these studies might need some qualification. With respect to the incidence study, the main problems concerning its validity have been discussed in Chapter 2 and Chapter 4 . The essence is that because medically treated burns were recorded by three registration systems over three levels of medical care, overlap in the registration between these systems is unavoidable. This may lead to some overestimation of the overall incidences. On the other hand, the rate of underreporting of the several registration systems is an important factor, which may lead to an overall underestimation. Although our incidence estimates may be biased to some extent, we feel confident that our data allow valid inferences with respect to the order of magnitude of the problem among various risk groups.

In our literature review (Chapter 4) the major potential threats to the validity are similar to those in other non-experimental studies: selection bias (publication bias), information bias (validity of the individual studies) and confounding (comparability of populations, risk factors and operationalizations of burn injury among the studies) (Bouter \& ter Riet, 1990). Publication bias could occur because investigators, referents or editors may have a preference for publishing research that shows statistically significant results and/or results that agree with existing knowledge. The main problem was the weak design of the available aetiological studies: all lacked a relevant control group. Furthermore, comparability of the available publications was rather poor. Due to the resulting 
bias, conclusions from our literature study must be drawn with caution. We felt that the available literature could only generate a number of plausible ideas about aetiological factors.

As is known from the methodological literature (Rothman, 1986; Kopec \& Esdaile, 1990) and as mentioned in the discussion sections of Chapters 3 and 5, there are some common serious problems concerning the precision and validity of case-control studies. One of the weaker characteristics of our study was the imprecise measurement of some of the risk factors. This was related to the fact that we measured all risk factors by means of a structured questionnaire, and thus relied on the perceptions and opinions of the parents themselves. For some of the factors, such as the temperature of the water or the housing situation, different procedures (e.g. direct observation) might have been more appropriate. In addition, systematic errors due to selective misclassification may have been a serious threat to the validity of our study. In a case-control study the resulting information bias can be a serious problem (Kopec \& Esdaile, 1990). The question here is whether the information obtained for cases and controls is comparable (Rothman, 1986; Bouter \& Van Dongen, 1988), and whether it can be expected that either cases or controls overreport (or underreport) risk factors. Because the study is retrospective, the parents of the cases may have given biased answers if they felt guilty about (the circumstances of) the burn injury. Another variety of information bias, recall bias, can arise if the parents of the cases remember exposure more accurately than those of the controls (Rothman, 1986). The reason for this could be that the accident leading to the bum injury probably serves as a stimulus in recalling all the events that might have played some role.

Another threat to the validity of our case-control study is that the relation between putative risk factors and the burn injury risk might have been obscured because we mixed different types of burn injuries, which could have different aetiologies. An example: if cases from our study brew coffee mainly manually and controls mainly automatically, this suggests that the risk for burns is higher among children in households where coffee is made manually. It would not seem very likely that the method of coffee making is causally related to other types of burns than scalds. Thus, the patient group for this risk factor ought to be restricted to scalds only. However, when we did a logistic regression analysis for some specific kinds of burn injuries separately (e.g. scalds), the results which emerged were almost the same as those found for all burn injuries together. This does, of course, not exclude the possibility that in a more homogeneous population some more specific risk factors might be identifiable. 
A final issue that threatens the validity of our case-control study is the presence of confounding, which relates to a distorted picture of the association between risk factor and burn injuries due to other factors which are associated with the risk for burns (Kleinbaum et al, 1982, Rothman, 1986). Confounding can lead to both overestimation or underestimation of the real risk associated with a specific factor. To control for confounding in our study, multiple logistic regression analysis was performed. In this analysis, every known potential confounder was adjusted for. However, this does not exclude bias due to unmeasured confounders or confounding due to imprecision and bias in the measurements. On the whole, it is very difficult to assess the exact value of the results from our case-control study. The fact that this was the first controlled study on the aetiology of burns especially makes a cautious interpretation necessary. On the other hand, some of the risk factors we found confirm plausible ideas about the aetiology, and we felt confident enough to focus on these factors in our study of the determinants of behaviour.

As described in Chapter 6, the nature of our study of the determinants of the behavioural risk factors for burn injuries was qualitative and explorative. In qualitative studies the achievement of an adequate level of precision and validity is problematic (Miles \& Huberman, 1985; Kirk \& Miller, 1986; De Leeuw, 1989). However, a qualitative method of research seems to be the best solution when the knowledge of the field of investigation is limited. To enhance precision, our interviews, which consisted of open ended questions, were recorded on tape. These interviews were typed out literally and most of the interviews were interpreted by three independent assessors. Where different interpretations were possible, phrases used by the respondents were discussed until consensus was reached. The validity of this study may have been hampered by the limited number of subjects and the complexity of the variables at issue. Therefore, extrapolation of the findings must be done with great caution: this study provides no insight into the importance of the determinants identified among parents of 0-4 year old children in general.

For an answer to the question of determinants of behavioural risk factors health educators usually turn to socio-psychological theories and models (e.g. Kok \& de Vries, 1989). The essence of these so-called theories of planned behaviour, such as the Fishbein \& Ajzen model (Ajzen \& Madden, 1986; De Vries et al., 1988), is that behaviour can be predicted by three kinds of determinants: (1) attitude, which is the weighing of all the advantages and disadvantages of performance of the behaviour, as seen by the individual; (2) the social influence, which is the influence of others on the behaviour; (3) self-efficacy / 
barriers, which stands for the perception of one's own ability to perform the (desirable) behaviour. In these kinds of studies, which are usually of a quantitative nature, respondents are asked about their attitude, the social influence and the efficacy / barriers they perceived with respect to a specific health problem (e.g. smoking). Safety behaviour, however, has some specific characteristics which complicate the study of its determinants. Firstly, the types of circumstances leading to injuries may number to fifty or more, which means that it is not possible to pinpoint one desired behaviour as linked with the prevention of injuries. Secondly, people are often not familiar with (the advantages and disadvantages of) all the possible preventive measures. Thirdly, the usefulness of preventive measures may depend on housing situations. Therefore, we introduced several desirable behaviours for preventing burn injuries by parents of 0-4 year old children and asked them retrospectively about their experiences.

The surplus value of our approach is that by eliciting salient advantages, disadvantages and barriers corresponding to the desirable safety behaviour, it resulted in valuable practical suggestions for the development of a health education programme directed at the prevention of bum injuries.

We think that this approach is a fruitful one, although we realize that the methodological problems described above may mean that the results have to be viewed with a certain degree of caution.

\section{$\square \quad$ IMPLICATIONS FOR FUTURE STUDIES}

When the studies presented in this thesis were started there was some evidence that burn injuries were a major problem in children aged 0-4 (Klasen \& Sauer, 1979; Thomas et al., 1984; Davies, 1985, see also Chapter 4), and that burn injuries have some specific behavioural causes, indicating that health education might be a successful prevention strategy. This belief was based on several case-series and some quasi-experimental epidemiologic studies on burn education interventions (McLoughlin et al., 1979; 1982).

After completion of the first two steps of the model for planning health education, these assumptions seem to be justified. Our study of the incidence confirmed the idea that 0-4 year old children are indeed the most important risk group for bum injuries, especially for scalds. And our case-control study showed that there do indeed seem to be some manipulatable risk factors for burn injuries that call for a health educational approach. Furthermore, our study of the determinants yielded information about the reasons why parents behave in 
a safe or unsafe manner with respect to the risk of burn injuries for their children. These results suggest that health educators should pay attention to the following difficulties:

1 Achievement of behavioural change is difficult, especially if the old (unsafe) behaviour has become habitual for the parents.

2 Parents do not always link the new safety behaviour with the prevention of burn injuries to their child.

3 If parents do have the intention to change their behaviour, there are three factors that make it difficult to actually achieve this behavioural change:

- Parents may find it hard to resist the pressure of other persons present. If these persons are not willing to adopt the new safety behaviour, it is very difficult to achieve behavioural change.

- The behavioural change may not fit in with the cultural pattern or lifestyle of the parents.

- Parents may not know how to perform the new behaviour.

Based on these results, the implications for a burn injury prevention programme could be formulated as follows. The first difficulty makes it preferable to recruit the parents of the children aged 0-4 for a health education programme before their own (and perhaps unsafe) behaviour has become habitual to them. This means that the parents need a health education programme immediately after they have had their first child, or even before that moment. In such a programme it is advisable to prepare the parents for the problems they are going to meet in introducing the new safety behaviour. The second difficulty makes it advisable to stress several circumstances which often lead to burn injuries. Health educators should also stress the possibilities of finding (safe) altematives to the desired behaviour. To deal with the third difficulty, health educators should teach parents social skills which they can use to resist the pressure of visitors and partners not to behave in a safe manner. Furthermore, health educators should transmit to the parents the knowledge and skills relevant to fulfilling the task of performing safety behaviour.

With this knowledge we have arrived at the third step of the model for planning health education (see figure $\mathbb{I}$ and Chapter 7 ), the behavioural intervention, which entails the modification of behaviour in a safer direction. An intervention directed at primary prevention of burn injuries in 0-4 year old children is currently being developed, under the title of "Hot for safety" (Grol et al., 1990). This intervention, which is not a part of this dissertation, includes a video tape, a manual for the supervisor and a leaflet with useful tips for parents. Based on the results of our study of the determinants, it stresses the link 





\section{Summary}

The central subject of this dissertation is the dissection of the burn injury problem among 0-4 year old children by focussing on the incidence, aetiology and determinants of the behavioural risk factors for burn injuries. The introduction to this dissertation (Chapter 1) provides some information on the background of the studies presented. Furthermore, it describes the theoretical framework for this dissection. In addition, the content of the various chapters is briefly described.

Chapter 2 presents the results from our study on the incidence of medically treated burns in the Netherlands, which were derived from three registration systems, covering patients treated in burn centres, in general and university hospitals and in general practices. The overall incidence rate of medically treated burns over these three levels of medical care is probably about 280 per 100,000 persons per year. This overall incidence figure appeared to be about 3 times as high for $0-4$ year old children: 775 per 100,000 persons per year. At all levels of medical care, scalds are the most frequent type of burns, resulting in an overall incidence rate among 0-4 year old children of 430 per 100,000 persons per year. Incidence rates are lowest among the elderly (55+), but this age group suffers a higher mortality from burns. Furthermore, it turned out that males are more prone to serious burns than females, whereas females are more often treated for less severe burns. Most of the accident circumstances for serious burns were related to profession, whereas most of the circumstances for less severe burns were related to household activities.

Chapter 3 provides a short introduction to the methodological framework for experimental and non-experimental studies into the aetiology of burn injuries. It explains that for this purpose burn injury incidences should be studied as a function of their risk factors. Central methodological issues are comparability of baseline prognosis, comparability of measurements and comparability of extemal circumstances. These principles are clarified by means of a number of fictitious examples of risk factors for burn injuries. It is explained that in preventive trials comparability may be achieved by randomization, blinding and placebo interventions. The main tools in non-experimental studies are de- 
liberate selection and multivariate analysis. In case-control studies special attention must be paid to the definition of the source population and to possible ways of reducing measurement incomparability.

In Chapter 4 the current state of knowledge with respect to the incidence and aetiology of burn injuries is reviewed. This review shows that although prevention of burn injuries has been given a good deal of attention in the past, it has never been subjected to a systematic approach which could result in a thorough knowledge of the incidence and the major risk factors and risk groups. The methodological limitations of the studies carried out in this field are striking. For instance, none of the studies of risk factors has used a control population for comparison. No figures are available on the total number of burn injury patients in the Netherlands. Estimates are derived from the situation in other countries, which yields an incidence of 4 per 1,000 persons per year. Scalds are relatively common in the $0-4$ age category. This is usually assumed to be caused by the stage of development of motor and cognitive skills, coupled with incorrect assumptions about these skills by parents. Men are found to be more often the victims of burns than women. Coffee and tea are assumed to be risk factors. Some methodological remarks are made about possible improvements to the quality of future studies and about the introduction of preventive measures.

Chapter 5 presents the results of our case-control study, which was conducted by means of a postal questionnaire among parents of children aged 0-4. Cases $(n=122)$ were $0-4$ year old Dutch children who visited emergency departments with burn injuries. Controls $(n=213)$ were a sample of the Dutch population of 0-4 year old children without burn injuries. The risk of burns was higher for children with other than Dutch (e.g. Turkish) ethnicity (OR-LR= 5.6; $\mathrm{CI}(90 \%) 2.6-11.9)$. Children who lived in relatively small houses turned out to run a higher risk of burns (OR-LR=2.5: $\mathrm{CI}(90 \%)$ 1.3-4.7). To our surprise, children belonging to lower socio-economic classes were found to have a decreased risk of bums (OR-LR $=0.3 ; \mathrm{CI}(90 \%)$ 0.1-0.6). Furthermore, among several manipulatable risk factors, the use of an oven window which gets hot while in use appeared to lead to an increased risk of burns (OR-LR=2.1; $\mathrm{CI}(90 \%) 1.3-3.5)$. The same holds for the storage of hot drinks in their original pots instead of in vacuum flasks (OR-LR $=2.0 ; \mathrm{CI}(90 \%) 1.2-3.1$ ). Cooking on a gas stove turned out to be another risk factor (OR-LR=2.5 CI(90\%) 1.1.-10.0).

Chapter 6 reports on a new qualitative approach to studying the determinants of behavioural risk factors for burn injuries which has been suggested en tested. In this approach, volunteers were asked to implement several safety behaviours to safeguard their children from burn injuries, in a consistent way, over a longer period of time. After this period they were interviewed by means 
of open ended questionnaires. In this chapter, the general description of this approach was illustrated by our own study on the determinants, which was conducted among 28 Dutch and Turkish parents of children aged 0-4. It was found that parents who implemented the new safety behaviour in a (relatively) consistent way were able to associate this new behaviour with the prevention of burn injuries, more so than parents who did not introduce it. Furthermore, the parents who implemented the safety behaviour reported that safety behaviour had become (more or less) habitual to them. In addition, this study yielded some valuable suggestions for the prevention of burn injuries, which can be used for the development of a burn injury prevention programme.

Chapter 7 presents a theoretical framework for planning and evaluating health education for those at risk of burns. It states that systematic planning consists of an assessment of the magnitude and severity of the problem, an analysis of the behavioural risk factors, a study of the determinants of the most risky modes of behaviour, the design of an optimal intervention, and the implementation of this intervention. The evaluation phase concerns the effects of these five levels (implementation, intervention, determinants, behaviour and injury risk). Some common pitfalls are mentioned and special attention is given to the study of determinants of behaviour and to the design of the intervention. Furthermore, the importance of pretesting health education material is underlined. In conclusion, some methodological remarks are made with the aim of improving the quality of future studies.

Chapter 8 provides a discussion of the results of the studies covered by this dissertation, and pays attention to their methodological limitations. Subsequently, it presents some general conclusions and formulates guidelines for future research.

Our incidence study makes us confident that our data allow valid inferences with respect to the order of magnitude of the problem among several risk groups. Our study of the literature allows the conclusion that the available literature could do no more than generate a number of plausible ideas about aetiological factors. It is very difficult to assess the value of the results from our case-control study. The fact that this was the first controlled study on the aetiology of burns makes a cautious interpretation necessary. On the other hand some of the risk factors we found confirm plausible ideas about the aetiology, and we felt confident enough to focus on these factors in our study of the determinants of behaviour. That study yielded much valuable information for the development of a health education programme, although we realize that because of some methodological problems the results have to be viewed with a certain degree of caution. 



\section{Samenvatting}

Het centrale onderwerp van dit proefschrift is de ontleding van het probleem van brandwonden bij 0-4 jarige kinderen, welke bestaat uit een studie naar de incidentie, etiologie en de determinanten van de gedragsgebonden risikofaktoren voor brandwonden. De inleiding tot dit proefschrift wordt gegeven in hoofdstuk 1. Dit hoofdstuk geeft achtergrondinformatie over het ontstaan van het onderzoeksprojekt, en gaat in op het theoretisch kader waarbinnen het projekt is uitgevoerd. Tot slot wordt in dit hoofdstuk kort ingegaan op de inhoud van de verschillende hoofdstukken.

In hoofdstuk 2 worden de resultaten gepresenteerd van een studie naar de incidentie van medisch behandelde brandwonden in Nederland. De resultaten zijn afkomstig van de gegevens van brandwondpatiënten uit drie registratiesystemen: brandwondpatiënten behandeld in brandwondencentra, ziekenhuizen en huisartsen. De incidentie van medisch behandelde brandwonden over deze drie niveaus van medische behandeling is ongeveer 280 per 100.000 personen per jaar. Dit incidentiecijfer is ongeveer 3 keer zo hoog voor $0-4$ jarige kinderen: 775 per 100.000 personen per jaar. Hete vloeistofverbrandingen zijn over alle niveaus van medische consumptie de meest voorkomende type verbrandingen en resulteren bij 0-4 jarige kinderen in een totale incidentie van 430 per 100.000 personen per jaar. Incidenties zijn het laagst bij ouderen (55+), maar deze leeftijdsgroep heeft een hogere mortaliteit als gevolg van brandwonden. Bovendien blijken mannen vaker ernstige brandwonden te krijgen dan vrouwen, terwijl vrouwen vaker behandeld worden voor minder ernstige brandwonden. De meeste ongevalstoedrachten voor ernstige brandwonden zijn gerelateerd aan beroep, terwijl de meeste ongevalstoedrachten voor minder ernstige brandwonden gerelateerd blijken te zijn aan huishoudelijke activiteiten.

Hoofdstuk 3 biedt een korte introduktie op de methodologische principes voor de opzet van experimentele en niet-experimentele studies naar de etiologie van brandwonden. Er wordt uitgelegd waarom de incidentie van brandwonden dient te worden bestudeerd als een funktie van risikofaktoren. Vergelijkbaarheid van de prognose van de groepen aan het begin van de studie, van de metingen en van de externe omstandigheden, zijn cruciaal in epidemiologisch onderzoek op dit gebied. In experimentele studies kan deze vergelijkbaarheid worden bewerkstelligd met behulp van randomizatie, blindering en placebo interventie. De 
belangrijkste hulpmiddelen hiervoor in niet-experimenteel onderzoek zijn selectie en multiwariate analyse. Met betrekking tot het patiënt-controle-onderzoek wordt er aandacht besteed aan het nauwkeurig omschrijven van de populatie waaruit de onderzochte brandwondpatiënten voortkomen en aan manieren om een gebrekkige vergelijkbaarheid van de metingen te voorkomen.

In hoofdstuk 4 wordt de huidige kennis met betrekking tot de incidentie en etiologie van brandwonden samengevat. Uit dit literatuuroverzicht blijkt dat, hoewel preventie van brandwonden in het verleden reeds aandacht heeft gekregen, er nooit aandacht is besteed aan een systematische aanpak van het probleem, welke kon resulteren in een grondig inzicht in de incidentie en belangrijkste risikofaktoren. Opvallend zijn de methodologische beperkingen van de uitgevoerde studies op dit gebied. $Z_{0}$ is er bijvoorbeeld geen enkele studie naar risikofaktoren geweest die gebruik heeft gemaakt van een controle groep. Er zijn geen cijfers beschikbaar over het totale aantal brandwondpatiënten in Nederland. Schattingen afkomstig uit andere landen tonen een incidentie van 4 per 1000 personen per jaar. Hete vloeistofverbrandingen komen het meest voor bij 0-4 jarige kinderen. Dit wordt vaak toegeschreven aan het motorisch en cognitief ontwikkelingsstadium van het kind in combinatie met een onjuiste inschatting over dit ontwikkelingsstadium door de ouders. Mannen blijken vaker slachtoffer van brandwonden te zijn dan vrouwen. Koffie en thee zijn mogelijke risikofaktoren. Tot slot worden er een aantal methodologische kanttekeningen gemaakt om de kwaliteit van toekomstig onderzoek op dit gebied te verbeteren teneinde preventieve maatregelen mogelijk te kunnen maken.

Hoofdstuk 5 presenteert de resultaten van ons patiënt-controle-onderzoek dat met behulp van schriftelijke vragenlijsten is uitgevoerd bij ouders van $0-4$ jarige kinderen. De patiënten $(\mathrm{N}=122)$ vormden een steekproef van 0-4 jarige Nederlandse kinderen die met een brandwond de poli-kliniek van een ziekenhuis bezochten. De controle-groep ( $N=213)$ bestond uit een steekproef van $0-4$ jarige Nederlandse kinderen zonder brandwonden. Het risiko op brandwonden was hoger voor kinderen met een andere dan Nederlandse (bv. Turkse) etnische afkomst $\mathrm{OR}-\mathrm{LR}=5.6$; $\mathrm{BI}(90 \%)$ 2.6-11.9). Kinderen die in relatief kleine huizen wonen hebben een hoger risiko voor brandwonden (OR-LR $=2.5$; $\mathrm{BI}(90 \%)$ 1.34.7). Opvallend was dat kinderen die tot een lagere sociaal economische klasse behoorden, een lager risiko voor brandwonden bleken te hebben (OR-LR=0.3; $\mathrm{BI}(90 \%)$ 0.1-0.6). Onder de manipuleerbare risikofaktoren bleek het gebruik van een ovenruit die aan de buitenkant warm wordt tijdens het gebruik een verhoogd risiko te hebben voor brandwonden (OR-LR=2.1; $\mathrm{BI}(90 \%)$ 1.3-3.5). Hetzelfde geldt voor het bewaren van hete vloeistoffen in hun originele potten in plaats van 
in een thermoskan (OR-LR=2.0; $\mathrm{BI}(90 \%)$ 1.2-3.1). Koken op een elektrisch fornuis bleek een preventief effect te hebben op het krijgen van brandwonden $(\mathrm{OR}-\mathrm{LR}=0.4 ; \mathrm{BI}(90 \%)$ 0.1-0.9).

In hoofdstuk 6 wordt een kwalitatieve onderzoeksmethode gepresenteerd en uitgetest ter bestudering van de determinanten van de gedragsgebonden risikofaktoren van brandwonden. In deze methode zijn vrijwilligers gevraagd om verschillende gedragingen ter preventie van brandwonden een aantal weken konsekwent thuis te vertonen. Na deze periode werden zij door middel van half-gestructureerde vragenlijsten geïnterviewd. In dit hoofdstuk wordt naast de algemene beschrijving van deze onderzoeksmethode ingegaan op onze studie naar de determinanten, die is uitgevoerd bij 28 Nederlandse en Turkse ouders van $0-4$ jarige kinderen. Het blijkt dat ouders die de (veiligheids-) gedragingen relatief konsekwent invoeren duidelijker de relatie tussen dit gedrag en het voorkomen van brandwonden weten te leggen. Bovendien geven de ouders die het gedrag konsekwent hebben ingevoerd aan dat dit gedrag (in bepaalde mate) een gewoonte voor hen is. Deze studie heeft tal van waardevolle suggesties opgeleverd die gebruikt zullen worden bij de opzet van een voorlichtingsprogramma ter preventie van brandwonden.

Hoofdstuk 7 presenteert een theoretisch raamwerk voor de planning en evaluatie van voorlichtingsactiviteiten (Gezondheidsvoorlichting en -Opvoeding (GVO)) ter preventie van brandwonden. Er wordt gesteld dat systematische GVO bestaat uit het aangeven van de omvang en emst van het probleem, een analyse van de risikofaktoren; een studie naar de determinanten van de gedragsgebonden risikofaktoren; de opzet en implementatie van een interventie en een evaluatie, welke ingaat op de effekten van deze vijf niveaus (implementatie, interventie, determinanten, gedrag en ongevalsrisiko). Een aantal veel voorkomende valkuilen worden genoemd en ingegaan wordt op de studie naar de determinanten en naar het opzetten van een interventie. Ook wordt er aandacht besteed aan het belang van pre-testen van voorlichtingsmateriaal. Tot slot worden er een aantal methodologische kanttekeningen geplaatst teneinde de kwaliteit van toekomstig onderzoek op dit gebied te verbeteren.

Hoofdstuk 8 bevat de diskussie van de resultaten en methodologische beperkingen van de studies die besproken zijn in dit proefschrift. Er worden een aantal algemene conclusies gegeven en aanbevelingen gedaan voor verder onderzoek. De resultaten van onze studie naar de incidentie maken uitspraken mogelijk met betrekking tot de omvang van het probleem van brandwonden bij verschillende risikogroepen. De literatuurstudie heeft plausibele ideeën over mogelijke risikogroepen opgeleverd. Het is moeilijk om aan te geven wat de resultaten van het patiënt-controle-onderzoek werkelijk betekenen. Met name het feit dat dit de 
eerste gecontroleerde studie naar de etiologie van brandwonden is, maakt het noodzakelijk voorzichtigheid te betrachten bij het interpreteren van de gegevens. Van de andere kant, blijken sommige risikofaktoren die wij vonden de bestaande ideeẻn hierover te bevestigen. Daardoor voelden wij ons gesterkt om deze risikofaktoren verder te onderzoeken in een determinantenstudie. Deze determinantenstudie leverde belangrijke informatie voor de ontwikkeling van een voorlichtingsprogramma, hoewel we ons realiseren dat vanwege methodologische beperkingen, deze resultaten eveneens voorzichtig dienen te worden geünterpreteerd. 


\section{Dankwoord}

Geachte lezer. Dit proefschrift kent slechts één auteur, hetgeen kan doen vermoeden dat het schrijven van een proefschrift een solistische aangelegenheid is. Dit is allerminst waar. Zeer veel mensen hebben een bijdrage geleverd aan dit uiteindelijke resultaat. De meeste van hen zijn anoniem: alle ouders van de $0-4$ jarige kinderen met of zonder brandwonden die bereid waren aan het patiènt-controle-onderzoek mee te werken. Zonder hen was dit onderzoek niet mogelijk geweest. Ditzelfde geldt voor de, overigens niet anonieme, Nederlandse en Turkse ouders die bereid waren deel te nemen aan de determinantenstudie. Ook zij hebben ertoe bijgedragen dat ik deze studie kon uitvoeren. Ik dank hen allen voor hun medewerking.

Daarnaast ben ik zeer veel dank verschuldigd aan mijn grote leermeester en all-round adviseur: Lex Bouter. Jouw stelling dat jonge onderzoekers recht op begeleiding hebben heb je naar mij toe constant waargemaakt. Voor een beginnend onderzoeker is immers niets belangrijker dan het hebben van een altijd beschikbare co-promotor met een enorm enthousiasme voor alles wat met wetenschap te maken heeft. Ik heb ontzettend veel van je geleerd. Beste Lex, heel hartelijk bedankt.

Vervolgens gaat mijn dank uit naar mijn promotoren die mij de mogelijkheid hebben geboden de wetenschapsgebieden GVO en Epidemiologie te verenigen. Gerjo Kok was op de achtergrond duidelijk aanwezig met kritische vragen over de voortgang van het projekt en met consciëntieuze commentaren op de diverse artikelen. Paul Knipschild heeft mij vooral in de begin- en in de eindfase aan creatieve ideeën geholpen en mij intensief begeleid bij de beschrijving van de resultaten van het patiënt-controle-onderzoek. Van zijn kritische opmerkingen heb ik veel geleerd.

De leden wan de vakgroep GVO dank ik voor hun collegialiteit. Het was een uitstekende, stimulerende én gezellige werkplek. Het voert te ver hen allen bij naam te noemen. Een uitzondering wil ik echter maken voor de volgende personen. Ree Meertens dank ik voor haar bijdragen en intensieve begeleiding van delen van dit proefschrift. Haar vermogen om steeds weer nieuwe ideeën over het opschrijven van resultaten te bedenken kende geen grenzen. Dit heeft geleid tot een verdere verdieping van het proefschrift. Daarnaast gaat veel dank uit naar Marjolein Grol. Hoewel onze ideeën over planning en orde nogal uiteen liepen 
was het prima samenwerken met jou. Je enthousiasme en doorzettingswermogen waren erg aanstekelijk. Vervolgens gaat bijzonder veel van mijn dank uit naar Jolanda Keijsers. Het is moeilijk om onze vruchtbare samenwerking in een paar regels te moeten samenvatten. Erg waardevol waren voor mij jouw assertiviteitsen relativeringstrainingen. Ik hoop dat onze samenwerking voortzetting zal vinden in het bureau Keijsers \& van Rijn!

Maar ook buiten de vakgroep hebben vele personen een bijdrage geleverd aan de tot standkoming van dit proefschrift. Vanuit de Nederlandse Brandwonden Stichting was Fred van der Putten de initiator van dit project. Daarnaast zijn binnen deze Stichting Hans Hoekstra, Hans van Nassau, Jeanne Hamers mij steeds behulpzaam geweest.

Vanuit de Stichting Consument en Veiligheid ben ik dank verschuldigd aan Saakje Mulder die mij niet alleen op zakelijk gebied uit de brand heeft geholpen.

Amold Kester bedank ik voor zijn snelle en deskundige hulp op het gebied van de statistiek. Bijzonder veel heb ik vervolgens gehad aan de adviezen van Jan Klerkx met betrekking tot spelling en opbouw van mijn engelstalige artikelen. Semahat Külcü dank ik voor het houden van de Turkse interviews en voor haar bijdrage aan het analyseren van de Turkse gegevens van de determinantenstudie.

Naast allerlei directe bijdragen zijn er ook nog een aantal mensen die gezorgd hebben voor de gunstige secundaire arbeidsvoorwaarden. Ook hen kan ik niet allen bij naam noemen. Een uitzondering wil ik maken voor mijn grote vriend Albert Huberts die bij de afronding van dit proefschrift veel concrete bijdragen heeft geleverd. Albert, ik hoop dat jouw talloze talenten in de toekomst uitdrukkelijker én onder jouw eigen naam in de openbaarheid zullen komen.

Mijn ouders hebben mij altijd gestimuleerd en gesteund. Zonder hen had ik het nooit zo ver geschopt. Jammer pappa dat je dit niet meer kunt meemaken; je zou trots op me zijn.

Tot slot wil ik mijn lieve doch ondoordachte vriend Coen bedanken. Lief, omdat hij mij de steun en rust heeft gegeven die noodzakelijk zijn voor het schrijven van een proefschrift. Ondoordacht, omdat hij hiermee ongewild heeft bijgedragen aan de bevestiging van zijn ongelijk: de door hem zo bewonderde vrouw weet ook buiten de keuken haar mannetje te staan! 


\section{Curriculum Vitae}

Olga van Rijn werd op 22 april 1962 in Maastricht geboren. In 1981 behaalde zij het VWO diploma aan het Stedelijk Lyceum te Maastricht. In 1985 sloot zij de studie Gezondheidswetenschappen, met als afstudeerrichting Gezondheidsvoorlichting en -Opvoeding (GVO) af, aan de Rijksuniversiteit Limburg. Vanaf januari 1986 tot juni 1987 werd zij aangesteld als toegevoegd onderzoeker bij de vakgroep GVO binnen de Faculteit der Gezondheidswetenschappen ten behoeve van het projekt 'Samenwerking tussen GVO-instanties en de RIAGG-preventie'. Vanaf juni 1987 werd zij in dezelfde funktie bij dezelfde vakgroep aangesteld voor het projekt 'Preventie van brandwonden in Nederland'. Haar postdoctorale scholing bestond uit deelname aan verschillende cursussen epidemiologie, zoals een cursus moderne epidemiologie gegeven door Prof. Kenneth Rothman en een cursus logistische regressie analyse door Prof. David Kleinbaum. Daarnaast volgde zij cursussen op het gebied van Gezonheidsvoorlichting- en Opvoeding zoals een PAOS-cursus gericht op voorlichting aan achterstandsgroepen en diverse cursussen statistiek. Vanaf 1987 heeft zij diverse artikelen gepubliceerd, gebaseerd op de uitkomsten van de twee genoemde onderzoeksprojekten. Vanaf april 1991 is zij als projektleider (gezondheidszorg) onderzoek aangesteld bij het Instituut voor Psychologisch Marktonderzoek (IPM) in Rotterdam. 